INTER NATIONAL MONETARY FUND

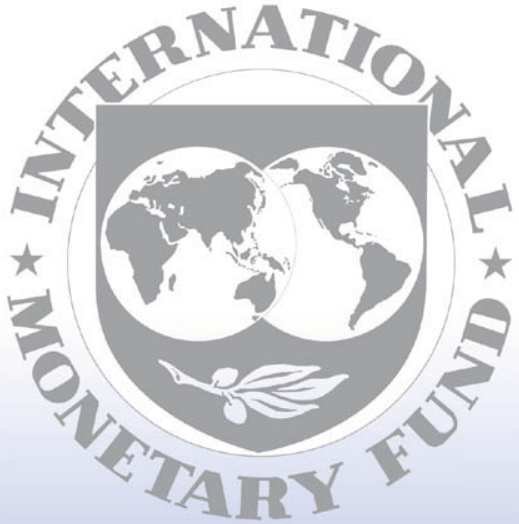

Staff

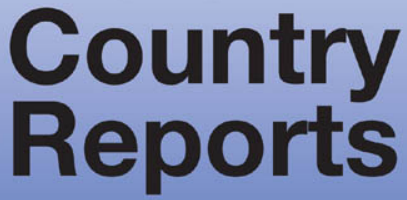




\section{Mongolia: Poverty Reduction Strategy Paper Progress Report}

Poverty Reduction Strategy Papers (PRSPs) are prepared by member countries in broad consultation with stakeholders and development partners, including the staffs of the World Bank and the IMF. Updated every three years with annual progress reports, they describe the country's macroeconomic, structural, and social policies in support of growth and poverty reduction, as well as associated external financing needs and major sources of financing. This country document for Mongolia, is being made available on the IMF website by agreement with the member country as a service to users of the IMF website.

To assist the IMF in evaluating the publication policy, reader comments are invited and may be sent by e-mail to publicationpolicy@imf.org.

Copies of this report are available to the public from

International Monetary Fund • Publication Services

$70019^{\text {th }}$ Street, N.W. • Washington, D.C. 20431

Telephone: (202) 623-7430 • Telefax: (202) 623-7201

E-mail: publications@imf.org • Internet: http://www.imf.org

Price: $\$ 15.00$ a copy

\section{International Monetary Fund Washington, D.C.}


This page intentionally left blank 


\title{
GOVERNMENT OF MONGOLIA
}

\section{ECONOMIC GROWTH SUPPORT POVERTY REDUCTION STRATEGY}

IMPLEMENTATION PROGRESS REPORT - 2004

\author{
Ulaanbaatar
}




\section{Contents}

Introduction

1.0 Relationship between Millennium Development Goals and Economic Growth Support and Poverty Reduction Strategy, and their Implementation Progress

2.0 Implementation Progress of Economic Growth Support Policies and Measures Implemented in 2003/2004

a. $\quad$ Analysis of Implementation of Macro-Economic Policies

b. Analysis of Implementation of Export and Industry Support Policies

3.0 The State of Poverty
a. Income Poverty
i. Poverty Measures
ii. Inequality

b. Poverty Status Profile

i. Poverty and Household Composition

ii. Poverty Spread and Geographical Location

iii. Poverty and Seasonality

iv. Household Ownership of Assets

v. Housing

4.0 Cross Cutting Issues
a. Governance
b. Gender
c. Regional and Rural Development, and Environment
d. Ensuring Sustainable Human Development
i. Population
ii. Education
iii. Health
iv. Social Protection

e. Participation

5.0 Poverty Monitoring and Evaluation

a. EGSPRS implementation monitoring and evaluation system

i. Data Collection

ii. Analysis

iii. Information Dissemination

Abbreviations

Annexes 


\section{Introduction}

Creating an environment to provide sustainable human development, increasing living standards of citizens, make the social services accessible and reducing poverty and unemployment became an important social sector objective of the Government of Mongolia. As a result of positive changes in the last few years on education, health and income, human development indicators of Mongolia were improved than in the level prior to the transition, macro economic condition was sustained and growth is generated. This indicates that either of human capacity that can provide economic growth and economic resources and opportunities that can provide further development growth is being created in the country. In order to provide consistency among these the government of Mongolia called the poverty reduction strategy as "Economic Growth Support and Poverty Reduction Strategy".

In order to implement the MDGs initiated by UN and an objective to reduce poverty in new millennium, the government of Mongolia finalized development of the EGSPRS in support of the World Bank, got the strategy discussed by the Board of the World Bank in September, 2003, started its implementation and is preparing the first implementation progress report. This report mainly summarizes policies and measures implemented during 2003-2004 for the implementation of the EGSPRS and their outcomes and results.

The EGSPRS will be implemented through the annual socio-economic guidelines and state budget. Therefore, the progress report ahs been prepared based on the implementation of the socio-economic guidelines and execution of the state budget.

The monitoring and evaluation system of the EGSPRS had been formed by the government resolution \#96 in 2004 and the draft progress report was discussed by members of policy committee and 5 sub committees, NGOs and donor community following the structure and improved accordingly. 


\section{One. Relationship between Millennium Development Goals and Economic Growth Support and Poverty Reduction Strategy, and their Implementation Progress}

The document 'Millennium Declaration', including eight essential goals of millennium development, was approved by UN summit conference in September 2000 and urgent issues that should be resolved by 2015 connected with such as poverty, health, education, environment worldwide partnership for development are considered in the declaration. The countries developed and successfully implemented their own plan and program to implement the promises and the goals.

Government of Mongolia developed first national report of implementation outcomes and process of millennium development objectives in 2004. Also first implementation statement of strategies to promote economic growth and to reduce poverty, which was developed, based on millennium development objectives, has been prepared.

The report and the statement both show present situation of population, revenue level, poverty reasons of Mongolia but they are different each other. The millennium development objectives covers a period to 2015 and 1990 year is considered a base year in addition to the national implementation report will be prepared every two year. In the national report, the present situation and outcomes of eight approved objectives were presented by of each objective and also urgent problems are considered.

The strategies to promote economic growth and to reduce poverty is implemented according to socio-economic guidelines therefore first implementation report has been prepared by way of making analysis in outcomes of socio-economic guidelines for 2004 and using other related studies results. Furthermore, inter-sectors issues such as gender, regional development, and governance and public participation are considered particular chapters. In the future, the government plans to update the strategy every three years and present reports annually, but the need to revise the EGSPRS before the planned revision time has risen due to the approval of the new government's action plan by the SGH and start of its implementation, availability of the results of 2003 Household Income and Expenditure and Living Standards Measurement Survey, and approval of medium term strategies for some sectors.

The urgent problem is to harmonize works, will be done scope of millennium development objectives and strategies to promote economic growth and to reduce poverty and supervision and auditing in outcomes of the works. President Administration and the Ministry of Foreign Affairs have been organizing the supervision and auditing in outcomes of millennium development objectives and National Statistical Office has prepared fundamental indicators of supervision. The supervision indicators of strategies to promote economic growth and to reduce poverty are being developed consistent with main purpose and indicators of millennium development objectives. 
In developing EGSPRS, the Government of Mongolia coordinated it with 8 goals and 18 objectives of the Millennium Development Goals, and their implementation are being organized in conjunction.

Poverty reduction strategy was aligned with MDGs mostly in terms of providing education, reducing maternal and child deaths, supporting gender equality and ensuring economic growth, and their performance for 2004 is explained under specific sections.

In the future, one of the problems faced by us is to estimate costs required to achieve MDGs, to build such capacity at the national level, and subsequently to build capacity to estimate the expenses within the frame of EGSPRS and annual medium term budget framework. To overcome this problem, UNDP initiated and launched a special project. 


\section{TWO. Implementation Progress of Economic Growth Support Policies and Measures Implemented in 2003/2004}

\subsection{Analysis of Implementation of Macro Economic Policies}

In the strategy documents to promote economic growth and to reduce poverty, issues to provide economic stability, to build an unrestricted market cooperation, to create a favorable environment to run a business in order to accelerate the economic growth of Mongolia are considered leading trends. Government of Mongolia views that a core of the implementation policy of strategies to promote economic growth and to reduce poverty is to provide macro economic stability.

\section{Growth in GDP}

In the strategy documents to promote economic growth and to reduce poverty, there are estimated that the real growth of GDP is 5.2 per cent in 2003 and real economic growth's alternative is 6 per cent in medium term or 2004-2007.

The Government of Mongolia recognizes that the primary basis for ensuring pro-poor economic growth is the macroeconomic stabilization, and made this as one of its priority goals.

Mongolia's GDP grew by 5.6 per cent in 2003, a fulfillment of the goal set out in Main Guidelines for Economic and Social Development in 2003 to attain at least 5.2 percent economic growth. In 2003 the economy grew thanks to 1.4 per cent increase in agriculture sector, 0.8 per cent in industrial sector and 3.4 per cent in service sector.

The preliminary estimate for real economic growth in 2004 equals 10.6 percent. Main Guidelines for Economic and Social Development in 2004 set out the goal of attaining 6.0 percent economic growth, which is the highest level provided in EGSPRS, and this goal has been fully achieved by this preliminary estimate. 4.5 percentage points of this growth come from agricultural sector, 4.2 from industrial sector, and 2 from service sector.

GDP amount per person reached 511.9 USD in 2003, an increase of 12.6 per cent over the same period of the previous year, and 605.5 USD in 2004, an increase of 18.3 percent over 2003. GDP real amount per person at the 1995 constant price reached 282.2 thousand tugrugs in 2003 and increased by 4.4 per cent compared with previous year. This increase for 2004 is 9.2 percent. The intermediate monitoring indicator to monitor implementation of EGSPRS provides for attaining 9.2 percent of per capita GDP in 2004, the goal which basically has been accomplished. 
Table 1. GDP indicators, 1999-2004

\begin{tabular}{lrrrrrr}
\hline & 1999 & 2000 & 2001 & 2002 & 2003 & 2004 \\
\hline GDP by year price, billion tugrugs & 925.3 & 1018.9 & 1115.6 & 1240.8 & 1461.2 & 1808.0 \\
\hline \multicolumn{1}{c}{ Changes in GDP, by percentage } & 13.2 & 10.1 & 9.5 & 11.2 & 17.8 & 23.7 \\
\hline GDP by 1995 year price, billion tugrugs & 625.9 & 632.5 & 639.0 & 664.9 & 702.4 & 776.2 \\
\hline Economic real growth, by percentage & 3.2 & 1.1 & 1.0 & 4.0 & 5.6 & 10.6 \\
\hline $\begin{array}{l}\text { GDP per person by year price, thousand } \\
\text { tugrugs }\end{array}$ & 392.3 & 426.2 & 460.1 & 504.6 & 586.9 & 717.7 \\
\hline $\begin{array}{l}\text { GDP per person by 1995 year price, } \\
\text { thousand tugrugs }\end{array}$ & 265.3 & 264.6 & 263.5 & 270.4 & 282.2 & 308.1 \\
\hline GDP, million USD & 905.6 & 946.6 & 1016.3 & 1117.5 & 1274.5 & 1525.3 \\
\hline GDP per person,US dollars & 383.9 & 396.0 & 419.1 & 454.5 & 511.9 & 605.5 \\
\hline
\end{tabular}

Economic growth in 2004 reached the highest level at 10.6, but its benefit to poor cannot be directly determined on the basis of just one year growth. EGSPRS is planned to be implemented in three year chunks, and the living standards measurement survey will be conducted every three years, so the effect of the growth on the population can be assessed by the end of the three year period.

Figure 1. Economic growth distribution, by percentage

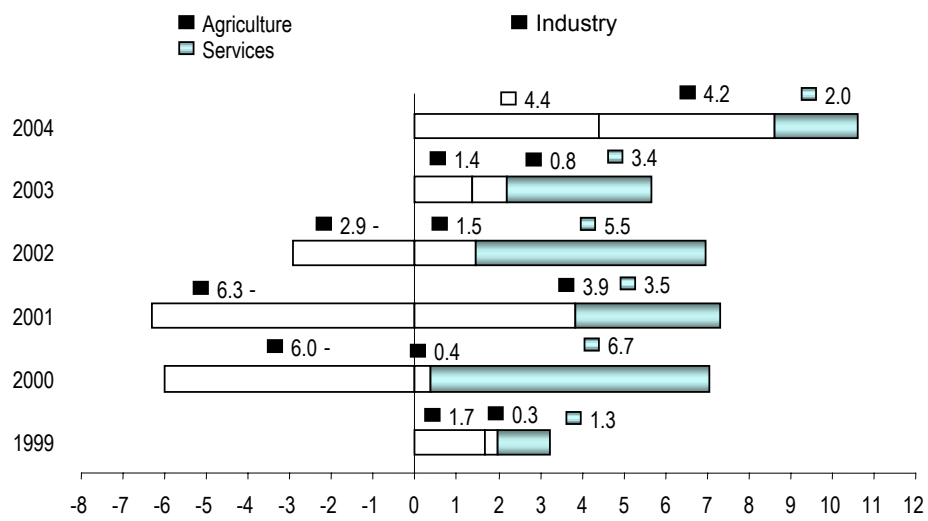




\section{The order of GDP structure is service, industry and agricultire for last two years. Figure-2}

GDP Structure, 2000

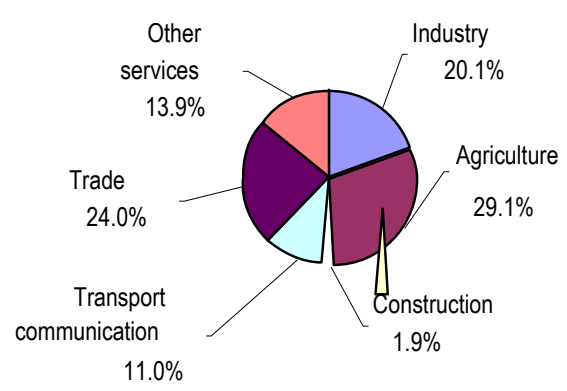

GDP Structure, 2004

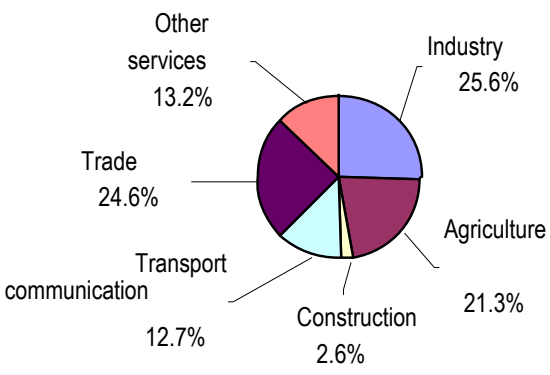

The growth in trade and service sector has been relatively stable in recent years while comprising the major part of GDP. The share of service sector in the total economy in Mongolia has increased from 49.0 percent in 2000 to reach 50.5 percent in 2004. That jobs were created in large numbers in the service sector has provided real results in reducing poverty.

Hotel and restaurant services has increased in 2004 over 2003 as a result of the relative increase in the number of foreign tourists. As the number of tourists increased, the number of passengers carried by rail and air ways increased by $9.6-16.7$ percent.

The share of industrial product in GDP has been increasing as it equaled 22.3 percent in 2003 and 25.6 percent in 2004. In the industrial sector, the mining sector grew by 30.8 percent, energy production by 6.3 percent, but the processing industry fell by 7.0 percent.

In the processing industry sector, manufacturing of garments shows signs of decline due to foreign trade situation. The 74.9 per cent increase in gold production led to the growth of the mining sector by 31.9 per cent. The government support of gold production from hard rock gold deposits caused the production to jump in 2004. From January 1, 2005, because the Hong Kong textile products are to be supplied to the US market at the same terms and conditions as Mongolian products, some foreign invested companies are wrapping up their activities, and as a result garment production decreased compared to 2003 while about 5000 workers were laid off at the end of 2004, negatively impacting the livelihood of the population. 
Table 2. Growth in industrial sector

\begin{tabular}{lrrrrrr}
\hline & 1999 & $\mathbf{2 0 0 0}$ & $\mathbf{2 0 0 1}$ & $\mathbf{2 0 0 2}$ & $\mathbf{2 0 0 3}$ & 2004Est. \\
\hline Mining & 3.2 & 6.6 & 9.6 & -6.9 & -1.3 & 31.9 \\
Manufacture & -2.8 & -3.3 & 31.8 & 22.1 & 2.1 & 1.5 \\
Electricity and purification & & & & & & \\
& 4.6 & 0.4 & 3.5 & 3.9 & 1.1 & 6.3 \\
Total industrial output & 1.1 & $\mathbf{2 . 7}$ & $\mathbf{1 6 . 5}$ & $\mathbf{4 . 7}$ & $\mathbf{0 . 4}$ & $\mathbf{1 6 . 5}$
\end{tabular}

In future, it is necessary to implement goals in the EGSPRS by increasing the share of processing in economic sector structure and to increase the level of mining production, especially encouraging final production.

Relatively favorable climate in 2003 and 2004 caused the herding sector to grow. The output of agriculture sector has increased by 18.9 per cent in 2004. Number of livestock reached 28.0 million, that is increased by 2.5 million or by 10.0 per cent compared with previous year; 9.2 million newborn were reared, which is more than 1.4 million compared with previous year and number of losses of adult animals will be reached 498.0 thousand which is less by 1.0 million compared with previous year. As a result of increase in number of livestock last two years, added cost of agriculture sector will be increased by 22.4 per cent in 2004 . The increase in the number of livestock has provided some effect in raising living standards of rural population.

In 2004, the total amount of harvested cereal reached 138.5 thousand tons in 2004, which is less 16.1 per cent compared with previous year. In 2004, were harvested 80.2 thousand tons potatoes, which are more by 1.9 per cent, 49.2 thousand tons vegetables, which less by 17.5 per cent compared with previous year. Government has implemented Seeds and Hay harvest program and has encouraged farmers last four years but because of climate and environment situation increase and decrease both have appeared in last four years in cultivation sector. Government implements a policy to develop irrigated cultivation in order to decrease the risk in agriculture sector.

Despite the economic growth has accelerated in recent years, this economic growth is provided by agriculture, mining or essential sectors' production therefore it can not be base of sustainable growth and employment can not increased respectively. Subsequently, there is a need for more efficient industrial sector to be developed. The parts of savings that are available as a result of the economic growth and increase in the income coming from foreign markets now can be used for reducing pension differences by increasing at higher rates pensions of citizens who retired before 1995 and for child money resources.

\section{Employment of the Population}

Increasing employment, reducing unemployment by creating significant number of jobs, and preparing highly skilled personnel meeting labor market requirements are all directed at the reduction of poverty. This is the main goal of the Government of Mongolia. In recent years the population grew by 1.2 percent and working age population on average by 3.4 percent in Mongolia. Especially, the share of youth aged 16-29 is relatively high in this growth. 
The total population of Mongolia reached 2504.0 thousand in 2004, of which 1488.9 thousand are the working age people, 959.8 thousand are economically active population or labor force, and 926.5 thousand are employed. The number of registered unemployed is 35.6 at the end of 2004, and the unemployment level is 3.4 percent.

In recent years labor engagement and unemployment indicators showed some positive changes, but unemployment and poverty remain a very sensitive social issue. That supply and demand on the labor market are not getting to the equilibrium level is related to the fact that on one side there are no sufficient jobs provided by businesses and on the other side unemployed citizens lack professional skills that meet needs of the market. Of registered unemployed, 72.1 percent have no vocational education while 57.6 percent are the youth aged 16-34.

As of 2004, 8329 foreign citizens coming from 65 countries work in Mongolia. By economic activity sector, 37.5 percent of the foreign citizens working in Mongolia are in the mining sector, 18.0 percent in construction, 10.4 percent in public administration and social insurance, 7.8 percent in the processing sector, and 7.5 percent are in education.

The number of working elderly increased by 1.3 thousand compared to 2003, showing interest on the side of elderly to work and increase their income.

Looking at the composition of employed by sector classification shows that 36.5 percent are employed in the agriculture, 16.6 percent in industry, 8.4 percent in trade, 6.2 percent in transportation and communication, 5.1 percent in construction and 28.8 percent in other sectors.

Comparing the numbers of 1995, 1999 and 2003 show that in most sectors the number of workers had uninterruptedly grown, but the number of employees in the agricultural sector dropped by 12.0 percent from 1999 to 2003 while it grew by 2.4 percent from 1993 to 1999 . This is related to the decline in the number of livestock due to droughts and zuds of recent years as well as to the rural to urban migration.

Also, the number of employees in the trade sector dropped by 1.6 percentage points after growing 1.6 point in the preceding period. 


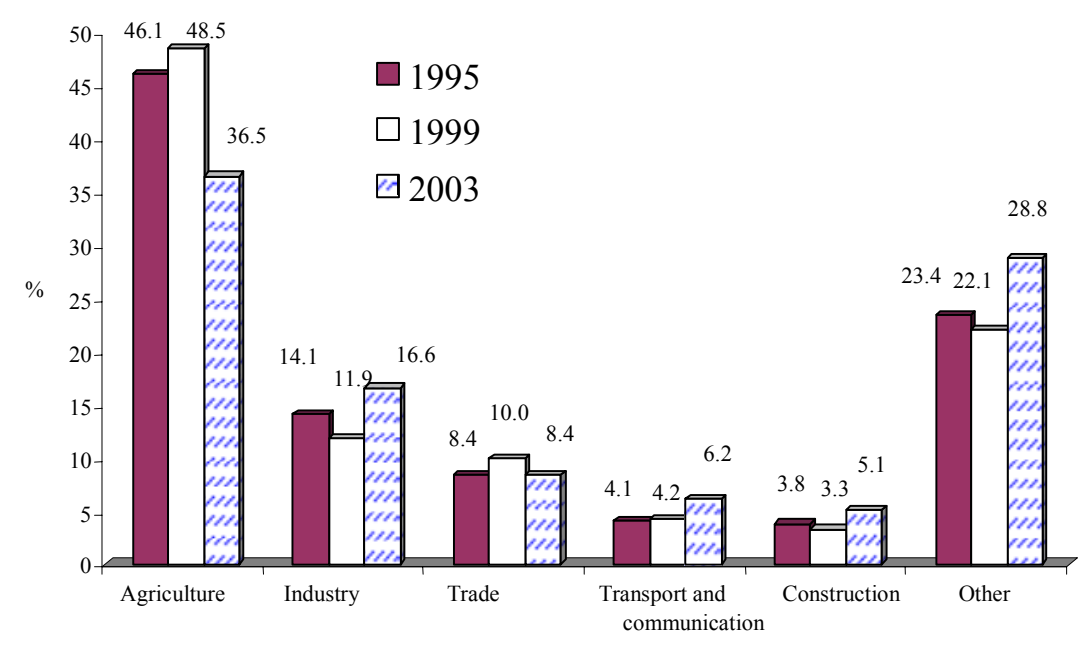

The number of those not engaged in labor has steadily declined in recent years, from 265.8 thousand in 2002 to 233.0 thousand in 2003, a decrease by 32.8 thousand. But the number of unemployed registered at the Employment Offices increased by 2.4 thousand, causing 0.1 percentage point increase of the unemployment level over the previous year. This is related to the intensification of the work of employment offices and increased interest of citizens to register at these offices and have them mediate for jobs.

The real unemployment number, as determined by the sum of unemployed population with no specific reason for unemployment and the number of unemployed registered at the employment offices, has steadily declined in recent years.

The government efforts in recent years emphasizing on studying changes and future trends in employment, amending related legislation and strengthening the capacity of people of implementing institutions have shown the results.

In order to support self-employed, the government financial assistance has increased in the form of small loans. As of 2004, Tg 939.6 million loans were disbursed from the Employment Support Fund to citizens and business entities interested in self-employment or establishing cooperatives and partnerships, helping to create a non-trivial number of jobs.

Also, at the national level a total of 13932 unemployed were involved in vocational training and re-training. Vocational training was provided in 6 districts of the capital by use of voucher training, while accredited training institutions are organizing such training in rural areas. 7747 vouchers were provided to 2485 citizens of 6 districts of Ulaanbaatar, and they were involved in short-term vocational training and earned respective professions.

Information and professional advice were offered to citizens of socially vulnerable groups on opportunities to provide them with working capacity, obtain professional skills and attend re-training. Citizens of vulnerable social groups were involved in training and respective degrees were granted. Employment offices are cooperating with the National Center for Vocational Training and Rehabilitation of Disabled Citizens. The center concluded a 
contract to organize training and mediate for job places in 2004 for disabled citizens in such areas as bakery, cloth making, gardening, hairdressing, cooking, handicrafts, beauty saloon and computer operation. In activities organized by employment agencies for the public, a total of 9097 people were involved of which 38.4 percent or 3490 were from socially vulnerable groups. According to Article 111 of the Law on Labor, a total of 203 disabled and physical difficulties were provided with the jobs.

Employment agency provided $\mathrm{Tg} 28.2$ million in loans to 56 citizens under the frame of activities to support employment in the area of agriculture in accordance with the Law on Labor, and this resulted in creation of 129 new jobs.

In order to improve access and effectiveness of services provided to poor, Sustainable Livelihoods Project with USD 18.6 million funding from the World Bank is being implemented in Bayan-Ulgii, Bayanhongor, Uvs, Uvurhangai, Tuv, Dundgovi, Umnugovi and Dornod aimags, and Sustainable Reduction of Rural Poverty Project with USD 16.6 million funding from International Fund for Agriculture Development is being carried out in Arhangai, Bulgan, Huvsgul and Hentii aimags. USD 3 million were allocated to intermediate financial institutions to lend to citizens for the purposes of engaging in and increasing their household production and income. Of this amount, a total of USD 541.2 thousand were allocated in small loans to 496 borrowers from 7 aimags and 1 district.

As a result of participating in the program, soum herders are learning skills to cooperate, improve the management for appropriate use of pastures, and mapping pasture reserves of the soum and bags. Also, engineering deep drill wells were rehabilitated in 16 soums as well as some 80 hand wells. As a result, the common and reserve pasture use improved and became usable over the area of 695.2 ha land. In addition, water supplies for about 3000 households and 285.8 thousand heads of livestock are on the way to be improved.

In 2004, 4 aimag veterinary laboratory buildings were renovated as 124 types of modern equipment, medicine, and diagnostic tools as well as a UAZ-469 jeep were supplied. As a result, the opportunity to make initial diagnosis of some types of animal transmittable diseases at the local level was created.

12 soum school dormitories, 9 soum hospitals and 10 soum kindergarten buildings were reconstructed in these 4 aimags. 32 mobile kindergartens operated over the 3 summer months as 2361 children of herder families were enrolled in these.

In 32 soums included in the program, the work to cultivate vegetables was organized, 2690 households were provided with seeds, of which 2681 households grew vegetables on average on the area of about 60 ha, and they harvested about 950 tons of vegetables, as one family average monthly income increased by about 50 percent.

In order to increase rural household income and teach them to technologies for production and services, training were organized in the area of hairdressing, carpentry, shoe repair, electric welding, sewing, make of mould wool items, processing of dairy and bakery; a total of 14898 people (by multiple counting) attended these training in 2004. 


\section{Salaries and Wages of Employees}

According to results of the sample survey by National Statistics Office, a comparison of the growth of the average salary of workers in business entities to the inflation level over the past three years shows that the average salary of employees as of the $4^{\text {th }}$ quarter of 2003 had increased by 32.9 percent over the $4^{\text {th }}$ quarter of 2000 . For the same period of time inflation was 14.9 percent.

Average monthly salary growth of employees by the 2000 fixed price was lower than the inflation level till the $3^{\text {rd }}$ quarter of 2001, and higher than the inflation level ever since.

By Resolution \#4 of 2004 of the Government of Mongolia the minimum monthly salary was increased to equal Tg 40000 .

If we look at the average salary levels by economic activity sectors, workers of financial intermediation ( $\mathrm{Tg} 123.5$ thousand), transportation, communication and warehouse sector (Tg 108.9 thousand), electricity, natural gas, and water provision (Tg 97.2 thousand), hotel and restaurant (Tg 97.2 thousand), mining industry (Tg 93.6 thousand) and construction (Tg 90.6 thousand) sectors earn higher salaries than those in other sectors.

By ownership type of business entities and organizations, employees of foreign invested businesses and organizations get higher than average monthly salaries, regardless of the ownership.

\section{Budget Policy Implementation of Mongolia}

In recent years, bugdet policies and financial activites of Government has conducted to prove macro economic sustainibility, to encourage private sector inverstment, to improve quality and suppliment of civil service and to allocate revenue to vulnerable people sufiiciently.

In order to implement these, Government works to create sustainable resource of budget revenue and to decrease tax burden on citizens, enterprises and entities, to provide implementation of 'Public Sector Management and Financing Law' effective from 2003, which was launched to reform of budget expenditure to introduce and to implement principles to supply goods and service behalf of government, and significant achievements were made in 2004.

With purpose of to reduce tax burden, $40 \%$, which was top tax bracket of corporation income tax, was decreased by 25 per cent and became $30 \%$ since the beginning of 2004, providing even more encouragement to businesspeople. As result of this activity, tax burden on business with annual income above 100 million tugrugs was decreased by 13 billion tugrugs annually. With the aim to increase citizens' real income and reduce tax burden, individuals with month income above 400000 tugrugs were levied tax $40 \%$ was decreased to $30 \%$ since beginning of 2004 . Therefore, tax burden on individuals with high income has decreased by 1.3 billion tug rugs and the real income has increased same amount. Also in order 
to increase individuals' savings, period to levy tax on stock dividends, revenue of beneficiary, interest revenue of loan and savings and other similar revenue postponed until 1 January 2005 and was again extended to 1 January 2008.

"Law of Mongolian citizen to be owned land" applied since 1 May 2003 and an legal environment that Mongolian citizen can own property 'land' or the most valuable thing from any kind of resources at first in history, was built successfully. Harmonized with it, when immovable property tax is levied on land which was owned to citizen's needs of family, tax deduction is $95 \%$ in capital city, $97 \%$ in aimag centers, $98 \%$ in towns and soums; on land, which was owned to citizen in purpose of farm except cultivation, tax deduction is $30 \%$ in capital city, $70 \%$ in aimag centers, $85 \%$ in towns and soums; on land, which was owned to citizen in purpose of cultivation, tax deduction is $95 \%$ in any regions. As a result of these measures, even poor citizens with low income have rights to own the asset such as land.

According to budget management legal reform, Governor General of Budget or Minister is responsibility to specific sector are allocated packages of budget in order to develop budget expenditure system more efficiently and to finance budget entities considering their outputs and performances of Government and related agencies decisions. Also Government works to provide clear and completed budget distribution as way of taking attention on forming Treasury single account system sufficiently and improving its reporting and presentation. In the late 2004, a new consolidated information network for State Treasure was introduced.

The statement of 2005 budget framework of Mongolia was approved by parliament and budget framework indicators were calculated compared with GDP in this statement. Therefore, the statements was used as fundamental documents in preparation of 2005 budget of Mongolia and socio-economic guidelines for 2005 .

Government of Mongolia implemets a policy to the budget overall balance deficit will be 5,9 per cent of GDP in 2004 and will not excses 5.5-4.5 per cent in 2005-2006 in addition to it is used as resource to finance the domestic investment.

According to the policy, budget revenue proportion in GDP will be 37.4 per cent in 2004 and will be decreased to 36.3 per cent in 2005-2006 онд.

Also Governement plans to reduce budget expenditure proportion in GDP and and it will be 43.3 per cent in 2004 then will be reduced to 41.8 per cent in 2005 .

\section{Source: EGSPRS}

According to actual budget performance of Mongolia in 2004, total budget revenue amounted to 713.1 billion tugrugs and general government revenue arrangement reached to 68.6 billion tugrugs or excessed by 10.6 per cent, general government expenditure amounted to 752.5 billion tugrugs as well as budget performance was at 102.8 per cent. According to 2004 state budget actual performance, the budget current balance was a surplus 167.4 billion tugrugs, the budget overall balance deficit was 39.4 billion tugrugs. The budget current balance surplus proportion in GDP was 9.3 per cent, the budget overall balance deficit proportion in GDP was -2.2 per cent. 
Table 3. Outcome indicators of state budget of Mongolia

\begin{tabular}{|l|r|r|r|}
\hline \multicolumn{1}{|c|}{} & \multicolumn{3}{c|}{ /million tugrugs/ } \\
\cline { 2 - 4 } & \multicolumn{1}{|c|}{2003} & \multicolumn{2}{c|}{2004} \\
\hline Total budget revenue and grants & \multicolumn{1}{|c|}{ actuals } & \multicolumn{1}{c|}{ By plan } & \multicolumn{1}{c|}{ actuals } \\
\hline Current revenue & 535795,7 & 649254,2 & 713113,6 \\
\hline Capital revenue & 526368,6 & 643031,5 & 706292,8 \\
\hline Grant revenue & 759,0 & 622,6 & 769,0 \\
\hline Total budget expenditure and net loan & 8668,1 & 5600,0 & 6051,8 \\
\hline Current expenditure & 616536,9 & 734331,4 & 752486,4 \\
\hline Capital expenditure & 446278,7 & 532574,9 & 538699,2 \\
\hline Net loan amount to be paid & 88819,7 & 104209,2 & 104886,8 \\
\hline Current balance & 81438,5 & 97547,2 & 108900,4 \\
\hline Overall balance & 80089,9 & 110456,6 & 167593,6 \\
\hline
\end{tabular}

Source: Ministry of Finance

According to dynamics of budget revenue, expenditure and deficit, performance, main indicators especially the budget current balance has improved noticeably therefore savings in public sector has raised too. While the savings is increasing, Government obtains a resource to finance the investments directed at reducing poverty and providing economic benefits for future development. The budget deficit has reduced continuously as a result of the increase in economic growth, the expansion in domestic production and service as well as the improvement in external trade in the past two years. In consequence of the budget expenditure reforms to improve expenditure management and to coordinate treasury cash flows efficiently has been done sufficiently furthermore it has provided a significant impact on the budget balance.

Figure 4. Budget balance, by share in GDP

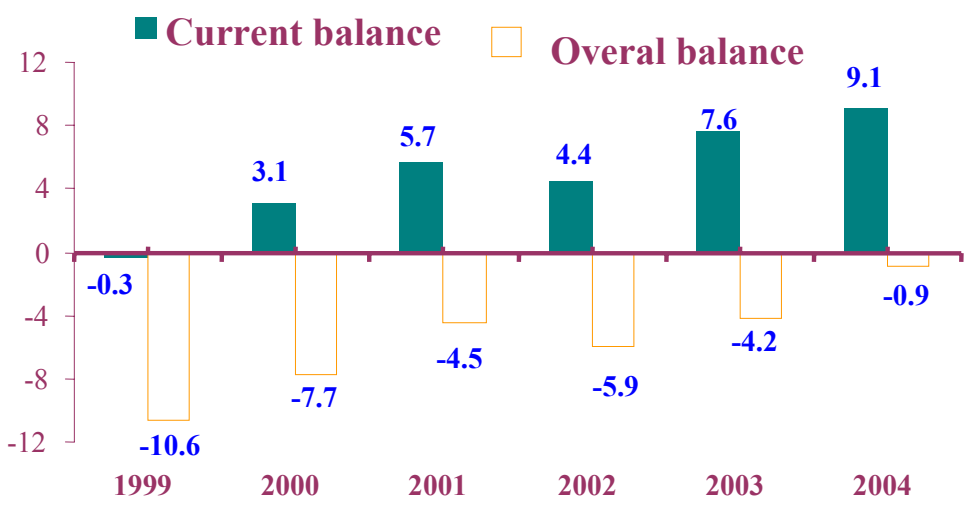

Source: according to 2004 preliminary results

The budget expenditure classes, which assign depression on the general government budget are wage expenditure class, comprises major proportion of the budget expenditure or covers 7.1 per cent of GDP, and goods and service expenditure, covers 12.6 per cent of GDP. In 2003 and 2004, the work to perform some public services on the basis of contracting, thus shifting more to the commercial basis was organized. But because this activity has been slow, 
salary and wage spending have not decreased significantly. State Great Hural of Mongolia approved Medium Term Strategy for Public Service Reform by Resolution \#24 of 2004. The main content of this strategy is to strengthen the strategy, planning and performance management of budget institutions, to improve human resource management in the public service, and to improve the system for public servant salaries and bonuses. The policy to implement the public service reform has found its reflection in Public Service Law, Public Sector Management and Financing Law and other relevant laws. This strategy has defined 3 priorities for public service reforms, which are:

1. Effective delivery of public services. This will be an important impetus for improving delivery of public services and subsequently implementing the poverty reduction strategy.

2. Emphasize work performance and results. The new strategy is based on outputs and results rather than inputs. One of the performance criteria indicators should be the equal delivery of public services to citizens, especially to poor and vulnerable groups.

3. Efficiency and simplicity. Public service of Mongolia will be provided on the basis of providing as many services as possible at the minimum cost, under a strict limitation for budget spending.

As the strategy is implemented, the efficiency in budget spending will improve. Therefore, it is needed to strengthen civil service capacity and to assemble a compacted and efficient civil service structure as well as to supply civil services to citizens as economical prices and to improve quality of the civil service outputs.

\section{Salaries and Wages of Employees of Budget Organizations}

The wage bill for budget organization employees equalled to 20.4 percent of total budget in 2003 .

Figure 5. Average salary of budget organization employees, in tugriks

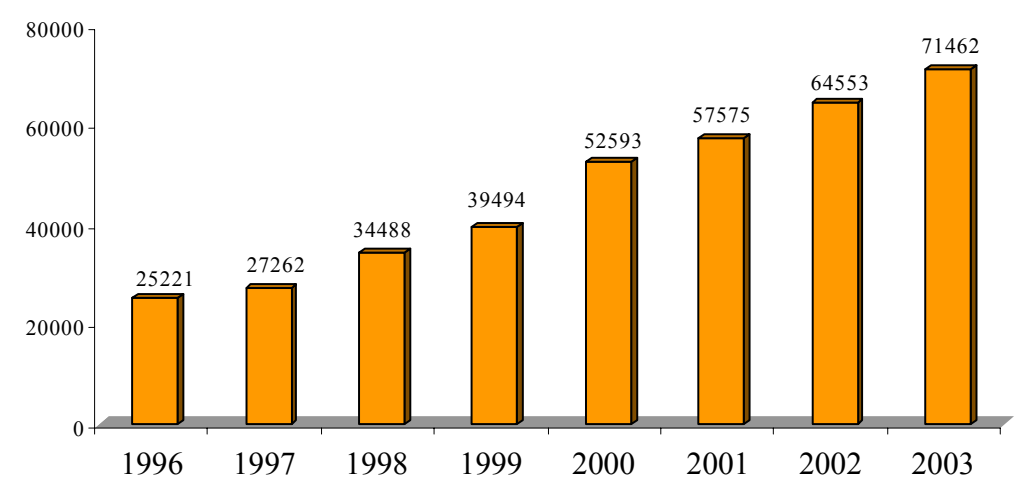

By the Government Resolution \#42 of 2004, the issue of increasing salaries and wages of budget organization employees was resolved. In doing this, public servant salaries were increased by an index of 7.5 and general budget managers were provided with rights to administer a cash bonus fund equaling 17.5 percent of the salary fund. 
According to the budget performance forecast of 2004, 69.0 billion tugrugs were used to the investments, which is higher by 21.3 billion tugrugs or by 46.8 per cent compared with 2003, hence 60 per cent of the investment was used for electricity, road contraction, transport, communication, tourism and public utilities; 20 per cent was used for education, health and social welfare sector financing.

In medium term, treasury single account system will be strengthened and service will be improved, the budget expenditure reporting and presentation will be clear and accountability. Therefore, the accounting report of assets to provide revulnerable people will be more transparently and the recourse will be increased.

Throughout the treasury single account system Government financial activities are implemented and payments are transferred therefore favorable environment has built to implement the provisions in Law of public sector management and finance that states to coordinate cash flows efficiently.

As a result of the implementation of united management cash flows of the government, cash flows planning has improved as well as there some possibilities have occurred for instance to control expenditure, financed from state budget, to utilize budget efficiently, to match the Government bond's interest rate at the minimum level, to increase results of investment and to control budget planning.

In the extent of treasury management and coordination, Government cash assets planning and the budget revenue collection have improved, external and internal loan burden has eliminated as well as budget entities' employers wages, pensions and allowances can be allocated on time independent from the budget revenue collection, the projects and operations, which are to be implemented according to budget investment planning, can be financed completely. As a result of social insurance fund has transferred into treasury account, there has made a development in the treasury account system as well as the circumstances to protect the social insurance fund from any kind of risks.

Government sold securities which amounted 41.6 billion tugrugs in 2004. Government has paid 109.5 billion tugrugs for basic payment of the securities, 3.1 billion tugrugs for interest payment (in total 112.6 billion tugrugs) to partnership parts and it means that Government has performed the contract duties successfully. Out of these payments, 62.0 billion tugrugs has been paid to Ivanhoe Mines Company, consisted of 60.4 billion tugrugs for basic payment of the securities and 1.6 billion tugrugs for interest payment. Therefore in 2004 bank debt promises amounted 6.0 billion tugrugs has been monetized and the residual is 14.0 billion tugrugs. 2.8 billion Tugrugs has paid for interest payment of debt promises. According to loan agreement, Government has paid 11.7 billion tugrugs for loan payment to Bank of Mongolia and the residual of domestic debt is amounted 105.3 billion tugrugs. 
Governement implements a policy to develop sophicicated debt management, to resolve the external debt payment without making additional depression on budget and to increase beneficts of the external debts.

In mediem term, open policy in external relationship of economic will be implmented continuesly and mutual beneficial cooperations will be developed. In medium term, debt service will not excess than 10 per cent of GDP.

In long term, loan amount, received from interogovernement cooperetion will be reduced and foreign direct investment in business sector will be increased. Furthermore, debt payment depression in the general government budget will be decreased and money to provide vulnerable people will be increased as well as social utilities abequacy to citizens will be enhanced.

According to 2004 actuals, the government disbursed 153.3 bln tugrug of external loan from international financial institutions and donor countries. In terms of loan purposes, 59 per cent of total foreign loan was spent for the infrastructure sector, 8.8 per cent or 13.3 bln tugrug for education, health and social welfare.

In addition, the government paid 21.1 bln tugrug as principal payment for previous year loan, 16.3 bln tugrug as interest payment and altogether it paid $37.3 \mathrm{bln}$ tugrug. The government paid USD50.0 mln for the govenrment Treasury Bills payment sold to the Ivanhoe Mines and USD1.3mln as its interest payment. Although Mongolia is paying amortizations and interest payment for the foreign loan on time, it is required to work more efficiently to develop and approve foreign loan strategy of Mongolia.

Millennium Challenge Corporation of United States declared that Mongolia is one of countries, who have a right to receive financing support from Millennium Challenge in May 2004. Followed by, National Board of Millennium Challenge Corporation organized open forum discussion including 750 people by three stages and selected projects and programs with objectives to provide economic growth and to increase work places in four sectors such as business development, infrastructure, education and health followed by submission of the proposal to Millennium Challenge Corporation of United States in December 2004.

The proposal of program for business support in extent of business development was delivered. According to this program, financial new instruments such as to increase long-term loan resources, which is used to develop private business, to promote high-beneficial investment, to investment by loan guarantee or securities will be launched in the market. The project to restore the $176 \mathrm{~km}$ longed paved road in routine UB-Lun-Erdenesant was proposed in infrastructure sector. 


\section{Inflation}

Government of Mongolia works with purpose that inflation level will be at approximately 5 per cent in medium term. Harmonized with this purpose, accurate monetary policy will be implemented and resource money growth will be kept at normal level. The policy to improve the supply of nessecary goods to citizens' will be implemented sustainably.

In recent years, the consumer goods and service prize index has been quit stability. The inflation level has decreased slightly from 2003 and it reached the lowest level of transferred period in 2002. The money supply increased because of individuals' saving raised rapidly therefore Because of the increase in oil prices on world markets, domestic market fuel price increased, and the Government implemented the money withdraw policy in the end of 2004 in order to keep macro economic growth, inflation level and foreign exchange rate in sustainability as well as the posivite outcomes have been came out. The outside bank money average growth was 9.1 per cent in 2000-2004. The major part of the money supply growth is savings growth of individuals and enterprices therefore the loan amount, provided by commercial banks to private sector has been increased.

Figure 6. Changes in inflation and money supply, by percentage from beginning of year

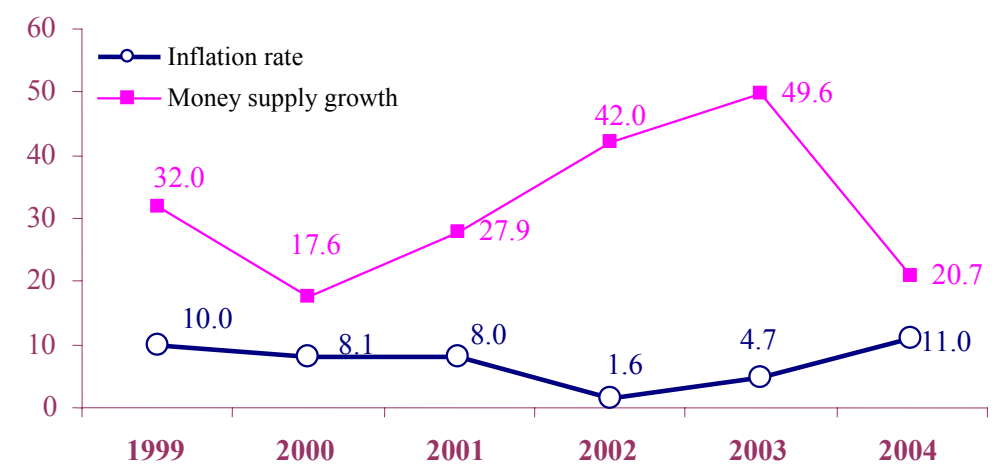

The inflation level was high-pitched in 2004, as mentioned before. The price increases in petroleum, fuel, transport and communication in world market influenced to the figure negatively. Also meat and meat production price increased by 24.1 per cent, housing, fuel and electricity price by 3.9 per cent, and transport and communication service price increased by

The main goal of the monetary policy, will be implemented in long and medium term, are to strengthen the sustainability in macro eceonomy, to create a monetary and financial environment to promote GDP growth, to deepen the financial intermediation, to expant the financial and commercial bank service. Bank of Mongolia will implement the flexible policy of foreign exchange rate continuesly coordinating with payment balance, demand and supply of foreign currencies between banks. 
21.9 per cent from beginning of year. As the fuel prices increased, goods and services prices also increased in 2004, negatively impacting livelihoods of poor citizens and further increasing the depth of poverty. In 2004, the government took measures to increase salaries and pensions by 25 percent, offsetting this effect of price increase.

There are some reasons of price increase in meat and meat products, at first, the meat supply was decreased respectively due to dzud in last several years and secondly, the meat transportation cost was increased due to implementation results of program to locate butcheries outside the city, and lastly, the increase of fuel prices. At end of 2004, inflation level was 11.0 per cent.

International commercial bank management and organization's best methods have introduced in bank sector of Mongolia in last several years. As a result of the competition to enhance financial intermediation and to improve paying capacity between commercial banks has been intensified, total money amount reached 847.0 billion tugrugs at the end of 2004 . According to the money supply composition, outside bank money is 16.9 per cent, bank accounts by tugrugs is 9.2 per cent and individual savings is 73.9 per cent.

\section{Exchange rate}

In the medium term, the goal to ensure stability of the value of tugrik in line with international and domestic conditions was set out.

Following the above goal, Bank of Mongolia worked with purposes to keep sustainable exchange rate between tugrugs and foreign currencies in order to improve economic competitiveness in world market and to create a sustainable environment of business.

The exchange rate between tugrugs and US dollars has been constant in last several years. For instance, the exchange rate between tugrugs and American was decreased by 3.8 per cent in 2003 and 3.5 percent in 2004.

Picture 7. Exchange rate, end of the period

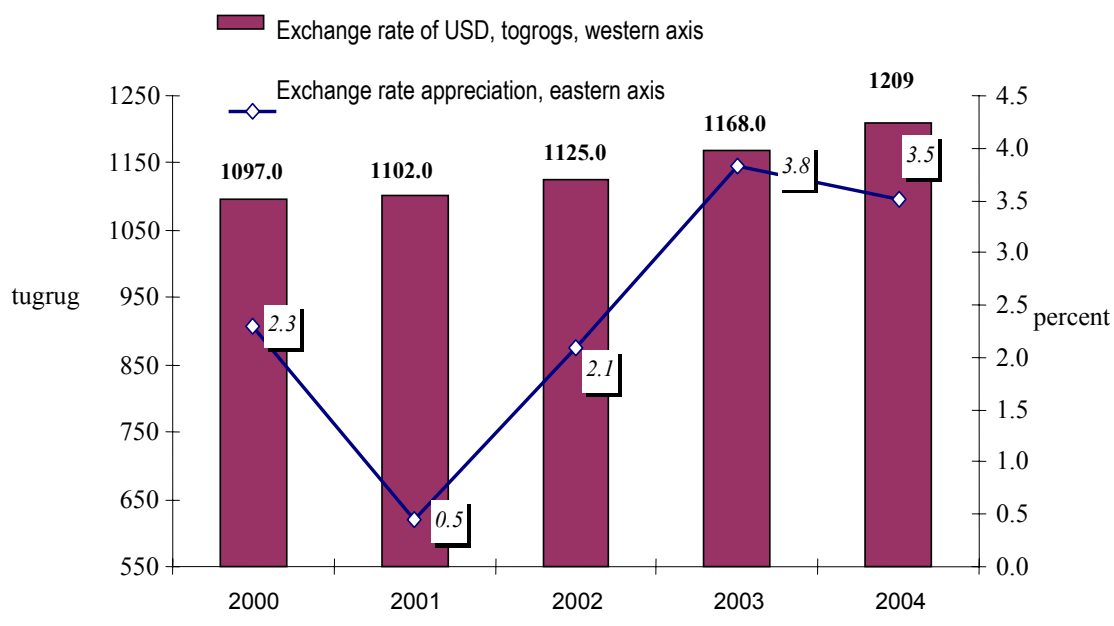


At the end December of 2004, the nominal exchange rate between tugrugs and US dollars was 1209.0. Also external trade situation in 2004 was good influenced positively to the exchange rate steadily. Generally, exchange rate of US dollars is decreasing in the world market has influenced slightly to the decrease of the exchange rate of tugrugs.

However total external trade balance deficit is 10 per cent of GDP but the exchange rate between tugrugs and foreign currencies is steadily due to the increases in individual Tran ferments from foreign countries and inflows of loans, grants, capitals and investments therefore this increases has reached to the amount, which can recover the foreign trade balance deficit. In 2004, export revenues increased and the foreign trade deficit decreased compared to 2003, significantly contributing to fully supply the foreign currency demand.

\section{Interest rate}

Government of Mongolia works with purposes to boost the fair competititon in bank and financial sector to launch new services, to update the techniques and technologies and to develop the control instruements. Therefore, we have planned to implement a staged-works to expand the bank and financial intermediation services to rural areas.

In the field of creating sustainable and accurate environment for bank and financial system, in 2003-2004 the Government of Mongolia have implemented the policies to keep credit real interest rate in the positive level consistence with inflation level as well as to build environment promoting economic growth as way of decreasing credit nominal interest rate.

At the end of 2004, the average interest rate of commercial banks was 30.0 per cent in tugrugs loan, 17.9 per cent in foreign currency loan that represent on average a 3-4 point decrease from the average rates in 2003 . The loan amount, provided to private sector reached 516.6 tugrugs in 2004 , which was increased by 53.8 per cent or by 180.7 billion tugrugs compared with the end of 2003.

It shows that economic activities have intensified and a demand of loan is relative higher, but still the Mongolbank monetary management and regulation policies to reduce interest rates produced certain results. 


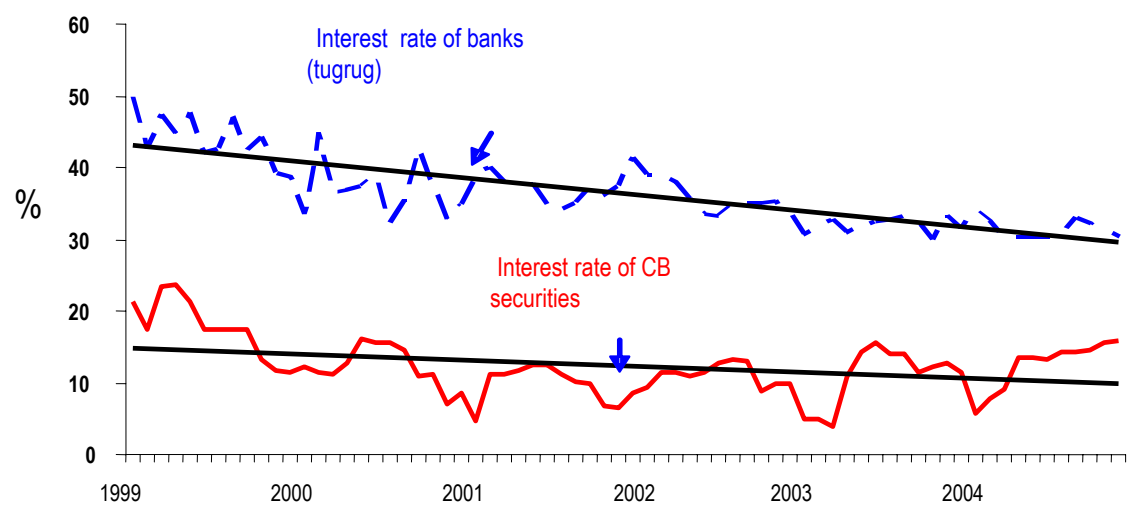

\section{Commercial Banks}

Government of Mongolia set the goals and implemented specific activities to intensify structural reforms of the banking sector, reassure the stabilization, create a health banking system by means of attracting foreign investments, and privatize the state owned banks to reputable domestic and foreign strategic investors and basically transfer them to the private sector, and as a result, the banking and finance sector performance improved in 2003-2004.

Table 4. Banking and Financial System Indicators

\begin{tabular}{|l|l|l|l|l|l|l|}
\hline No & & 2000 & 2001 & 2002 & 2003 & 2004 \\
\hline 1 & M2/ GDP & 25.4 & 29.7 & 37.9 & 48.1 & 46.8 \\
\hline 2 & Loans/GDP & 6.6 & 12.1 & 18.7 & 30.3 & 33.5 \\
\hline 3 & Total Assets/GDP & 22.1 & 29.8 & 39.7 & 52.0 & 57.0 \\
\hline 4 & Out-of-bank Cash/ДНБ & 10.0 & 9.8 & 9.7 & 9.0 & 7.6 \\
\hline 5 & Deposits/GDP & 15.5 & 19.9 & 28.2 & 33.6 & 34.6 \\
\hline
\end{tabular}

As activities of banking and financial institutions stabilized and became more active, the confidence of citizens, business entities and organizations in banks revived, and this positively impacts economic growth. Over the period of 2000-2004, the ratio of total banking sector assets to GDP increased by 2.6 times, deposits by 2.3 times, total loans by 5.1 times and banks' own equity by 1.8 times.

Deposits of citizens increased by $\mathrm{Tg} 135.2$ billion in 2004 compared to 2003. This indicator shows that activities of banks and non-bank financial institutions improved and confidence of citizens in banks has increased.

According to the rural investment environment survey conducted by the NSO in 2004, the list of the top 10 problems in engaging in business activities is led by the interest rate, macroeconomic instability and access to credit. Exactly because of this the Government of Mongolia proclaimed 2005 the Year of Microfinance. 


\section{Micro finance}

Micro finance means to serve people who cannot be covered under the banking and financial services. Currently, the micro finance has more and more commercial character not only in Mongolia but also throughout the world, and types of micro finance service is widening. The micro loans are being used to meet consumption needs and provide working capital needs rather than long term investment financing tool. The services for customers such as employed workers, micro businessmen, herders, farmers, civil servants, pensioners, students and unemployed people have been extended constantly, and have been introducing new types of services such as leasing, insurance, cash transfer and other payment and settlement services while not being limited to deposits and loans.

For our country, we believe that XacBank and AgBank have been accumulating the best experience in reducing poverty, supporting employment and supporting small and medium enterprise. XacBank has about 30 thousand borrowers, of which 8.6 percent are in rural areas, while AgBank had 38 thousand borrowers in 2003 and 68 thousand in 2004. Of the borrowers, 99 percent received Tg 1-5 million. In the area of microfinances, XacBank provides loans to 141 soums and Khaanbank through its 390 branches; the average loan monthly interest fluctuates between 2-3.5 percent, indicating the increase of opportunities for citizens to borrow low interest money.

In the last several years, following the micro, small and medium business and population micro loan needs, the NBFIs (Non Bank Financial Institutions) are developing much faster. In 2002, there were 34 NBFIs but in mid 2004 the number of NBFIs increased up to 108 . Total working capital of the NBFIs reached 12.6 per cent of total banking sector capital and 2.6 per cent of total assets. Minimum working capital requirement for the NBFIs is 100 $\mathrm{mln}$ tugrug in capital city and $1 \mathrm{mln}$ tugrug in rural area. The government and the World Bank have selected 6 NBFIs in order to develop micro financing in the rural area. Under the World Bank Micro Finance Development Fund 150mln tugrug of loan was issued, and MSWL (Ministry of Social Welfare and Labour) and the Employment Promotion Bureau issued $120 \mathrm{mln}$ tugrug of loan to some NBFIs respectively.

Out of total 600 Deposit and Saving Cooperatives (DSC), 327 are located in Ulaanbaatar, 243 are working in the local areas. Although there are no provisions in the Law on Cooperatives on state facilitation and supervision for the DSC, the Central Bank has been executing such finction recently.

The NGOs can play an important role in increasing capacity of poors to receive micro loan and to efficiently use them through involving them under their trainings. Currently, international NGOs such as ADRA, World Vision and Ger Initiative etc are piloting tools for poors. In particular, the ADRA Mongolia NGO has developed a program using two different approaches for micro finance since 2002. They identify citizens who are unable to receive a loan, but are capable for doing business and have business skills, involve them under business planning, marketing and loan management trainings, give them a concessional in terms of collateral loan for them together with XAS bank. Customers who did not meet ordinary loan requirement of the XAS bank, could have access to loan due to the project support and repaid the loan successfully which led them to have constant loan access of the XAS bank. 
Support of the government of Mongolia and international banking and financial institutions is playingan important role in developing micri finance.

The Central Bank is participating in three international institution funded projects as on-lender:

1. "SME development promotion project" equals to $5.1 \mathrm{mln}$ euro for export promotion. This project is being implemented according to the agreement between the government of Mongolia and the German government. The projectc has been implemented throigh TDB and Mongol Post banks.

2. ADB funded Agriculture Sector Development project implemented since 2002. The Central Bank on-lent USD4.4mln to the particpated in the agriculture sector developmewnt propject commercial banks: Mongol Post, Zoos, XAS and Ag Bank.

3. The loans are being issued under the Employment Promotion Fund.

Under the Sustainable Livelihood Project of the IDA-a member of the WB Group, the Micro Finance Development Fund was established and started to issue loans to support economic activities of the rural poors and low income families and deliver services to encourage their sustainable livelihood. Loan amount starts from 35 thous. tugrugs and 95 per cent of total issued loans were used to create livelihood sources for the household life. As of September, 2004 average loan amount per customer was $1.14 \mathrm{mln}$ tugrug, loan repayment was 99 per cent and annual average interest rate was 36 per cent.

In terms of the loans issued by the Loan Repayment Fund of the National Program to Support Household Livelihood Capacity, the loan repayment was at 95 per cent, 2 per cent of interest for the loan up to 6 months, the first phase loan is 500 thous. tugrug for poor and low income families and second phase loan was up to $1 \mathrm{mln}$ tugrug. According to the loan issuing rules, the loan issuing has been continued for aimags and districts where loan repayment rate is above 70 per cent.

\section{Insurance}

EGSPRS set goals to reform and change objectives, roles and diversity of products of insurance services, in consistence with the state policies to support economic growth, and with the development of the real sector.

\section{Insurance policies are focused on improving legal environment, making optimal monitoring and management of insurance company assets, expand products and coverage of insurance, and reinforce international standards.}

Under this purpose, the number of insurance companies increased and state owned insurance companies were privatized, resulting in increased service quality and competition. The ration of insurance payments and premium revenues has been decreasing every year since 2001. This is related to the increase in premium revenues of insurance companies from year to year. 
Table 5. Insurance Premium Revenue and Compensation /in bln tugrug/

\begin{tabular}{llclc}
\hline Year & $\begin{array}{l}\text { Insurance } \\
\text { Revenues }\end{array}$ & Premium & Compensation & \multicolumn{2}{l}{$\begin{array}{l}\text { Compensation, } \\
\text { Insurance } \\
\text { Revenue } \\
\text { /percent/ }\end{array}$} & $\begin{array}{c}\text { Premium } \\
\text { Ratio }\end{array}$ \\
\hline 1999 & 3.7 & 0.7 & 18.9 \\
2000 & 4.2 & 1.0 & 25.2 \\
2001 & 5.1 & 1.7 & 34.2 \\
2002 & 6.1 & 1.1 & 18.1 \\
2003 & 6.3 & 1.2 & 19.1 \\
2004 & 7.9 & 1.4 & 17.7
\end{tabular}

Law on Insurance and Law on Professional Participants in Insurance were amended in 2004 in order to put the development of the insurance market on a right track, increase and expand the scope and products of insurance services, improve legal environment for more optimal use of unused balance of insurance company assets, create efficient and appropriate monitoring and supervision system and bring procedures, bylaws and standards to the international levels.

As these laws were approved, the legal ground for the insurance system to shift to the commercial basis was created. The law requires that the minimum level of insurance institutions charter fund be Tg 500 million, and it was prohibited to create this fund by use of loan funds. This serves as an important step to prevent from different risks.

Also, a package of insurance related rules are being prepared in order to create a set of standards and criteria indicators for insurance activities as well as for their monitoring and inspection, and to develop and apply modern methods that meet international standards for measurement of these standards and indicators.

Citizens deposit insurance law is being newly developed in order to improve the confidence level of citizens and businesses in banks, expand the scope of financial intermediation by increasing resources of banks and support real sector of the economy.

Under the World Bank technical assistance project, an index based livestock insurance system model is being developed in order to compensate for economic losses incurred by livestock sector due to natural disasters, droughts and zud, to lower the burden on the state in protecting livestock, and to create a legal environment for establishing a reserve fund for overcoming potential risks.

\subsection{Analysis of Implementation of Export and Industry Support Policies}

\section{Foreign trade}

Foreign trade intensified as domestic demand had increased due to the economic growth, and increase in money supply, budget current expenditures, and domestic and foreign investments. By the preliminary results of 2004, total foreign trade turnover reached USD 1864.9 million, an increased of 31.6 per cent compared to 2003. Total foreign trade balance turned a deficit of USD 158.3 million, a decrease by USD 27.1 million compared to 2003. 


\section{Government of Mongolia plans to reduce the foreign trade deficit to 10 per cent of GDP in the medium term.}

The trade made with neighbor countries constitutes the major proportion of the total foreign trade turnover, indicating that they remain the main trade partners for Mongolia.

Exports. By preliminary estimates for 2004, exports reached 853.3 million US dollars, which is an increase by 38.5 per cent or by 237.4 million US dollars compared with the same period of 2003.

The exports of gold and copper, prices for which were very high in the world market throughout the year, constituted the major part export revenues. Although a minor share of exports, handicrafts made by poor and vulnerable group people provided non-trivial export revenues. But because of the low probability of copper prices being at the same high levels, there is a need for intensifying policies to produce and export new brand products.

Imports. The imports reached 1011.6 million US dollars in 2004, which is an increased by 26.3 per cent or 210.6 million US dollars compared with the same period of the previous year. The volume of imports has increased continuously in last several years in relation to the development of mining, processing industry and infrastructure.

In 2004, plant origin product imports increased by 31.4 million US dollars, mineral product imports by 64.8 million US dollars (of which 60.6 million dollars come from increase in fuel imports), iron and iron product imports by 27.2 million US dollars, equipment and transportation imports by 50.4 million US dollars. These comprise the major part in the increase of imports equaling to 173.8 million US dollars. The volume of imported inventory, machinery and equipment is high due to the amount of work related to building roads, implementation of projects to improve utility services and construction and development that are funded by loan or grant funds.

Foreign direct investment. In 2003, foreign companies received licenses to invest USDF 196.8 million, of which USD 131.5 million of direct investments were made. However, in 2004 the foreign direct investments equaled to USD 95.5 million. This drop is related to the decrease in textile production. 
Figure 9. Foreign Direct Investments, in million USD.

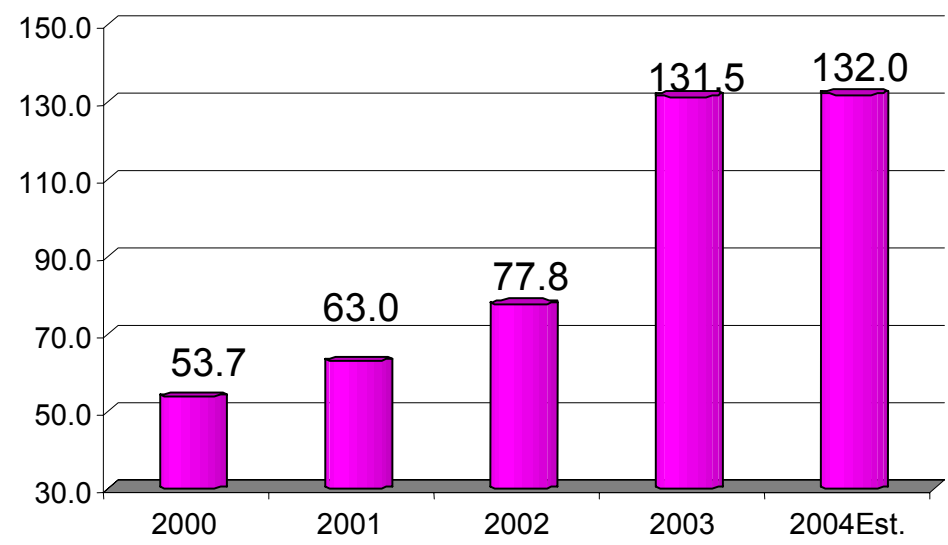

\section{Industry}

The main content of EGSPRS is the issue of increasing income of citizens and reducing poverty by creating jobs on the basis of supporting exports and industrial output. Under this frame, the following activities have been implemented in 2003 and 2004.

Government of Mongolia has worked with the policy to increase investments in this sector in order to attain the goals in Government Action Plan, such as to reach the economic growth of 6.0 per cent in 2004 and to intensify the structural reforms based on private sector with export orientation.

Foreign and domestic investments in the mining sector will be increased in the medium term as a result of creation of the legal environment for business operations and the improvement of industrial infrastructure. The level of prospection of new mineral depostis will be increased in the medium term. In the mining sector, mining, processing and final product production by use of industrial technology will be emphasized.

Compared with the previous year, the total mining and extracting output increased by 30.8 percent in 2004 at the 1995 constant prices. In 2004, mineral products worth $346,538.8$ thousand US dollars were exported. This is a twofold increase over 2000 and 61.5 per cent increase compared to the same period of 2003.

As a result of the policy to support the export production, goods and raw materials amounted 853.3 billion US dollars exported in 2004, which was increased by 38.6 per cent compared with the previous year. 
The total amount export goods in 2004 consisted of $40.6 \%$ by mineral products export; $28.1 \%$ by pearl, fashion and non-fashion jeweler, and decorative; $22.8 \%$ by textiles and textile articles; $2.9 \%$ by live stocks, animal and planting products, food; and 2.7 per cent by raw and possessed hides, skins, fur and articles. There were 63 tourist camps in 1999 and there are 160 tourist camps with 7000 beds in 2004 .

The commercial banks are working with the policy that do not excess the loan interest rate for companies, which produce goods and services for export and top interest rate is 3.0 for them.

In spite of production volume has increased therefore mining and its sales has risen but the cost of a product has been increasing due to the uncovered mines have become more deepen, the copper volume in ore has been decreased, the geology situation has become worse, the price of energy and some kind of raw materials has become more expensive. Therefore, it is necessary to launch modern technology in mining manufactories. So that, the manufactory is working now on establishment of Mongolia and Israeli join-venture 'Shim technology' and its equipments installation in order to process molybdenum concentrate completely and produce final products.

Figure 10. Copper concentrate and fluorspar flotation concentrate, in million USD

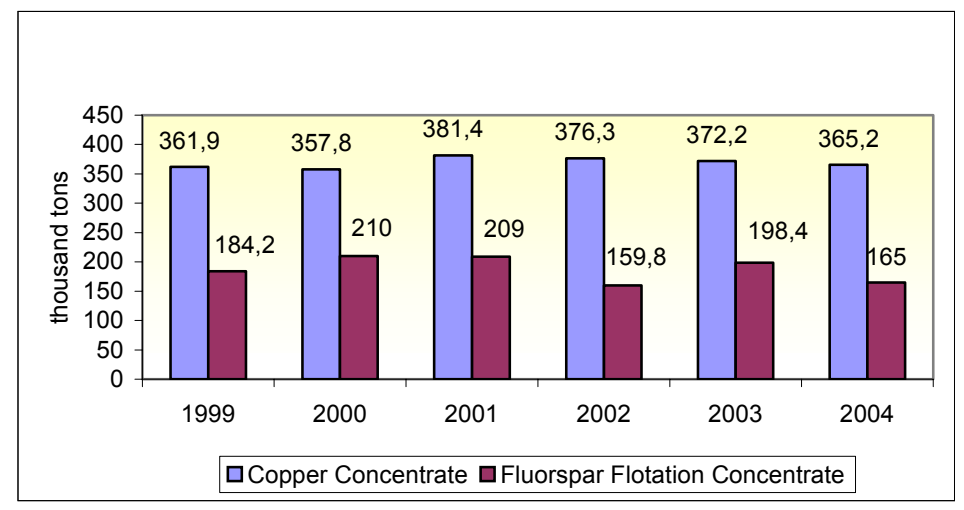

The project proposal that to build a fabrication in around to Erdenet manufactory in order to produce final copper products was developed successfully. Followed by, in Outo cumpu manufactory in 2004, the experiment to develop the concentrate by autoclave method was made and as results the cathode copper was produced successfully. Government has worked to take attention to improve the operation of 'Erdmin' manufactory, who is working in poor owe resource and hence 641 ton pure cathode copper was produced in 2000 then this amount was increased dramatically that 1476 ton in $2001,1500.0$ ton in 2002, 1341.1 ton in 2003, 2376.1 ton in 2004 pure (99\%) cathode copper was produced. It means that, this amount was increased by 77.2 per cent in 2004, compared with the precious year. 'Erdmin' manufacture received 2000 thousand ton unbalanced owe with $0.8-0.82 \%$ from uncovered mines of "Erdenet" manufactory and then made an agreement with "Erdenet" manufactory to create new spoil heap named Erdmin-2 in October 2003 and this work has done as well as the spoil heap is used now. Since the spoil heap has been used, it is become possible to increase the production volume by 35 per cent. The feasibility study, that research the capacity to 
produce 25 ton cathode copper in a day is performing cooperating with 'Erdenet' manufactory in the present.

The measures to create accurate criteria between essential production number and recourse of raw materials, to improve utility capacity of equipments and to increase exports were undertaken in the textile sector one of main sectors in manufacturing in 2004.

Figure 11

Cashmere Processing Sector Output

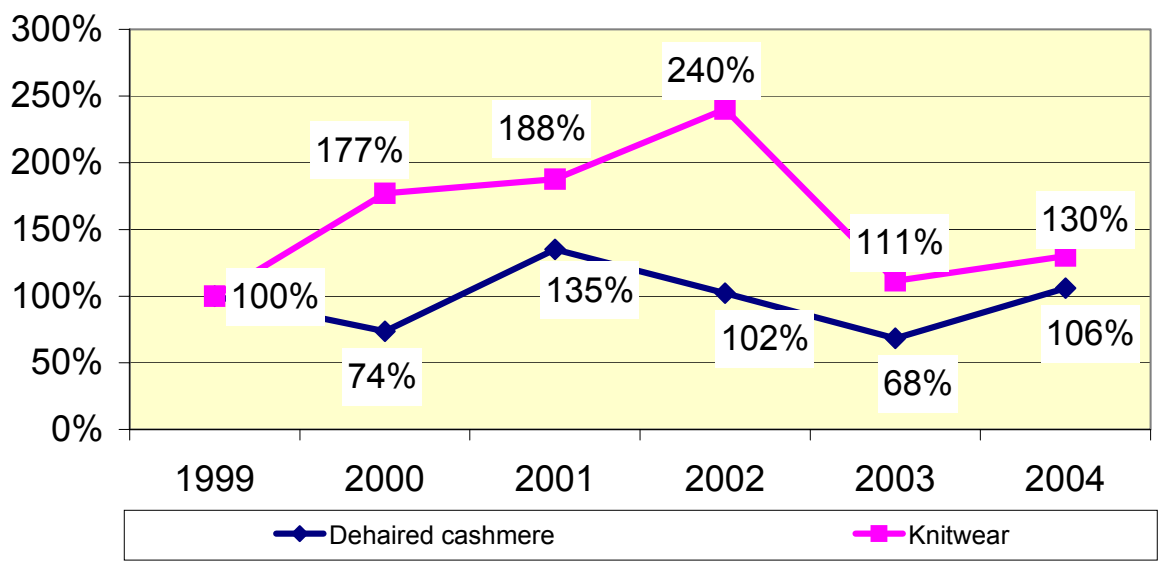

The policy that the manufactories producing final products are exempted from VAT and custom duties, have applied from 2001 and as a result, the capacity to fabricate the cashmere products increased by 2 times. As a consequence of the import products proportion in the total production has being increased in domestic market, the clothing production and furs processing were decreased by 16.4 per cent; the processing, hidden articles and boots production were decreased by 50 per cent; the productions wooden and wooden articles were decreased by 46.4 per cent.

Government of Mongolia approved a program named "Developing manufacture of sewn products" by government resolution \# 207 (2003) and has been implementing it. Government has implemented the measures such as not to rely tax on inventories ordered by foreign users and cancelled the license requirements on sewn and knitted products.

There nearly 100 enterprises work in clothing production sector in present time and 38.3 per cent or 36 enterprises from them are owned 100 per cent by foreign investors, 46.8 per cent or 44 enterprises are joint ventures and 14.9 per cent or 14 enterprises are owned by domestic investors. From of the foreign invested enterprises, 35 per cent are invested by People Republic of China, 13.7 per cent are invested by Hong-Kong, 23.7 per cent by Republic of Korea, 8 per cent are invested by Taiwan and 20 per cent are invested by United States of America, Canada and Great Britain.

In the sewn and knitted production sector, there were 37.2 thousand products were produced and the products amounted 97.0 thousand US dollar were exported. 
The meat processing manufactories were certified and for 2004, 27 slaughtering livestock were brought a right to export products. According to custom statistical information, total meat and food products exports were reached 13469.5 thousand US dollars in 2003 then this was decreased in 2004 and reached 7737.3 thousand US dollars. Because of the dzud and droughts, which were continued from 2000 to 2003 the number of horses and cows decreased dramatically therefore meat reserves were declined too as well as due to the information about livestock disaster was occurred in 2004, Federation of Russia, major exporter of Mongolia was imposed the restriction on imports of meat and meat production. 


\section{THREE. Poverty status}

Findings of 2002/2003 LSMS and HIES surveys as well as 2002/2003 Labor Force Sample Survey, "Ulaanbaatar Poverty and Migration" survey and other relevant surveys conducted by the Poverty Research Group were used for the analysis on poverty status.

\subsection{Income poverty}

\section{Box 1: Goals and Objectives}

- By 2015, halve the proportion of citizens with income below the minimum subsistence level

- Obtain 5.2 percent real GDP growth in 2004

- Achieve 3.8 percent growth in agricultural production (animal husbandry) in 2004

* Government of Mongolia, EGSPRSP, Ulaanbaatar, September 2003

Monitoring Indicators of EGSPRS

Analysis of the state of poverty was based on relevant poverty estimates of 2002/2003 HIELSM Survey as the survey is the main information source on income poverty. Income poverty indicators became basis of monitoring relevant EGSPRS objectives.

HIES/LSMS of 2002/2003 was conducted on the basis of revised sampling design and methodology to make them consistent with international standards, and in addition this was carried out as the combination of 2 separate surveys, Household Income and Expenditure Survey (HIES) and Living Standards Measurement Survey (LSMS).

The 2002/2003 HIES covered 3308 households and poverty indicators were revised in national, rural and urban and regional levels.

\subsubsection{Poverty measures}

When the poverty coverage is described based on the minimum poverty line, it was estimated that 36.1 percent of total population or 900.0 thousand people live in poverty1. In other words, 36 people out of 100 in Mongolia have no capacity to purchase basic need food and non-food consumer products. This fact shows that the poverty is widespread in the country. Poverty incidence level is lower in urban areas (30.0 percent) than in rural areas (43.0 percent). The lowest level of poverty in the country is in Ulaanbaatar. 5 out of 9 poor people live in soum centers and rural areas. Poverty depth index is at 11.0 percent and poverty severity index equals $4.7 \%$ (Table 1 ). These poverty determination indicators show that there is high inequality among the poor.

\footnotetext{
${ }^{1}$ Total population of Mongolia in 2002 is estimated at 2,475,400 basd on the 2000 population census.
} 
Table 6. Key Poverty Indicators (country average by urban and rural in percents)

\begin{tabular}{|l|c|c|c|}
\hline & Incidence, P0 & Depth Index, P1 & Severity Index, P2 \\
\hline Urban & 30.3 & 9.2 & 4.0 \\
\hline Rural & 43.4 & 13.2 & 5.6 \\
\hline $\begin{array}{l}\text { Country } \\
\text { average }\end{array}$ & 36.1 & 11.0 & 4.7 \\
\hline
\end{tabular}

Source: HIES 2002/2003

\subsubsection{Inequality}

In 2002-2003 the Gini coefficient, an index for the consumption gap, was estimated at 0.329 based on per capita consumption (with price adjustment). The poverty inequality exists more in urban areas rather than rural areas. The richest $20 \%$ of population has 5.5 times more consumption than the poorest $20 \%$. (Figure 12)

Figure 12. Gini coefficient: 1995,1998, 2003

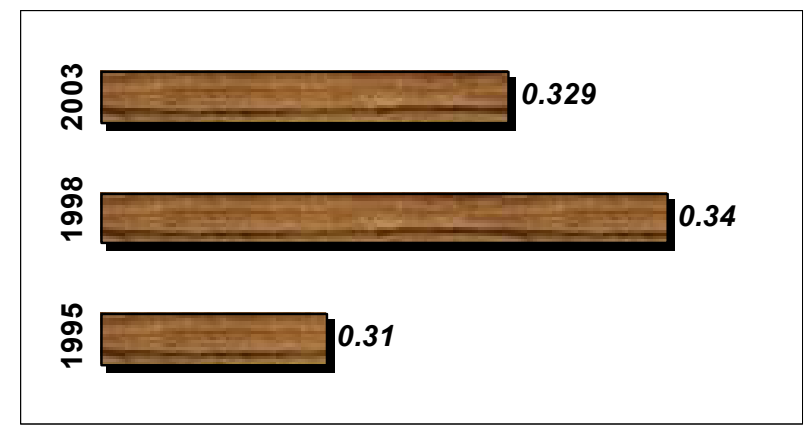

Source: "Living Standards Measurement Survey" /LSMS/

1995, 1998, NSO

HIES 2002/2003

\section{Increasing poverty indicators for measuring human capacity and participation}

Poverty is a multi-faceted, complex phenomenon in Mongolia just as it is in other countries. Therefore, it is necessary to define poverty using not only income measures but also social degradation, capacity and participation attitudes and measures. It is important 'to define poverty not only by low income, but also by lack of capacities (opportunity and access to education and health services'2.

\section{Capability Poverty}

\footnotetext{
${ }^{2}$ Amartya Sen, Nobel Prize winning economist
} 
Education and health indicators as well as living environment and housing are competent indicators of the person's well-being. These indicators determine the poverty in terms of capability. In Urban Poverty and In-Migration survey, the index to measure the capability poverty has been calculated based on three groups of indicators: housing conditions; access to the education and health services. The following 9 variables were included in that indicator: (a) type of dwelling: house, apartment, dormitory (not ger and not dwellings not intended for living); (b) electricity; (c) drinking water from protected well or centralized; (d) centralized dust hole as garbage disposal unit; (e) indoor flush toilet; (f) health insurance; (g) distance to school being less than $2 \mathrm{~km}$; (h) distance to health professional being less than $3 \mathrm{~km}$; and (i) access to health professional.

\section{Social Inclusion Poverty}

The accessibility to information, friends as well as social support, and networking are determinants of the well-being. The social inclusion indicator a summary index that has been constructed based on three variables. These variables are: whether the household gets assistance from their khuree in their everyday life; participation in the community work; and lastly, knowledge about the existing projects and programs that are implementing to improve the living standards of the population.

The results of the survey indicate that poverty is apparent in 55 percent of Ulaanbaatar population in terms of either income/consumption, capabilities or social inclusion (Figure 14). 33 percent of population is poor in terms of income/consumption, 24.5 percent in terms of capabilities, and 24.3 percent in terms of social inclusion. Two or three types of poverty overlap for 21 percent of the poor population.

In the future, there is a need to develop certain methodology that can be used for determining capability poverty in national and regional levels. However, these indicators should not replace traditional poverty indicators but should be an information source for the policy makers.

The PRG by the MOF conducted a study on "Current methods that are used for determining household living standards and comparing these methods with similar countries" in 2004 under the funding of the UNDP MON 01/U01 project. The study was done by the research team "Human resources and social protection fund".

As a result of the study, a new method to determine household living standards by indicators that can express living capability of population was introduced. Under the new methodology, 3 package, 11 indicators and 71 measures were selected to determine the living standards of the households. Joint order (\#05/07) of the minister of social welfare and labor and a chairman of the NSO was made in 2005 on the pilot usage of the new methodology and accordingly, the method is being used on a pilot basis to determine household and citizens living standards for the "Child Money" program. 


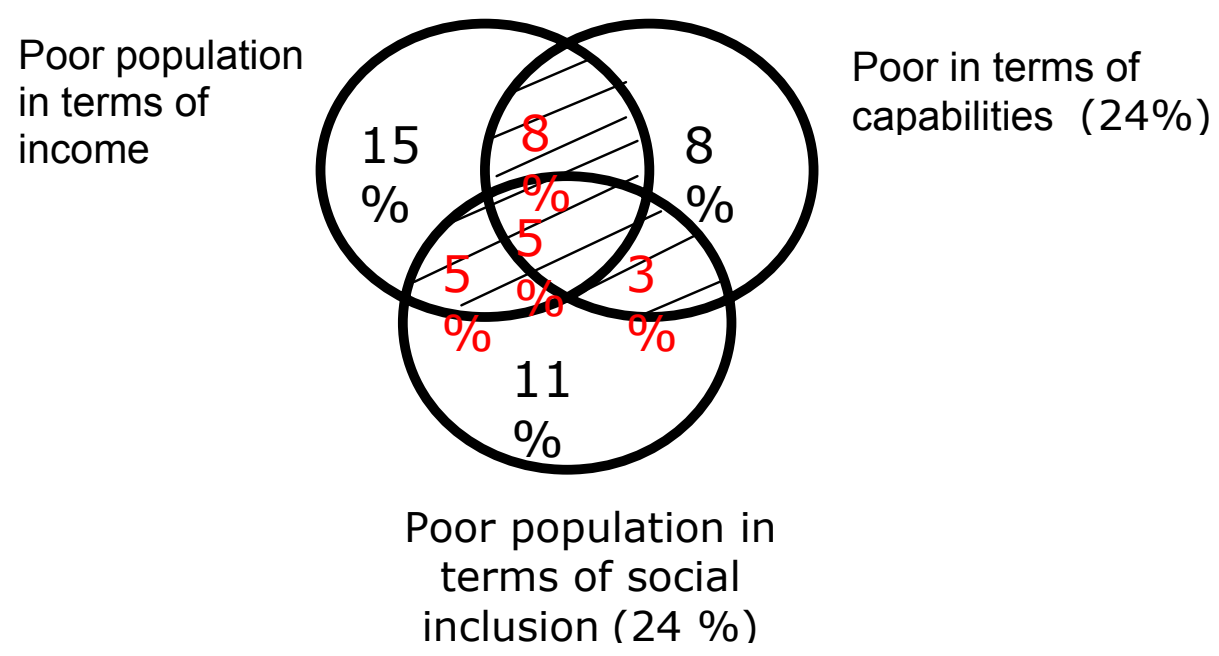

\subsection{Poverty Profile}

Poverty includes various restrictions such as unhealthiness, lack of human capabilities, limited access to infrastructure, lack of food nutrition, shortage of goods and services and lack of capabilities to express religious and political views etc. This is a range of different indicators that expresses livelihood picture and each of them has its own importance. These indicators should be helping policy makers to pay their attention to multi sides of poverty.

\subsubsection{Poverty and Demographic Groups}

The 2002-2003 HIELS sample survey results show that poverty incidence increases uniformly as the size of household increases (Table 2). Probability of a household with up to three members being poor is about 10 percent. One fifth of Mongolian total population lives in households with up to three members, but these people comprise one tenth percent of total poor. 24-34 \% of households with 4-5 members fall in the poor category. These households comprise around half of total population, take two fifths of poor. Also, the poverty level of households with more than five members is about 50 percent. For households with 8 and more members, seven persons out of ten belong to the poverty line - or live in poverty - and these people comprise $1 / 5$ of the total poor population. 
Table 7. Main poverty indicators, by the household size

\begin{tabular}{|c|c|c|c|c|c|c|c|c|c|}
\hline \multicolumn{2}{|c|}{ National Average } & \multicolumn{5}{|c|}{ Household Size } & \multirow[b]{2}{*}{6} & \multirow[b]{2}{*}{7} & \multirow[b]{2}{*}{$8+$} \\
\hline & & 1 & 2 & 3 & 4 & 5 & & & \\
\hline $\begin{array}{l}\text { Poverty Incidence } \\
\text { (Headcount) }\end{array}$ & $\begin{array}{l}36.1 \\
(1.4)\end{array}$ & $\begin{array}{l}1.2 \\
(0.9)\end{array}$ & $\begin{array}{l}7.4 \\
(1.8)\end{array}$ & $\begin{array}{l}15.5 \\
(1.7)\end{array}$ & $\begin{array}{l}23.5 \\
(2.0)\end{array}$ & $\begin{array}{l}34.4 \\
(2.2)\end{array}$ & $\begin{array}{l}48.5 \\
(3.0)\end{array}$ & $\begin{array}{l}57.4 \\
(4.0)\end{array}$ & $\begin{array}{l}69.4 \\
(3.7)\end{array}$ \\
\hline Poverty Depth & $\begin{array}{l}11.0 \\
(0.6)\end{array}$ & $\begin{array}{l}0.4 \\
(0.4)\end{array}$ & $\begin{array}{l}1.8 \\
(0.4)\end{array}$ & $\begin{array}{l}3.6 \\
(0.5)\end{array}$ & $\begin{array}{l}6.2 \\
(0.6)\end{array}$ & $\begin{array}{l}9.1 \\
(0.8)\end{array}$ & $\begin{array}{l}14.9 \\
(1.2)\end{array}$ & $\begin{array}{l}19.0 \\
(1.7)\end{array}$ & $\begin{array}{l}26.1 \\
(2.3) \\
\end{array}$ \\
\hline Poverty Severity & $\begin{array}{l}4.7 \\
(0.3) \\
\end{array}$ & $\begin{array}{l}0.2 \\
(0.2)\end{array}$ & $\begin{array}{l}0.5 \\
(0.1)\end{array}$ & $\begin{array}{l}1.2 \\
(0.2)\end{array}$ & $\begin{array}{l}2.3 \\
(0.3)\end{array}$ & $\begin{array}{l}3.5 \\
(0.4)\end{array}$ & $\begin{array}{l}6.1 \\
(0.7)\end{array}$ & $\begin{array}{l}8.1 \\
(0.9)\end{array}$ & $\begin{array}{l}13.3 \\
(1.6) \\
\end{array}$ \\
\hline \multicolumn{10}{|l|}{ Additional indicators: } \\
\hline $\begin{array}{l}\text { Average share of poor } \\
(\%)\end{array}$ & 100.0 & 0.0 & 0.9 & 5.6 & 15.0 & 21.2 & 21.2 & 15.7 & 20.5 \\
\hline $\begin{array}{l}\text { Average share of } \\
\text { population }(\%)\end{array}$ & 100.0 & 1.3 & 4.2 & 13.0 & 23.0 & 22.3 & 15.8 & 9.9 & 10.7 \\
\hline
\end{tabular}

Note: Standard errors of the survey sample are given in parentheses.

Source: HIELSS 2002/03.

\subsubsection{Poverty Spread: Geographic Distribution}

Mongolia spans over a wide longitude range and has regions with very diverse geographic characteristics including Gobi, steppes, forests, lakes, high mountains and hill ranges and each location has its own specifics in terms of climate, Fiona and wild animals. The country is also landlocked. These specific features have significant and various implications on economic development status and household living standards.

The results of 2002/2003 HIELS sample survey show that poverty status varies significantly across regions. (Poverty indicators are show by geographical distribution in Table 3). Mongolia is divided into 4 economic regions such as Western, Hangai, Central and Eastern, and Ulaanbaatar is considered a separate region due to its specifics even though it is located in the central region. Poverty incidence in the Western region is high as about 50 percent of the population lives in poverty. 38 percent of population in Hangai region and 34 percent in Central and Eastern regions are poor. Poverty incidence is lowest in Ulaanbaatar as one third of the capital city population is poor. $1 / 4$ of poor comes to the western region where $1 / 6$ of the country's population resides. In comparison, another $1 / 4$ of poor live in Ulaanbaatar where the third of the population is concentrated. More than $1 / 4$ of the poor population lives in Hangai region, $1 / 5$ in the central region, and remaining 9 percent in the eastern region. 
Table 8. Main poverty indicators, by regions.

\begin{tabular}{|c|c|c|c|c|c|c|}
\hline & $\begin{array}{l}\text { National } \\
\text { Average }\end{array}$ & Western & Hangai & Central & Eastern & Ulaanbaatar \\
\hline $\begin{array}{l}\text { Poverty Incidence } \\
\text { (Headcount) }\end{array}$ & $\begin{array}{r}36.1 \\
(1.4)\end{array}$ & $\begin{array}{l}51.1 \\
(3.5)\end{array}$ & $\begin{array}{l}38.7 \\
(2.9)\end{array}$ & $\begin{array}{c}34.4 \\
(3.0)\end{array}$ & $\begin{array}{l}34.5 \\
(4.4)\end{array}$ & $\begin{array}{l}27.3 \\
(2.6)\end{array}$ \\
\hline Poverty Depth & $\begin{array}{l}11.0 \\
(0.6)\end{array}$ & $\begin{array}{l}14.6 \\
(1.3)\end{array}$ & $\begin{array}{r}12.3 \\
(1.3)\end{array}$ & $\begin{array}{r}10.1 \\
(1.4)\end{array}$ & $\begin{array}{l}12.4 \\
(2.3)\end{array}$ & $\begin{array}{r}8.1 \\
(1.0)\end{array}$ \\
\hline Poverty Severity & $\begin{array}{r}4.7 \\
(0.3) \\
\end{array}$ & $\begin{array}{r}5.7 \\
(0.7) \\
\end{array}$ & $\begin{array}{r}5.2 \\
(0.7) \\
\end{array}$ & $\begin{array}{r}4.3 \\
(0.8) \\
\end{array}$ & $\begin{array}{r}6.6 \\
(1.6) \\
\end{array}$ & $\begin{array}{r}3.3 \\
(0.5) \\
\end{array}$ \\
\hline \multicolumn{7}{|l|}{ Additional indicators: } \\
\hline $\begin{array}{l}\text { Proportion of population } \\
\text { under poverty line }(\%)\end{array}$ & 100.0 & 24.0 & 25.8 & 18.6 & 8.9 & 22.8 \\
\hline $\begin{array}{l}\text { Number of people under } \\
\text { poverty line (thousand } \\
\text { people) }\end{array}$ & 894.0 & 214.4 & 230.5 & 166.3 & 79.1 & 203.8 \\
\hline Share in population $(\%)$ & 100.0 & 17.0 & 24.1 & 19.5 & 9.3 & 30.2 \\
\hline $\begin{array}{l}\text { Population size (thousand } \\
\text { people) }\end{array}$ & 2475.4 & 419.8 & 596.1 & 483.4 & 229.0 & 747.3 \\
\hline Urbanization $(\%)$ & 55.4 & 34.8 & 31.3 & 40.6 & 42.0 & 100.0 \\
\hline
\end{tabular}

Note: Total population for 2002 is based on the 2000 Population and Housing Census. Standard errors of the survey sample are given in parentheses.

Source: HIELSS 2002/03.

\subsubsection{Poverty and Seasonal Fluctuations}

One of the specifics of Mongolia in relation to poverty is the issue of seasonality. The 2002/2003 HIELS sample survey results show that poverty incidence is higher in the 2nd and 4th quarters by 5 percent (Table 9). Consumption level is generally higher in the warm season (3rd quarter), and the lowest in the long winter season (adjusting for the increased consumption during Lunar New Year Festival that takes place in January-February). Poverty incidence fluctuations can be attributed to changes in any seasonal fluctuations affecting specifics of the economic cycle in Mongolia.

Table 9. Main poverty indicators, by seasons

\begin{tabular}{|l|r|r|r|r|r|}
\hline & $\begin{array}{r}\text { National } \\
\text { Average }\end{array}$ & Quarter I & Quarter II & Quarter III & $\begin{array}{r}\text { Quarter } \\
\text { IV }\end{array}$ \\
\hline Poverty Incidence (Headcount) & 36.1 & 29.1 & 40.3 & 33.5 & 41.2 \\
& $(1.4)$ & $(3.0)$ & $(2.7)$ & $(2.8)$ & $(2.9)$ \\
\hline Poverty Depth & 11.0 & 8.0 & 11.7 & 10.3 & 13.7 \\
& $(0.6)$ & $(1.0)$ & $(1.1)$ & $(1.2)$ & $(1.4)$ \\
\hline Poverty Severity & 4.7 & 3.1 & 4.9 & 4.4 & 6.1 \\
& $(0.3)$ & $(0.5)$ & $(0.6)$ & $(0.6)$ & $(0.8)$ \\
\hline
\end{tabular}

Note: Standard errors of the survey sample are given in parentheses.

Source: HIES/LSMS 2002/03.

\subsubsection{Household asset ownership status}

Asset ownership status is one of the important factors in determining the population living standards. Asset capacity provides an opportunity for households to alleviate impacts of economic instability and seasonal fluctuations in agricultural production. 
Livestock. The main agricultural production of the country is animal husbandry. Almost half of the labor force is engaged in agriculture, especially in animal husbandry and related labor. Each of the main five types of livestock provides different support and opportunities to household livelihoods. Raising goats provides opportunities to participate in cashmere business, having sheep or camels to do wool trade, and cattle or horses to process meat and diary products. Almost four people out of 10 have livestock.

The 2002/2003 HIES survey indicates a negative correlation between rural animal husbandry engagement and poverty. Poverty incidence of herders is shown by per capita heads of livestock. As the size of per capita livestock increases, the poverty incidence are lower both in rural and urban areas.

Even though in urban areas the proportion of population owning livestock is worse off compared to that which does not, among owners, the more livestock they hold, the less poverty they experience. This relationship is clearer in rural areas, yet for holdings greater than twenty bods per capita, poverty appears to be stable.

Land. For households engaged in agriculture, land is an important type of asset. According to the household survey, 13 percent of population is using land for crop and vegetable culture. According to the HIES sample survey, engagement in agriculture is not creating enough opportunities to improve living standards. Compared with non-poor, the poor are mostly dealing with farming and 17 percent of poor and 11 percent of non-poor are engaged in agriculture.

Monetary assets. Monetary assets are one of the main types of the household wealth. According to the $2002 / 2003$ HIELS sample survey results, $15 \%$ of urban and $7 \%$ of rural population have cash asset. $90 \%$ of survey respondents named lack of money as the reason for not keeping monetary deposits. Only 5 percent of poor households, and 15 percent of non-poor households have own financial assets.

\subsubsection{Housing}

One of the main indicators defining population living standards is the type of housing people possess and their possibilities to be covered under the infrastructure services.

Housing types. Ger is the common type of housing for Mongolian population. 44 percent of the population lives in gers, one third in separate residence houses, and one fifth in comfortable communal apartment buildings. Poverty incidence is relatively higher among ger residents, and lowest among comfortable communal apartment building residents. This tendency can be observed for urban areas as well, as probability of dwellers of comfortable apartment buildings falling into poverty is half of that of ger and residence house dwellers. However, for rural areas poverty incidence is not dependant on the type of housing, and equal among all types of housing. More than 70 percent of rural poor live in gers, 25 percent in residence houses, and 3.6 percent in apartment buildings. In rural areas, poverty spread resembles the spread of the population, as three people out of four live in gers, and one out of four lives in houses, indicating no correlation between housing type and poverty status.

Infrastructure services. Living standards and condition will be enhanced through providing the population with infrastructure services such as improved water supply, hygienic 
facilities that meet health requirements, energy and heating. Water supply and hygienic facilities that did not meet the appropriate requirements directly influence population health and increase sickness and its spread. Shortage of energy negatively effects public education and investment. Poverty scope is high among the households who received one of these services but living condition of those households who received all of these services is well.

The household survey indicates that three fifths of the country have access to improved sources of water, half to improved sanitation facilities, three quarters to electricity, and four out of ten households to all of them.

Living conditions and drinking water supply in ger districts are at a highly insufficient level. The number of households using unreliable drinking water in ger districts of Ulaanbaatar is 30 times of those in apartment districts, as many in ger districts have to queue for long hours and sometimes are left without water overnight. ${ }^{3}$

\footnotetext{
3 'Urban Poverty and In-Migration' survey report, 2004
} 


\section{Four. Cross-cutting issues}

EGSPRS, looking at the cross-cutting issue of ensuring sustainable human development, emphasizes its dependency on economic growth and income created on its basis, and includes many issues such as creating income-generation opportunities for the poor, engaging citizens in decision-making processes, strengthening the governance, and ensuring civil society participation and gender equality.

Poverty Reduction Strategy states that one of the ways for the population to come out of poverty and vulnerability is to ensure wide engagement of citizens, specifically poor and women, in decision making at all management levels. For the above-mentioned purpose, many important activities were carried out in 2003-2004. Some of them in certain areas are described below.

\subsection{Governance}

Under the framework of policies directed at supporting sustainable livelihood of population and reducing poverty, the Government is paying attention to strengthening the state roles and its intervention in consistence with market principles and to ensuring civil society participation not only in socially oriented projects and programs, but also in developing, implementing and monitoring processes of all level macro-economic and social policies.

Three presidential and 4 parliamentary elections have been conducted in Mongolia since 1990. Citizens' political activity and participation in political actions have declined since the early 1990s. Overall, participation in elections in rural areas is much higher than that in the urban areas.

Table 10. Presidential and Parliament Elections of Mongolia.

\begin{tabular}{|c|c|c|c|c|c|}
\hline & \multicolumn{3}{|c|}{ Election participation (\%) } & $\begin{array}{c}\text { Decrease in } \\
\text { participation in } \\
\text { election }\end{array}$ \\
\cline { 2 - 5 } & 1993 & 1997 & 2001 & 2004 & -11.1 \\
\hline Presidential election & & & & & -9.8 \\
Urban & 90.2 & 80.5 & 79.1 & & -17.0 \\
Rural & 94.1 & 86.6 & 84.3 & & -10.9 \\
Parliamentary election & & & & & \\
Urban & 93.2 & 88.3 & 76.2 & & \\
Rural & 96.9 & 94.4 & 86.0 & & \\
\hline
\end{tabular}

\section{Governance and justice}

The Government of Mongolia, newly established as a result of the $4^{\text {th }}$ regular election to the State Great Hural of Mongolia, has determined its action program to be implemented in the coming four years on the basis of platforms of 'Motherland-Democracy' Coalition and MPRP for Election-2004 and consensus built after the election. The main objectives of the Government actions are to: 
- upgrade the quality of public service to a new level by strengthening the capacity and accountability of public service institutions and civil servants, expanding civil participation at all levels of decision-making and ensuring transparency;

- deepen legal reforms in all spheres of political, economic and social life and substantially improve standards for ensuring human rights and creating safe living environment;

- sustain higher rates of stable, private sector-led economic growth by providing support for access to new markets on the basis of knowledge and information, and by implementing a regional development concept to reduce disparities in development between urban and rural areas;

- conduct social policy aimed at improving living standards of families and households by providing them with a stable legal environment, adequate infrastructure and a financial environment conducive for accumulating savings, owning, possessing and disposing immovable property such as land and houses; and

- carry out human development policy aimed at educating citizens who respect education, culture and their national traditional heritage, and who are highly conscious about protection of the natural environment, values of democracy and their own rights, and who are able to contribute to the development of their country by taking advantage of various opportunities provided by the globalization process.

By the Law of Mongolia on Approving the Composition of the Government Cabinet, Deputy Prime Minister and Ministers for Construction and Urban Development, Road, Transport and Tourism, Fuel and Energy as well as Ministers of Mongolia were endorsed.

By Resolution \#14 of 2004 of the State Great Hural on Approving General Scheme of System and Structure of Public Administration Institutions, Unfair Competition Regulation Agency under Deputy Prime Minister, and State Specialized Inspection Agency and General Administration of Disaster Protection under the Ministers of Mongolia were established with the status of regulatory agencies.

\subsection{Gender}

\subsubsection{Gender equality, policies implemented to ensure gender equality, results and future work}

The Government adopted the National Program on Gender Equality in 2002. Starting in 2003, budget allocations necessary for reaching the objectives stated in the program have been included in the annual state budget in the priority areas for supporting economic and social development.

The Resolution \#16 of 2003 of the SGH proclaimed 2004 'The Year of Support of Family Development' for the purposes of intensifying the implementation of Mongolian state policies on development of families. A national committee, composed of Chairman of Social Policy Standing Committee of the SGH, Social Policy Advisor for the President, Chief of the Cabinet Secretariat of the Government, Minister for Social Welfare and State Secretaries of all ministries, was established. 
The National Program on Ensuring Gender Equality aims at improving living standards for people and eradicating negative phenomena in the society by developing a favorable environment for men and women to participate equally in development as well as benefit equally from the benefits of development.

The program shall be further aligned with Mongolia's development phases and it shall be implemented until 2015.

The renewed establishment of the National Committee on Gender Equality in 2005 was a positive step towards developing a mechanism for ensuring gender equality that is in line with international standards. The National Committee is composed of Social Policy Advisor to the Prime Minister, Ministers of the Government, President of the Network of Women NGOs and President of Mongolia Men's Association.

In order to fulfill the objectives stated in the program, the Government is paying much attention to involving civil society via cooperation with such NGOs as the National Center against Violence, Mongolian Women's Federation and Democratic Women's Association on the basis of contracts.

\subsubsection{Developing Capacity for Gender-Sensitive Budgeting}

The UNDP Resident Representative Office in Mongolia, in cooperation with the Ministry of Social Welfare and Labor and the Ministry of Finance and Economy, has implemented a project on "Developing Capacity for Gender-Sensitive Budgeting" in 20032004. The project aimed at strengthening national capacity for designing gender-sensitive budgets, developing gender-sensitive budget analysis and ensuring broad participation of Governmental and non-governmental organizations in this process. Within the framework of this project, gender analysis of state budget spent in employment and social sector was conducted by contracting NGOs. 


\section{Box 2: Gender-Sensitive Budget}

A gender-sensitive budget is not budget specifically tailored for men and women but it is important for identifying priority areas and allocating funds on the basis of the needs of the population, especially of the vulnerable groups.

Gender analysis of the budget allows for the identification of gaps and inequalities of budget allocation and coverage. Gender-sensitive budgets help eliminate inequalities and are aimed at increasing their efficiency.

Gender-sensitive budgeting was initiated in 1997 by Tanzania's Gender Network Program that had involved about 20 NGOs. The program also involved governmental organizations and carried out gender inequality analyses of budgets in health, education, local government, and agricultural sectors.

Although the gender sensitive budgeting initiative was initiated about 20 years ago, it is only since the Fourth Global Forum of Women held in Beijing in 1995 that it has developed by resolving gender issues, planning, implementing, monitoring and developing policy recommendations for ensuring gender equality.

There are many examples of conducting gender sensitive budget analyses on the basis of partnerships by Governments and NGOs Barbados, Fiji, South Africa, Canada, Philippines, Sri Lanka, Mexico and Zimbabwe.

Research results showed that public servants lack gender knowledge, that they do not take into account gender issues in policy development and planning, and that gender statistics are not fully adequate in the sectors covered in the research. Thus, there is a dire need to improve gender information in the policy development and gender analysis process, upgrade its quality, develop policies which take gender factors into account and implement those policies. As the results of the project research from 2003-2004 show, it is necessary to conduct training programs to develop national capacity to undertake the above-mentioned tasks.

Within the framework of the efforts to develop and strengthen national capacity for gender-sensitive budgeting, a gender specialist has been appointed on a temporary basis to work in 2003 within the Poverty Research Unit of the Ministry of Finance and Economy. In addition, there are public servants in charge of gender issues working at the line ministries who organized training programs with the purpose of developing capacity for gender-sensitive budgeting. Khangai, Western, Eastern, Central and Ulaanbaatar regional workshops involved aimag and soum Governors and deputy governors, State Fund and budget professionals, public servants in charge of social issues, and civil society and NGO representatives.

Advocacy and public education activities have also been conducted explaining main concepts and the significance of gender-sensitive budgeting through daily newspapers, radio and TV programs. As a result of the above activities, employees in administrations of down to the soum level have obtained general understanding of gender sensitive budgeting. 
The funders of the project, the Japanese Women's Development Fund, has chosen Mongolia as one of the countries that is successfully implementing the gender-sensitive budgeting initiative and has planned to include a short documentary on Mongolia's example in their 2003 annual report. Preparations for the documentary are currently on-going.

\subsubsection{Gender Issues in Governance}

Within the framework of Good Governance Program, the Government aims at increasing women's political participation and eliminating violence against women.

Table 11. Representation of Women in terms of Parliament Seats

\begin{tabular}{|l|c|c|c|c|}
\hline \multirow{2}{*}{ Election years } & \multicolumn{2}{|c|}{ State Great Khural Candidates } & SGK Members & Elected \\
\cline { 2 - 5 } & Total & Women & Total & Women \\
\hline 1992 elections & 298 & 23 & 76 & 3 \\
1996 elections & 302 & 28 & 76 & 7 \\
2000 elections & 603 & 66 & 76 & 9 \\
2004 elections & 263 & 33 & 76 & 5 \\
\hline
\end{tabular}

9 women members elected to the SGH in 2000 comprised 11.8 percent of all members, and this number decreased in 2004 as 5 women were elected comprising 8.4 percent.

\section{Public Education Materials and Manuals on Gender}

The Women's NGO Coalition has developed and distributed in small numbers a manual on Gender Equality and Legal Status in order to raise public awareness of gender issues. The public has positively assessed the manual and requested for its wide distribution in rural areas.

UNFPA, MoH and Press Institute jointly prepared and distributed a package of information on domestic violence issues for the general public and media representatives.

Taking into account the fact that men are more prone to cardiac diseases and some types of cancers, as well as to accidents and injuries, as compared to women, there is a need for improving knowledge and information of men on the issues of healthy living and protection of health. Also, MoH, Health Development Center and UNFPA are working together to increase participation of men in reproductive health issues.

The ADB and the World Bank have jointly conducted a Country gender Assessment in order to map gender issues in Mongolia and help policy-makers and other stakeholders to take existing gender gaps and inequalities in planning for poverty reduction. During the discussion of the report involving governmental bodies, NGOs, and other partners working in the area of gender and development, the Country Gender Assessment report was evaluated as an important and useful document that provides basic information for systematizing the understanding of gender and developing strategies and programs. 


\subsection{Regional and rural development, and environment}

As defined in the EGSPRS, one basis for implementing the strategy to accelerate economic growth and reduce poverty is to create favorable conditions for accelerating regional economic growth and social progress and reducing rural and urban development gap, and eventually mitigating excessive concentration of the population by means of ensuring the appropriate use of regional, natural, agricultural, agronomy and human resources.

Policies to create a legal environment to support regional development in the medium term, to define strategic priority areas for development, and to improve the banking, financial and infrastructure network of given regions are carried out.

Therefore, there is a need to consider the issue of rural population and poverty in view of regional and rural development policies.

\subsubsection{Implementation of policies and measures of regional development}

In order to implement Law of Management and Coordination of regional development, Regional Development National Committee members and its rule, working guideline were approved. Regional national committee on the law and approved procedures is head by the Prime Minister, and includes heads of the regional councils and ministers; its activities started in 2004. Also heads of regional councils were appointed. The general plan to develop 8 regional pillar centers till 2020 and to the special plan to develop Khar-Khorum city which is a pillar center of Khangai region were prepared and finalized. Also the work to develop the program of development of Western, Khangain, Central and East regions was implemented with financing from the science and technology fund in 2004. For the purpose of to implement the regional development concept in aimag and soum levels, the basic to set the inter-soums regions, the centers of group settlements was developed cooperating with Citizen's Representative Committees aimags. Also, the study for new administrative division is being carried out in relation to the structure for regionalized development. If this issue is resolved, Mongolia will have 4 aimags. But there is a need for treating this issue with care. Although merging and enlargement aimags and soums has a positive side in saving on budget spending, the possibility of interruptions in education, health and other social services delivered to citizens cannot be neglected, and especially and first of all affecting the poor. Therefore, negative consequences should be carefully looked at.

The ADB TA that developed methodology on what needs to be done in order to support development in rural areas, especially in lower developed regions The MON-3948 "Master Plan Development Capacity-Building Regional Development" project implemented since 2003 with the technical assistance of ADB is completed and the recommendations produced by the project are being reflected in the regional policy development.

As it is shown in the Action Program of the new government established as in the result of the SGH election of 2004, the government is preparing proposals to develop watering system, intensified animal husbandry and farming in combination nearby the pillar centers of each region and is investigating required funding opportunities in view of foreign programs and projects and domestic financial resources. 
An order of Minister of Finance and Economics was issued to take some measures related to the coordination of 2004 budget performance and many activities such as development of small and medium enterprises in aimags and regions, development of infrastructure and wholesale trade networks, social protection improvement of the population, comprehensive preventive measures to protect the livestock against the natural disasters and supporting the implementation with investment, tax and credit policy were implemented since the beginning of the year.

The "Development of Agriculture Sector" program aimed to improve banking and financial services in regions and rural areas and implemented through the Mongol Bank is bringing positive results. In the framework of this project, 3.1 billion MNT worth loans were disbursed in 2003-2004 and the amount of savings allocated in the banks by that region's people increased by average of 130 percent. Also, the funds for the ADB project aimed at creating jobs are replenished by the interest for these loans, so the funds available for further loans have increased, proving to be an important measure to increase total loan funds.

Government of Mongolia promotes to establish the branches of commercial banks and non-financial institutions in countryside and rural so that the measures to provide rural areas population by adequacy, open and quick bank and financial services also information are implemented through the branches of Bank of Mongolia within the implementation activities of Regional and Rural Development Concepts of Mongolia. Also, the project on supporting savings and credit cooperatives has been implemented since 2003 with the support of ADB.

Under the national program "Hundred thousand solar gers" to improve provision of rural electricity supplies, in 2004, finalize establishing hydro power stations in Tosontsengel soum, Zavkhan, Munkhhairkhan soum, Khovd and Uyench, and implement establishing wind power stations in Erdenetsgaaan soum, Sukhbaatar, Bugat soum, Gobi-Altai and Salhit mountain of Tuv aimag.

As a result of implementation of measures to connect about 10 soums and settlements in each of 2003 and 2004 to the centralized power network by use of state budget funds, cultural and living conditions for the citizens of these soums improved as public restaurants, bars, service centers and shops and processing of household tools and items have been launched locally.

The Government of Mongolia approved a National Program called "100000 Solar Ger" to provide electricity to herdsmen by using renewable energy and it is being implemented it in three stages during 2000-2010, providing solar systems to 5000 households in 2000, 45 thousand households in 2001-2005 and 50 thousand households in 2005-2010 respectively. For the implementation of "100000 Solar Ger" program 200.0 million MNT from state central budget in 2001, 396 million Yen from the Japanese non-project grant aid in 2003 are used and 50 million Yuan from the Chinese grant aid in 2004 going to be used for the purchase of solar systems. 11170 solar systems were procured with non-project Japanese grant aid. In 2003, more than 11100 new households received solar system and as of 2003, a total of about 24500 households had already their own solar systems. In 2004, solar systems were supplied to 20620 households. Therefore, rural herders, who for centuries have used the light of candles, can now enjoy permanent light, and even can watch National TV. 
In order to expand the service coverage of mobile telephony services in aimag centers and major settlements, the transmission system was upgraded with the investment of Postal and Telecommunication Administration and Mobicom company, a mobile phone operator, is carrying out series of works to expand its network coverage and in first half of 2004 introduced the cellular phone services in Shariin gol soum of Darkhan-Uul aimag, Bayangol soum Selenge aimag and Zaamar soum of Tuv aimag. The Skytel Company started to expand its service coverage in some aimags and major urban settlement where service is not yet been available.

The following are some of the measures implemented on creating jobs in rural areas: Supporting the population's employment in rural areas and dedicating to the citizens who wish to operate in livestock herding and cropping, the developing of a draft amendment law to make additional changes in provisions related to rural employment support of the Law on Employment Support is in progress. As result of loans amounting 28.2 million MNT issued to 58 people from the Employment Support Fund for cropping and livestock herding, 129 new jobs were created.

Under the "Green Revolution" national program aimed to increase household income, 30 portable tractors, 30 irregation facilities for 1 hectar field respectively, 15 greenhouses with 1800 sq.m at 50 per cent cheaper price were allocated to the entities, cooperatives and citizens in order to simplify farmers' hand work and to extend their industries.

The work to involve over 200 branch divisions, business entities, cooperatives and citizens from 22 aimags for planting 133 tones of potato seeds and 2.5 tones of domestically produced and certified tomato, cucumber, onion, carbage and carropts seeds in over 800 hectares of field was organized in order to support vulnerable group household farming business.

In order to support sell of products produced by household farmers, "Golden Fall"new agricultural product exhibition was organized in Ulaanbaatar in September, over 350 business entities and individuals from 10 aimags and capital city attended the event and sold over $350 \mathrm{mln}$ tugrug of products. In total, over 50 types and 2000 tones of vetegables were sold at the exhibition.

Under the scope of the "Green Revolution" national program, 141 agroparks were working in the local areas in 2004, involved around 46.5 thousand people for 890 trainings, prepared 40 copies of manuals and recommendations and distributed.

In addition, 1393 entities and 126.8 households dealt with farming business, planted potato in 6.4 thousand hectares, vegetable in 3.6 thous. Hectares, fruits in 187.5 hectares and collected 59.4 thous. tones of potato, 35.4 thous. tones of vegetable, 1998.8 thous. tones of fruits and increased household income by 206 thous. tugrug on average.

Under the framework of implementation of the government approved program "Supporting intensified livestock development" selected proposals from the aimag, soum citizens and business entities on dealing with intensified milk and meat cow, wool sheep, piggery and poultry farm business in the regional pillar centers, supported 16 entities with 
concessional loan equal to 38.0 mln tugrug and SME Support Fund under the supervision of the President issued $51.5 \mathrm{mln}$ tugrug of support for 14 projects from Ulaanbaatar, Zavkhan, Tuv and Arkhangai aimags respectively.

Involving 69 farming businesses of Ulaanbaatar city, Tuv and Selenge aimags under the French grant and conducting artificial insemination for over 600 cows actually supported core livestock breeding suitable with the regions followed by based on the herds developing the farmers of the cow-herds for meat and milk, the sheep-herds for meat-cashmere and cashmere-meat, pigs and fowls and the cow insemination is at $81.2 \%$ in present which is considered as satisfied indicator.

Under the best breeding sub program, 25 business entities and citizens that deal with intensified and core livestock breeding and selection were given $90.5 \mathrm{mln}$ tugrug of concessional loan with repayment terms.

In 2004, trainings and seminars were organized to enhance qualification of entities dealing with breeding service jointly with institutions such as center to introduce agricultural scientific achievements in industry, Agricultural University, Livestock Institute, Federation of livestock veterinarians and breeders. For instance, organized training to prepare technicians who should do the artificial insemination using best breeding herds in the regional pillar centers, farming business training and seminar to grow milk cows in Batsumbar soum, Tuv aimag, workshop and presentation for those who grow thick and thicker wool sheep in Hongor soum, Darhan -Uul, training on "Intensified milk farming" and "Intensified sheep and goat industries and its management" jointly with MASHAAB center of Israel while involving over 40 scientists, specialists and herders working on these areas and a training for specialists in charge of breeding livestock registration and information fund in Ulaanbaatar respectively. A training was organized on conducting artificial insemination using deeply frozen semen and prepared 12 technicians in Darkhan-Uul, Selenge, Arhangai, Orkhon and Bulgan aimags and another 10 technicians under a project implemented by France.

According to the government resolution \#89 (2004) to reduce losses in farming industry due to natural disaster and to support some business entities, 4.9 bln tugrug of debt of over 600 entities that received loans from the state reserve pool and 2.8 bln tugurg of debt of 195 entities that received loans from the wheat fund were abolished.

\subsubsection{Implementation of environmental policy activities}

Water. As the Government of Mongolia declared the year of 2004 as the year for the Water Policy Reform and in order to improve the policy and its legal foundation to be followed for the efficient and effective use of water resources, improve the management structure of water sector and clarify the legal basis for the use and ownership of water facilities, a revised version of Law on Water was developed and approved by the Parliament on April 22, 2004.

Based on the analysis of the current level of water reserve, its utilization, protection, rehabilitation, research and exploration of water reserve, a program -"Water Reform XXI" aimed to define activities to be carried out by the Government of Mongolia in next 20 years with regard to the water and management of watersheds for the efficient use of the water 
reserve has been approved by the resolution \# 57 of 2004 of the Government and its implementation was started. The mission of this program is to increase the water reserve, serve the population with fresh water meeting sanitation requirements, and improves the water supply for intensified agriculture and mining and to create healthy and safe environment for human livelihood by implementing proper use of water without endangering the ecological balance.

As the new revised Law on Water was approved, some relevant changes and amendments were made to Law on Special Protected Areas, Law on Water Supply Urban Areas and Water Sterilization, Law on Disbursement of Proceedings from Natural Resource Use Fees for Environment Protection and Rehabilitation of Natural Resources.

These measures constituted important strides for the strengthening of watershed and water reserve management, coordinated use of regional water reserves with the regional development plan, regulating the activities for the protection of watersheds and river basins and increase the participation of local administrative bodies, citizens and business entities in the implementation government policy on water.

As the right to use the underground water and the permit to drill bore-holes are issued by the local authorities, these permits do not have professional opinion of water organizations, do not correlate with water reserve, water use or water use limitation policy and they allow the uncontrolled use of water in one hand, and in the other hand, water users' information are not recorded in water database, which makes difficult for the water authorities to conduct additional research and other activities on water reserve and in order to solve these problematic facts, the matter of establishing an independent institution in-charge of water issues was resolved at the end of 2004 .

Forests. In order to improve the forestry sector management, a revised National Forestry Program was approved and established a government implementation agency Environment, Forest and Water Resource Authority under the direct supervision of Minister of Nature and Environment as well as the nature and environment departments in aimags and groups that will be in-charge of forest management on contractual basis in areas with forest reserve. The officials of those bodies are involved in local and abroad capacity-building trainings with the assistance of foreign countries and international organization to improve national capacity. The initial phase of a project implemented by the World Food and Agriculture Organization to support the National Forestry Program is successfully completed and the second phase of the project is already started.

Involving the unemployed and local people for the forest rehabilitation, restoration of forest health and protection of forest reserve and increasing not only the state budget intervention but also the participation of private sector contributed to sufficient supply of saplings that is sufficient to meet existing demand. The project for the fight against harmful insects is being successfully implemented. Some programs are already underway to introduce the promising technology and methodologies to process satellite pictures and data to remote sense the forest community, plant population, water census, forest organization, forest and steppe fires and damage of harmful insects. 
In 2000-2003, the forest restoration and rehabilitation work was carried out for 34241 hectares with the funding from the state and local budget and the own funding of timber harvesting businesses. During this period, the forest restoration work quality showed improvement thanks to the effective coordination efforts to improve the monitoring the forest restoration technology, selecting the most needed areas for forest rehabilitation, centralizing the activities in aimags and supplying good quality saplings.

In 2004, contracts have been signed with the nature and environment departments of aimags and capital city for the forest rehabilitation work in 9755 hectares and supply of seeds and saplings. In recent years, 94.6 million saplings and 16.4 tons of seeds were used for the forest rehabilitation work. The infected areas with harmful forest insect spread widely since 2000, reaching 10.0 million hectares, and the hotbed of active insect infection reached 250.0 thousand hectares, the extremely dangerous pine tree disease covered area of almost 40.0 thousand hectares, and those areas urgently needed counteraction. As the situation was critical, in disaster level, the Government of Mongolia decided to use additional fund from the reserve and other sources and the fight against the harmful forest insects and deceases in 2001-2003 covered a total area of 77537 hectares, three times larger area than the initially anticipated. The research work for harmful forest insects and diseases was carried out covering 1234.0 thousand hectares, fulfilling the task by 123.4 percent. The result of the research constitutes important tool to develop and implement the fighting tactics and strategy against the harmful forest insects and deceases in the future. But destruction of forests intensified significantly in 2002-2004, and many thousand hectares of land lost their forests.

Desertification. Number of meetings and conferences were held with foreign countries and international donor organizations and some projects and activities have began to work together and receive some financial assistance for the fight against the desertification and sand movement in Mongolia and to conduct research work on the yellow dust originated from Mongolian Gobi deserts that causing great deal air pollution in Asian countries. The National Program for Fight against the Desertification and its first phase implementation plan was approved by the resolution \# 141 of June 4, 2003 and the implementation process is underway. The National Committee for the Fight against Desertification is established and it started the implementation of projects for the fight against desertification in some aimags with high sand movements.

We believe that these activities directed at reducing desertification will provide real effect on lives of the poor citizens.

Animals. It has become necessary to conduct research work on the location, distribution and numbers of rare and endangered wild animals such as wild camel, Mongolian saiga tartarica, Gobi bear, reindeer, snow-leopard, wild ass, beaver, otter, pheasant, sturgeon etc and take measures like home-breeding and acclimatizing.

Since transition to the market economy relations in the early 1990 s, some people are living by excessively destroying and using the natural wealth while others are becoming rich by making wealth out of it. For subsistence purposes, poor also contribute to recklessly destroying forests and animals. The clear evidence of this is the significant decline in such animals reserves as marmots and deers as they are on the brink of elimination. 
Plants. In recent years, as the use of plants and vegetation is increasingly active, people are picking medicine and food herbs that are recorded in the Red Book and all types of wild fruits directly from the nature for the purpose of selling, which constitutes not only a breach of laws and regulations but also negative influence for the restoration, protection and use of rare and exotic plants. As consequence, the natural characteristics of plant-cover is deteriorating; plant resources, distribution and types of species are decreasing; and the restoration process is slow for some plants.

Waste and disposal. In order solve the "Improve the complete waste collection and removal" issue included in the "Waste Removal Plan Without Harming Environment" approved by the resolution \# 256 of 2001 of the Government with the improvement of waste management, a project proposal was elaborated and submitted to relevant authorities to establish centralized waste dump areas in Darkhan, Erdenet and Choibalsan cities and improve the solid waste management. A study is being conducted on the possibility of implementing this with the participation local residents of the cities.

In parallel with the activities organized for the burying of city's waste dump points without harming the environment and establishing proper and centralized waste dump, the goal to introduce some incentive mechanisms for the waste sorting, waste exterminating and waste reprocessing was set forward.

Air. A draft law on responsibility and penalty for the air pollution is being developed. As result of promotional campaign about the advantages of full-burning stoves with less smoke how can help for the reduction of air pollution and waste and step by step supply of new stoves to the households of ger districts, more than 10 thousand stoves were manufactured and sold. Using quick fire igniter accelerates the burning and lighting time of coal to 5-10 minutes (used to take 10-40 minutes) reducing the smoldering time of coal and consequently, the air pollution. The existing air pollution monitoring system was expanded by adding two new sensors to the Ulaanbaatar's network. But as a result of the increase in the number of immigrants to Ulaanbaatar from rural areas, the level of smoke in Ulaanbaatar has not decreased significantly.

Under the environmental protection and creating new energy source policy and objectives, government resolution \#140 (2001) was amended and measures to exempt equipment and facilities imported into the coal and gas sector through foreign investment from VAT, customs duties and to exempt entities dealing with business in the gas sector from the corporate income tax are being implemented. in order to reduce air pollution of Ulaanbaatar city, a draft proposal to build non smoky fuel factory was prepared, supported by government and submitted to Japanese government.

Minerals. A policy was followed in 2003-2004 to improve legal frame to enforce the business entities and organizations to rehabilitate environmental damages caused during exploitation of underground resources and establish a structure where the permits are granted considering the technical and technological conditions of the licensees for the exploration and exploitation of mineral resources. 


\subsection{Ensuring sustainable human development}

\subsubsection{Population}

According to data prepared by National Statistical Office, Mongolian settlement population reached 2504.0 thousand end of 2003, increased by 28.6 thousand or 1.2 per cent than previous year and it is similar as average growth of world population4 /1.17 /. But population of Ulaanbaatar city increased by 5.5 per cent.

Figure 14. Annual average growth of population, by percentage

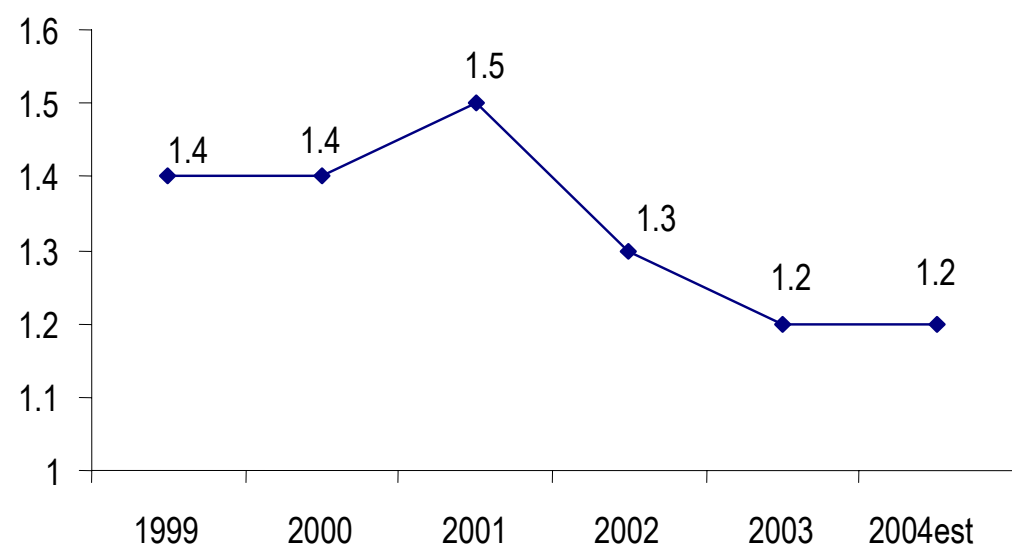

However number of population is increasing but annual average growth of population is decreasing in recent years and it is related with fall of birth number.

Some demographic indicators

\begin{tabular}{|c|c|c|c|c|c|c|c|c|c|}
\hline \multirow[t]{2}{*}{ Years } & \multirow{2}{*}{$\begin{array}{l}\# \text { of } \\
\text { persons } \\
\text { /by } \\
\text { thous/ }\end{array}$} & \multirow{2}{*}{$\begin{array}{l}\text { Population } \\
\text { growth } / \% /\end{array}$} & \multirow[t]{2}{*}{ Density } & \multicolumn{3}{|c|}{ Age structure $/ \% /$} & \multirow{2}{*}{$\begin{array}{l}\text { Demographic } \\
\text { overload }\end{array}$} & \multirow{2}{*}{$\begin{array}{l}\text { Ratio } \\
\text { on } \\
\text { sex }\end{array}$} & \multirow{2}{*}{$\begin{array}{l}\text { Core } \\
\text { age } \\
\text { /by } \\
\text { age/ }\end{array}$} \\
\hline & & & & $\begin{array}{l}0- \\
14\end{array}$ & $15-64$ & $65+$ & & & \\
\hline 1980 & 1685.4 & 2.6 & 1.1 & 43.5 & 51.5 & 5.0 & 98.6 & 100.4 & 17.4 \\
\hline 1985 & 1914.7 & 2.5 & 1.2 & 41.7 & 53.7 & 4.6 & 91.5 & 100.4 & 18.0 \\
\hline 1990 & 2153.5 & 2.7 & 1.3 & 41.5 & 54.4 & 4.1 & 83.7 & 99.4 & 18.9 \\
\hline 1995 & 2243.0 & 1.6 & 1.4 & 38.0 & 58.2 & 3.8 & 71.9 & 98.7 & 20.4 \\
\hline 2000 & 2407.5 & 1.4 & 1.5 & 33.8 & 62.7 & 3.5 & 59.5 & 98.1 & 22.1 \\
\hline 2001 & 2442.5 & 1.5 & 1.6 & 32.8 & 63.7 & 3.5 & 56.9 & 98.1 & 22.4 \\
\hline 2002 & 2475.4 & 1.3 & 1.6 & 32.6 & 63.9 & 3.5 & 56.6 & 98.5 & 22.4 \\
\hline 2003 & 2504.0 & 1.2 & 1.6 & 32.6 & 63.9 & 3.5 & 56.6 & 98.5 & 22.4 \\
\hline
\end{tabular}

Mongolian population growth was provided by net rise of normal movement until 1990s and outside movement has affected unfavorably for population growth in last 10 years. According to Household Income and Expenditure and Living Standards Measurement Survey conducted by NSO, the impact of migration on poverty is high for our country. Specifically, existence of high numbers of poor people in Songinohairhan, Bayanzurh and Han-Uul districts is related to a high level of in-migration in these districts due to official allocation of new land

\footnotetext{
${ }^{4}$ Resource: CIA World Factbook
} 
in line with the capital city's long term plans. Because many of urban-to-rural migrants have problems with their documents, they are not able to access basic services. Also, provision of electricity, schools, hospitals and water decreased and got overburdened, and the cases showcasing insufficient capacity of district or horoo administration employees have increased.

Figure 15. Migration to Ulaanbaatar, by regions, by thous, persons, as of 2003-2004

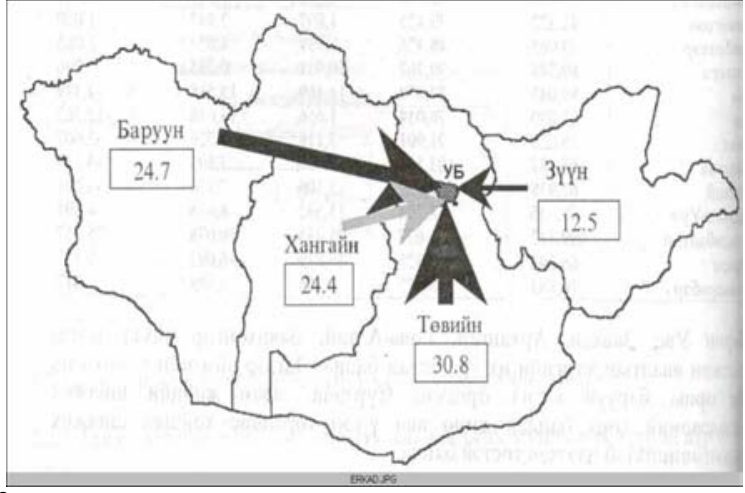

Source:

Population and housing census of 2000: Key results, NSO

* 24.7=Western; 24.4=Hangai; $30.8=$ Central; $12.5=$ Eastern

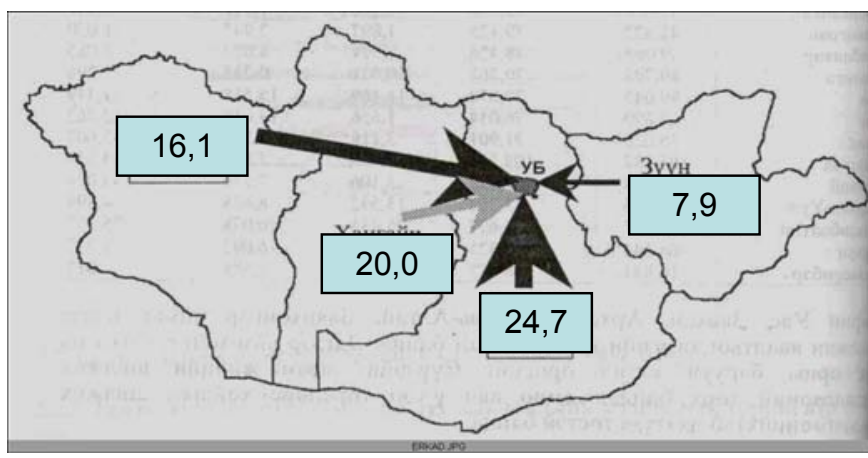

Domestic migration of Mongolia and state policy issues, 2004,UNFPA 16.1=Western; 20.0=Hangai; 24.7=Central; 7.9=Eastern

The core age of population was 17.4 in 1980, and though it increased by 5 years to reach 22.4 in 2003, Mongolia has maintained its relatively young age structure.

Mongolian average life expectancy is 63, out of male average life expectancy is 60 and female average life expectancy is 66 furthermore it has not increased last 4 years. Because of the decline in number of birth from 1990s and change in age group of 15 and less than 15, illustration of diagram of population's age groups has been changed. It is shown from the diagram that the roof is become thin due to number of 0-4 and 5-9 aged people have turned into less than number of 10-14 aged people.

The following population pyramid shows that the number of females aged 70 and more is higher than the number of males and it is shown that death rate of the male is high. 
Figure 16. Diagram of population age groups and sex
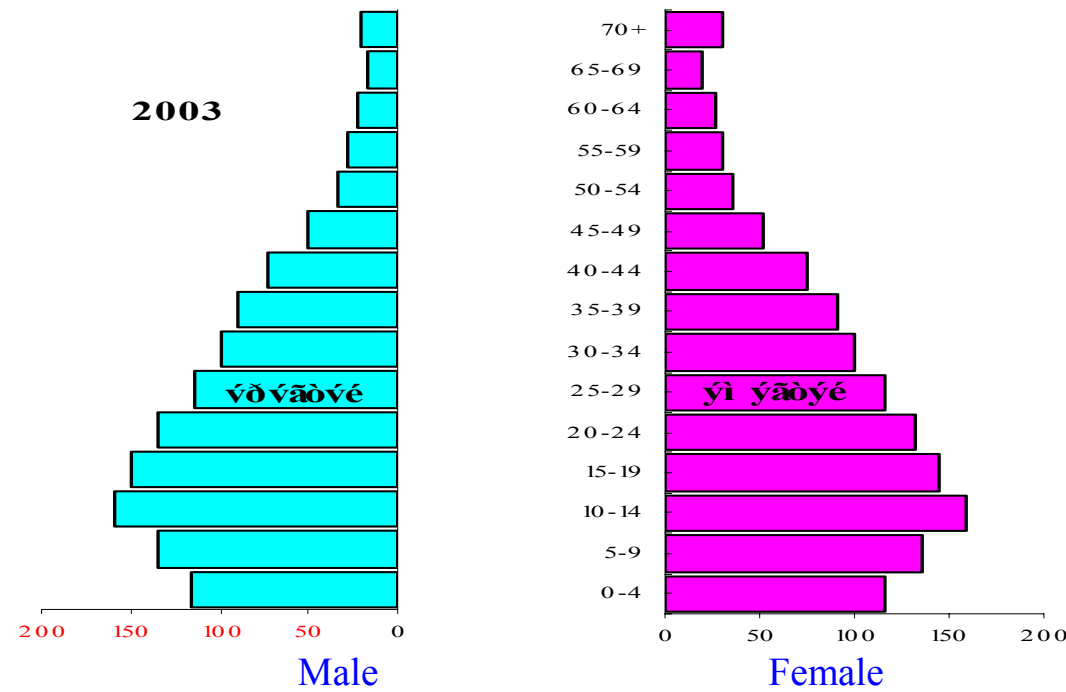

Although Mongolia's HDI did not improve since 1999, but due to positive trends (Table 13) in the last several years, the HDI of Mongolia reached 0.679 in 2002 according to the estimates of the NSO.

Mongolia's human development index became 0.679 in 2002 , ranking the country $117^{\text {th }}$ from 175 countries in the world, while by the gender development index which equals the value of HDI (0.679), the country ranks $95^{\text {th }}$ from 144 countries, which indicates that Mongolia is one of the countries showing significant success in providing gender equality.

Table 13. Human Development Index of Mongolia

\begin{tabular}{|c|l|l|l|l|l|l|l|l|}
\hline Year & $\begin{array}{l}\text { Average } \\
\text { Life } \\
\text { Expectancy } \\
\text { (years }\end{array}$ & $\begin{array}{l}\text { Literacy } \\
\text { of } \\
\text { Adults }\end{array}$ & $\begin{array}{l}\text { Primary } \\
\text { and } \\
\text { Secondary } \\
\text { Education }\end{array}$ & $\begin{array}{l}\text { GDP } \\
\text { per } \\
\text { capita }\end{array}$ & $\begin{array}{l}\text { Life } \\
\text { Expectancy } \\
\text { Index }\end{array}$ & $\begin{array}{l}\text { Education } \\
\text { Index }\end{array}$ & $\begin{array}{l}\text { GDP } \\
\text { Index }\end{array}$ & HDI \\
\hline 1990 & 63.7 & 96.5 & 60.4 & 1640 & 0.645 & 0.845 & 0.467 & 0.652 \\
1992 & 62.8 & 97.7 & 54.3 & 1266 & 0.638 & 0.824 & 0.424 & 0.626 \\
1995 & 63.8 & 98.9 & 57.0 & 1267 & 0.647 & 0.849 & 0.424 & 0.635 \\
1998 & 65.1 & 96.5 & 62.0 & 1356 & 0.669 & 0.850 & 0.435 & 0.651 \\
1999 & 63.2 & 97.8 & 66.0 & 1707 & 0.636 & 0.872 & 0.472 & 0.661 \\
2000 & 63.2 & 97.8 & 69.6 & 1838 & 0.636 & 0.884 & 0.486 & 0.669 \\
2001 & 63.4 & 97.8 & 69.6 & 1968 & 0.639 & 0.884 & 0.497 & 0.674 \\
2002 & 65.5 & 97.8 & 69.7 & 2125 & 0.642 & 0.884 & 0.510 & 0.679 \\
\hline
\end{tabular}

Source: Mongolian Human Development Index 2003, p.8 
Impact of population factor on a country's development is high, and the state policies on population were endorsed in 1996. As a result of joint efforts of the government and local public administration institutions, significant success was reached in creating legal conditions conducive to population development, and improving health, education, food and housing provision and employment, development, registration and research of population groups.

But because of the need to resolve the problems arising from the stagnation in the growth of population, and to align this need with the long and medium term strategy documents that were negotiated and agreed on the international level, Mongolian State Policies for Population were revised by the $\mathrm{SGH}^{5}$ by approving Resolution \#21 of April 23, 2004 on State Policies of Mongolia on Population Development.

The purpose of this policy is to ensure the stable growth of the population and create conditions favorable to long, healthy, peaceful and creative living and development of the people, and serves as the base document for Economic Growth Support and Poverty Reduction Strategy being implemented by the Government of Mongolia. Besides looking at the personal development, the policy addresses the issue as a package to ensure the development of population groups by means of aligning population issues with development plans, supporting optimal growth of the population and improving the quality of human life, and to create an optimal system for implementing the policy on the basis of partnerships.

Within the framework of the Economic Growth Support and Poverty Reduction Strategy the goal to create a favorable environment for human development, reduce unemployment and poverty and improve access and quality of basic social services was envisioned.

One of the priority areas of the government activities is to ensure sustainable human development by improving the quality and access to basic health and education services, and improving social safety net by means of supporting activities directed at increasing employment and income of the population. In doing this, as stated in the EGSPRS, poor and vulnerable groups will be provided with basic social services at the equal level so that they are provided with increased opportunities to engage in labor and economic activities.

Creating an environment where education, food provision and health services delivered to people meet elementary service standards would prevent incidence of poverty, vulnerability and especially falling into intergenerational poverty, and serve as one of preconditions to come out of poverty.

The basic problem that the poor face to go out of poverty line is lower level of their human capacity. Investing in education and health is an important step to improve living conditions of poor. International practice proved that such kind of investment enhances labor engagement and productivity, which is their main capability.

\footnotetext{
${ }^{5} \mathrm{SGH}=$ State Great Hural or Parliament
} 
Box 3: Goals and objectives

- All girls and boys are to be covered under the primary education by 2015

- In 2004 , to have the education expenditure in GDP at $8.2 \%$

- By 2005, to have no gender difference in primary and secondary education and by 2015 , to have no gender difference in all stage of education

* Government of Mongolia, EGSPRS, Ulaanbaatar, September, 2003

Monitoring indicators of the EGSPRS

Level of school enrolment. According to the data from National Statistical Office, there are 560119 children, aged between 7 and 16, in the country in 2004 of which 98,0 /548741:560119/ are enrolled in general education schools at present.

According to the 2002/2003 HIES survey, primary school coverage is at around 90 per cent.

Looking at the findings of HIES survey, adult school coverage rate is comparatively high. ${ }^{6}$ According to the survey results, over $80 \%$ of 18 and older age people have non complete secondary education or 8 year education, one tenth have primary vocational education, one fifth have higher education, one tenth have primary education, and one twentieth has no primary education. While considering population education level by their living conditions, richer people have higher education. One fifth of the poorest group has no education or primary education and this number is twice higher compared with the richest group.

Education expenditure. According to 2004 preliminary results, up to 9 per cent of GDP was spent for the education sector. Poor population is benefiting more from the state expenditure spending for primary education than the non poor group, these two groups have equal access to the state budget expenditure for the secondary education and non poor group is benefiting more from the state expenditure for higher education.

According to 2002/2003 HIES survey, cost per student is shown by cost amount, rural and urban disparities, education expenditure of non-poor household is more than the poor households, in particular, it is 50 per cent more for primary and secondary education respectively. Although the trend is the same both in rural and urban areas, the expenditure is higher in rural area by 25 per cent.

Measures implemented by the state from the beginning of 2002 to reduce school dropouts, and to promote school enrolment of children of poor and vulnerable group households were continued in 2003 and 2004. These include:

\footnotetext{
${ }^{6}$ Person at 18 age or older than this age belongs to the adults. 10 per cent of total adults are covered under any certain stage of school at the moment.
} 
Table 14. Some Education Expenditure

\begin{tabular}{|l|l|l|l|l|l|l|}
\hline & \multicolumn{2}{|c|}{2000} & \multicolumn{2}{c|}{2003} & \multicolumn{2}{c|}{2004} \\
\hline & $\begin{array}{l}\text { Number } \\
\text { of } \\
\text { children }\end{array}$ & Spending & $\begin{array}{l}\text { Number } \\
\text { of } \\
\text { children }\end{array}$ & Spending & $\begin{array}{l}\text { Number } \\
\text { of children }\end{array}$ & Spending \\
\hline $\begin{array}{l}\text { 1. State spending On free } \\
\text { provision of school items to } \\
\text { children of families from } \\
\text { socially vulnerable groups or } \\
\text { with 4 and more children } \\
\text { studying in general education } \\
\text { schools }\end{array}$ & 33781 & 573.5 & 71463 & 1143.4 & 62500 & 1000.0 \\
\hline $\begin{array}{l}\text { 2. Costs for GES dormitory } \\
\text { children }\end{array}$ & 26898 & 1105.8 & 33364 & 2876.6 & 35600 & 3521.4 \\
\hline $\begin{array}{l}\text { 3. Costs for Vocational } \\
\text { Training Center dormitory } \\
\text { children }\end{array}$ & 1646 & 50.3 & 3820 & 337.3 & 4729 & 487.4 \\
\hline
\end{tabular}

Some results of the measures implemented in education sector in 2004. In order to provide and started the preparation works, transferring the system of schools of general education to 11 years studying system, the time schedule and working graphic for transferring into the 11 years studying system was developed, approved and enforced by an order \#1 (2004) of Minister of Education, Culture and Science. According to the graphic, the work to involve 7 year old children, besides the $1^{\text {st }}$ grade of GESs, in " 0 " groups of kindergartens in the academic year of 2004-2005 was organized.

In accordance with 11 years studying plan and program in 2004-2005 academic year, the trainings for teachers, who will work in the ' $\mathrm{O}$ ' groups were organized in the capital city and aimags in August of 2004 and provided them by necessary guidelines and handbooks.

The measures transferring into 11 years studying system was started from the activities that 8 years old children and extra 7 years old children were involved in the kindergarten ' 0 ' or the $1^{\text {st }}$ grade groups of schools of general education and are taught according to new studying program from 2004-2005 academic. In the academic year, 77.3 thousand children are studying in the first class, out of 10.5 thousand children are involved in the kindergarten ' 0 ', and 66.8 thousand children are studying in the first grades of general education schools.

The project proposal "Improving the quality of pre-school education" was developed and Vice Minister of Education, Culture and Science and Director of the Save the Children Fund /United Kingdom/ signed on the memorandum and is ready for implementation. As the results of the implementation of the project, the enrollment, environment and training quality of the pre-school education will improve.

The social service extent for children aged 0 to 7 , the working tendency, the handbooks fro parents, secondary schools' teachers and the kindergarten's teachers have issued.

Within the measures to provide the pre-school education to the children of herding families, the book entitled 'My book' for children aged of herding families was developed and 
published funding by Representative Office of UNESCO. About 100 exercises and homework, which influences to children's development are included in this book and these will support to herding parents to develop their children from kids. Also illustrated training program of the summer and temporary trainings and its handouts were revised based on research results how the teachers use them, and were published funding by the Save the Children Fund /United Kingdom / and then were delivered to rural areas.

In 2004, 10072 kids were involved under summer mobile kindergartens for herding families. Such kindergartens worked in 412 bags of 18 aimags. For the summer training covered $43.7 \%$ of pre-school aged children of herding families and 83.5 million tugrics was transferred. List of toy, training aids and supplies required for kindergarten was prepared and submitted to UNICEF, UNESCO and Education Development Agencies. As a result, the UNICEF disbursed $42.0 \mathrm{mln} \mathrm{Tg}$ of toys and figures and $12.0 \mathrm{mln} \mathrm{Tg}$ of books and handouts to 10 soum kindergartens where they implement a project, the UNESCO disbursed $2.4 \mathrm{mln} \mathrm{Tg}$ of toys and $2.0 \mathrm{mln} \mathrm{Tg}$ of books and handouts to 10 soums under financing of the project 'Delivering complex education and cultural service to herders'.

As a result of the above mentioned activities pre-school enrollment (2-6 ages) in the academic year of 2004-2005 reached $44.9 \%$. In relation to moving to 11 year schooling starting from 2004-2005 academic year, 7-year-old kids are not included in the pre-school education coverage.

In accordance with regulation to provide one child of vulnerable family and a family with 4 and more kids who all study in the secondary school with school supplies free of charge, 62.5 thousand children were given 1000.0 thousand Tg of school supplies.

1319 computers were delivered to 330 secondary schools in assistance of state budget investment, ADB loan, Government of Vietnam, Mongolian Association to cooperate with Sea Countries and 'Sakura' project etc. As a result, 2004 objective to computerize secondary schools is achieved.

Government decided to limit of newly enrolled college and university students in 20042005 who want to receive tuition fee loan and grant at 8905 , informed the universities about it and issued loans and grants to students. Compared with 2003, the number of students eligible for student loan and grants increased by 2805.

By the decision of the government, about $\mathrm{Tg} 20.0$ billion debt payments accumulated by use of state education fund loans that were never repaid, were written off. This measure in essence targets the poor as these loans were mostly given to children of families who could not pay their tuitions on their own.

The government under its resolution \# 244 in 2004 approved 'National program on literacy Education', The program enriched understanding about the literacy education and defined main government objectives, implementation approaches and mechanisms on giving literacy and basic education for population on mandatory basis and to accelerate public policy implementation

In the academic year of 2003-2004, 2480 students graduated from pedagogical institutes and colleges, out of which 969 young teachers were appointed to work in rural schools. 
Created database on the number of teachers required for general secondary schools throughout the country by profession and region, on work vacancies, need for work places, information about teachers seeking for employment and regulated demand and supply through coordination of information. In the last few years, professional teacher supply reached $98 \%$ in urban and $91 \%$ in rural areas as a result of improved participation of local institutions and public in letting the teachers work on sustained basis in the rural areas.

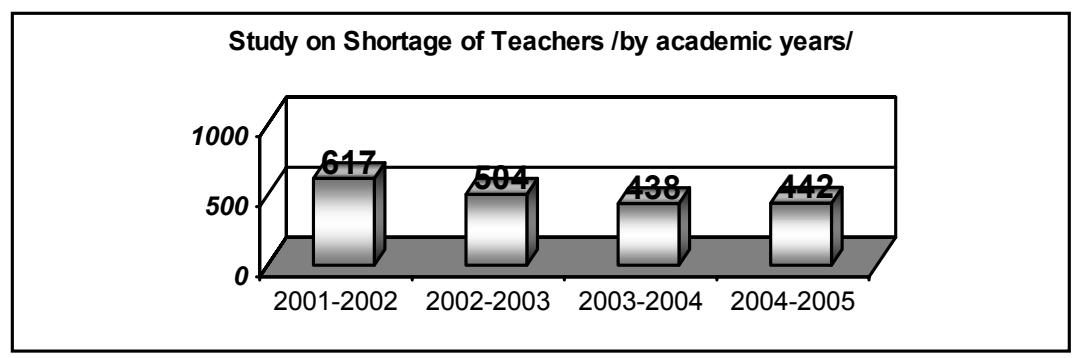

Vocational training centers (VTC) are conducting training on around 100 professions. Curriculum of common 12 professions has been developed and 'Comprehensive Model/Standards on Professional Education and Training', has been revised and approved based on findings of pilot that started in 1998. Its implementation started in 2004. As a result, an opportunity to develop and approve training standards in participation of training institutions and social partners.

According to the joint order/decree of the Minister of Education, Culture and Science and Selenge aimag Governor, VTC in Sant soum of Selenge aimag was merged to the general secondary school of that soum and restructured them as "General Secondary School with vocational training', that finances from the local budget. This will launch a practice of providing professional education in general education schools in the future.

In order to supply vocational education and training methodology centres and regional centres with sufficient training equipment, USD 210.0 thous of equipment was supplied to the technical college of Uvs, Dornogobi, Uvurkhangai, Dornod, Darkhan and Mongolian-Korean technical colleges in one year at the level envisioned for 2003-2004.

In the academic year of $2004-2005$, the number of VCT reached at 35 which is an increase by three than the previous year. In total, 21.9 thousand students are studying there and 9.6 thousand of which are newly enrolled students. In 2004, there are 7980 graduates of which 5267 graduates have professional education certificate. For the first time, the graduates had such certificate that can also guarantee that they obtained complete secondary education. There is a need to intensify reforms of vocational education centers to meet the needs to prepare workers with skill to work on modern technology and equipment that are being fast introduced in business entities and enterprises in the country. 
Box 4: Goals and objectives

- $\quad$ By 2015 , reduce the infant mortality of child under 5 by two-thirds percent.

- $\quad$ By 2015 , reduce maternal mortality by three fourths.

- In 2004, reduce maternal mortality per 100000 live births up to 120 .

- Keep total health expenditure at $10.2 \%$ in 2004 and bring the expenditure share to $4.4 \%$ of GDP.

- Expand health insurance coverage for poor and vulnerable group people.

- By 2015, reduce share of people who do not have access for secure consumption water twice.

* Government of Mongolia, EGSPRS, Ulaanbaatar, September 2003

EGSPRS monitoring indicators

According to the 2003 "Reproductive Health of Mongolian Population" survey findings, total birth coefficiency in the last five years is 2.5 and it indicates that Mongolian woman gives 2.5 births in her lifetime. According to 1998 survey the coefficiency was 3.1 , but under the 2003 survey the indicator was decreased. Birth rate is different in various population groups. The TBC for urban women ( 2.1 children per woman) is lower than the TBC of rural women (2.9 children per woman). In terms of region, the birth rate is the lowest in Ulaanbaatar (1.9), highest in south region and the average birth rate in Central, Eastern and Western regions is fluctuating between 2.6-2.9. The higher woman education, the lower the TBC. In particular, TBC for lower educated woman is 3.2 and this indicator is 2.4 for higher educated woman.

Birth rate for women who do not have any income, or have less income or have lower education is higher than the others. Similar to the education, once income is increased, birth rate is decreasing at the same time.

Looking at 2001-2004, there is a decreasing birth rate trend in population growth. Main factors effecting the decreasing birth rate is the increased marriage age, interest to have small family depending on economic condition, breast feeding takes long time and increasing need of the pregnancy prevention methods etc. All these factors are identified by the survey.

99 per cent of women covered under the survey are aware of at least one of the latest prevention method and it shows that Mongolian women's knowledge about the pregnancy prevention method is good.

However, usage of those methods varies from a population group to a group.

Comparing the results of reproductive health surveys of 1998 and 2003 shows that, average first marriage age of women increased from 20.8 to 21.6.

The high existing rate of using the pregnancy prevention method in Mongolia, decreasing undesired birth rate and high rate in total family planning need etc indicate that the Reproductive Health program is being implemented successfully. But abortion rate remains 
high and the incidence of sexually transmittable diseases has not decreased as they continue to be priority issues.

According to the registration database of the $\mathrm{MoH}$, infant mortality rate decreased from 23.5 in 2003 per 1000 live births to 22.8 in 2004, and mortality rate of children below 5 years decreased from 31.3 in 2003 to 29.5 in 2004, showing the potential to fulfill the goal of reducing infant and child diseases and mortality.

Maternal mortality per 100000 live births decreased from 124 in 2002 to 109.5 in 2003 and to 98.8 in 2004, which is the unprecedented success. Mortality rate for mothers with lower education and many kids is common. This indicator is also high for poor herders and unemployed.

By Decree \#35 of 2005 of the Minister of Health, the revised 'Strategy for Reducing Maternal Mortality' was approved, and this strategy sets as a goal to reduce maternal mortality per 100,000 live births to 90 by 2007. This strategy also plans to issue 'Certificates' starting in 2006 to poor family mothers to prevent them from birth deaths, and to prepare 'Volunteer Assistants' for mothers. Local authorities will develop similar strategies for reducing maternal mortality with adjustment for the local specifics.

Health Expenditure. The Government of Mongolia is shifting its attention to introducing current achievements of the medical science, new practices, technologies and equipment in the health sector activities, thus increasing its spending on the sector. In order to improve the financing of the sector, amendments were made to Health Insurance Law in 2004. In 2004, health spending per capita and medicine expenditures per patient increased.

Table 15. Health Expenditure

\begin{tabular}{|l|r|r|r|}
\hline & \multicolumn{1}{|c|}{2002} & \multicolumn{1}{c|}{2003} & \multicolumn{1}{c|}{2004 Est. } \\
\hline 1. Health Expenditures /million Tg/ & 62197.5 & 62299.7 & 78895.7 \\
\hline 2. Medicine Expenditures /million Tg/ & 8604.1 & 9503.9 & 10362.4 \\
\hline 3. First aid service expenditures /million Tg/ & 45858.6 & 44661.8 & 57467.8 \\
\hline 4. Per capita health expenditures /thousand Tg/ & 38,4 & 14,9 & 31,2 \\
\hline $\begin{array}{l}\text { 5. Per patient medicine expenditures /thousand } \\
\text { Tg/ }\end{array}$ & 17,0 & 18,3 & 19,4 \\
\hline
\end{tabular}

Some results of the measures implemented in 2004 in the health sector: The system that essential health assistances are provided to population by household hospitals or soum hospitals, have developed and the activities to introduce the household hospital system in capital city, centers of aimags and some settlements have finished successfully.

In order to improve the quality of essential health assistances performed by household hospitals and to develop the financing mechanism more efficiently, the expense tariff per person was increased and 10 population groups with different tariffs was decreased to 2 also the poverty percentage was determined differently in suburban districts and central districts. So that, the sustainable and accountability financing mechanism of the household hospitals was improved and the ger districts with vulnerable and poor people were financed more than 
others also it has possible that the adequacy and quality of essential health assistances and services can get better further. But as the health insurance fund provides funding for family clinics on the basis of per insured citizen, difficulties occur in the funding of family clinics and a condition limiting uninsured citizens' ability to receive aid and services was created. Within the development of "The master program of health sector", the documentary entitled "The expense coverage in medium term" is being developed, the financing to household hospitals and soum hospitals estimated by a person will be implemented fully financing payment method will trend to the adequacy and quality of essential health assistances and services as the result of implementation of the measures to finance the essential health assistances and services from the state budget completely and to finance the second and the third stage hospitals from the health insurance fund by use of new payment methods. In accordance with above mentioned the financing change, the expense estimation and research study of a technical assistance project funding by Asian Development Bank is being made.

The working group is charge of to develop the assistance and service lists, which are included in the essential health assistance, and the essential assistance standard developed the essential health assistance lists and it was approved by the order 297 (2003) of Minister of Health and was applied.

Therefore, with the purposes to develop the individual's health insurance system more efficiently and to develop the insurance strategy documentary, the government has implemented the technical assistance project cooperating ADB since the beginning of 2004 . According to new amendments in the Law of Individual Health Insurance, citizen of Mongolia have to get insured from 1 January 2003. Furthermore, within the activities to implement the provision of the law, the issue was discussed by Health Insurance Board and then the measures, such as to involve the unemployed and self-employed people, herders, students and pupils in the insurance and to provide without charge the certificates of the health insurance to citizens who did not have, have implemented successfully. In future, it is necessary to organize the measures to remove the difficulties faced in payment settlement of hospitals because of the accounting system of the health insurance departments, and to amend laws on health and health insurance of citizens.

In the total 172 automobiles were provided to the health offices of the capital city and centers of aimags were provided in 2000-2004 and the park reform performance was reached $60.6 \%$ per cent as well in total 157 automobiles were provided to soums and the park reform performance was reached to $42.4 \%$ per cent, out of 36 automobiles from them were provided in 2004.

The immunization issue was included in the health education standard which was developed newly.

Concentration dosage equipment was installed in 6 factories that involved under the JFRP 9005 project designed to improve maternal and infant nutrition, produced 9257 tones of flour enriched by vitamin B, metal zinc and other minerals in 2003, and over 20 thousand tones of flour in 2004 and supplied hospitals, schools, kindergartens and vulnerable group of people. 
In order to create an opportunity to provide iodinated salt consumption up to 50-60\% of the population salt pools were built on the two salt deposits of Uvs and Zavkhan aimags and an experiment has been started since August 2004, which has been successful so far. Study findings done by the public health department of the Ministry of health in 2004 shows that the iodinated salt consumption of the population reached 76 percent and mid term objective of the program has been achieved.

Infant and maternal mortality rates have declined as a result of policies implemented to strengthen inventory base and increase the capacity and effectiveness of personnel of the health sector.

By Decree \#213 of the Minister of Health, communicable meningitis and hemophiliacs B vaccines were included in the mandatory immunization plans, and its implementation started.

In order to implement the sub program that to fight against the infectious diseases 7729 children who did not get immunization were immunized.

The mother's resting rooms are being worked in health and research study centers of 90 per cent of all aimags and soums and 80 per cent of mothers, who are should involved, are rested in that rooms.

New practices improving the quality of health services in general and specifically reproductive health services are being introduced with the help of UNFPA, and there is a need to spread the implementation of the project to the nationwide level.

The majority of Mongolian women, or about 95 percent of them have heard about STDs while 96 percent have heard about HIV/AIDS, and they obtain information mostly from TVs, newspapers and other media. If the information about STDs is received on average from 2.5 sources, information about HIV/AIDS is received from 2.6 percent, showing almost equal number of sources of information for women for the two types of diseases. 95 percent of women believe that they can prevent themselves from STDs, while 96 percent believe that HIV/AIDS can be prevented.

According to 1998 survey, 5.7 per cent of women answered that it is impossible to prevent from HIV/AIDS, but according to 2003 survey, this indicator became 4.1 per cent and declined by 1.6 points. In addition, percentage of women with misunderstanding declined from 4.6 per cent in 1998 to 1.9 per cent in 2003. Looking at the above indicators, it might be concluded that women's knowledge about HIV/AIDS prevention has increased after the first survey though still many women have misunderstandings.

In the five years since the first survey was conducted, the birth rate of girls decreased from 9 percent to 7 . But if this indicator was 2.2 times higher in rural areas compared to urban areas in 1998 (13 percent vs. 6 percent), the survey of 2003 shows that this ratio decreased in both rural and urban areas, but rural rate increased compared to urban as it is 2.5 times of the urban (12 percent vs. 5 percent).

If 92 percent of teenagers heard about HIV/AIDS in 1998, this number became 90 percent in 2003. The number of teenager girls who do not believe it is possible to protect 
themselves from HIV/AIDS increased by 2 percentage points (from 5 percent in 1998 to 7 in 2003), and those with incorrect understanding on HIV/AIDS decreased by 3 points (from 5 percent in 1998 to 2 in 2003). In other words, it could be concluded that the knowledge of teen girls has increased.

According to the Decree \# 33 of 2004 of Minister of Health, 5 aimags, 2 districts of the capital city, the first and the second clinic maternity hospitals, The Health and Research Study Center, which were selected by subprogram of 'The health reproduction' implementing in cooperation with Population Fund of UN, were delivered 23 kinds of diagnostic and medicinal equipments of the health reproduction amounted 197.5 million tugrugs. Also, all aimags and districts of the capital city were delivered 24 kinds of the necessary medicines and instruments of the health reproduction amounted 257.1 million tugrugs. According to the order 123 of 2004 "To deliver the equipments and training the applications" of Minister of Health, the equipments amounted 40.6 million tugrugs, which were purchased in 2003 funding by the health reproduction project of World Health Profession's Organization, and the handbooks 'The medical care and service for pregnancy and prenatal' amounted 6.2 million tugrugs were delivered to the health offices of aimags and the capital city and the hospital under jurisdiction of them. According to the order \#140 of 2004 of Minister of health, the necessary medicines amounted 38.3 million tugrugs were delivered to the health offices of aimags and the capital city by 'The health reproduction' sub program implemented by Population Fund of UN.

\subsubsection{Social protection}

Social protection has an important role to play in reducing poverty. In the case of Mongolia, there is broad scale social safety net and consists of social insurance and social welfare. $^{7}$

By Resolution \# 239 of 2003 of the Government of Mongolia, Social Protection Sector Strategy Document was endorsed. This document includes general trend for long term (10 year) and short and medium term activity areas for development of the social protection sector, and is very significant in bringing the quality of social protection services to a new level.

\section{Social welfare}

The following measures were implemented in 2003 and 2004 regarding the issue of improving the quality of social welfare services by making them consistent with market principles, as it was reflected in the social protection sector strategy.

By Resolution \# 5 of the Government of Mongolia, Childcare benefit provided from the Social Welfare Fund was increased by 20 percent to equal Tg 12420 starting from March 1, 2004.

The information chains for street children have worked since 2002 and approximately 1086 children are registered. At the end of 2004, 504 street children were registered and 66 of them retuned to home and 481 of them are moved to the children care center. About 50

\footnotetext{
${ }^{7}$ In order to protect some risks, the social insurance consists of public pension, unemployment and sick benefits. The social welfare is designed for group of people who necessarily require for protection. For instance, benefit and compensation for invalids and losing bread winners etc.
} 
children are registered annually in the division is responsibility for determining home address of the children, checking and delivering.

The working group, consisted of participations from Ministry of Justice and Domestic Affairs, Ministry of Social Welfare and Labor, Ministry of Health and Administration Department of Ulaanbaatar City worked to develop a proposal to resolve the problems of noncontrolled children, homeless people. Therefore, the implementation plan of sub-program to involve the vagrant people and children in the social life was approved by government resolution \#138 (2003) and it is being implemented. General Policy Office and State Center of Citizens' Registration are participated in this work.

Table 16: Size of Pension and Allowances disbursed from Social Welfare Fund

\begin{tabular}{|c|c|c|c|c|c|c|c|}
\hline \multicolumn{2}{|c|}{ Size ofsocial pension and allowance } & $\mathbf{1 9 9 9}$ & $\mathbf{2 0 0 0}$ & $\mathbf{2 0 0 1}$ & $\mathbf{2 0 0 2}$ & $\mathbf{2 0 0 3}$ & $\mathbf{2 0 0 4}$ \\
\hline \multirow{3}{*}{ Per capita } & Pension & 10000 & 10000 & 10000 & 12000 & 14400 & 14400 \\
\cline { 2 - 8 } & Benefit & 9000 & 9000 & 9000 & 10350 & 10350 & 12420 \\
\hline
\end{tabular}

/Tugrug/

Within the reform of sub sector of the social care, which was included in the social welfare sector strategy documentary, the regulation and modules for the implementation of the experiment projects of care and services were prepared based on society and colleagues.

\section{$\underline{\text { Social insurance }}$}

The two insurance systems coexist in the social welfare sector. The one of these is the system that insurants or commission payers can be provided by pension and allowances using the commission revenues paid by employees and employers. As of the end of 2004, . . percent of the employers in the organized sectors are involved in the mandatory insurances also ... . percent of herders and self-employed people are involved in the voluntary insurances.

The extent of individual retirement account system has expanded and many activities have been done to deal with the debts of the pension insurance commission in 2003-2004. Since the individual retirement account system launched in 2000, 173.3 thousand insurants or 100 per cent of the mandatory insurants, and 21.1 thousand insurants or 79.3 per cent of the voluntary insurants have opened the individual retirement accounts and their interest revenue amount ware calculated. Within these activities, the information page of the individual retirement account has been delivered to the people who have opened the individual retirement accounts. Furthermore, the insurant can be provided by information about the accumulated money amount in the individual retirement account and its interest revenues.

Table 17: Provided pension amount from the social insurance fund

\begin{tabular}{|l|c|c|c|c|c|c|}
\hline \multicolumn{1}{|c|}{ Pension amount } & $\mathbf{1 9 9 9}$ & $\mathbf{2 0 0 0}$ & $\mathbf{2 0 0 1}$ & $\mathbf{2 0 0 2}$ & $\mathbf{2 0 0 3}$ & $\mathbf{2 0 0 4}$ \\
\hline $\begin{array}{l}\text { The minimum amount of the full } \\
\text { pension }\end{array}$ & 16000 & 16000 & 18850 & 22600 & 22600 & 32000 \\
\hline $\begin{array}{l}\text { The minimum amount of the } \\
\text { proportional }\end{array}$ & 10000 & 10000 & 12375 & 14860 & 15000 & 20000 \\
\hline The average pension & 13600 & 18200 & 19500 & 21900 & 25700 & 33700 \\
\hline
\end{tabular}


According to government resolution \#3 (2004) to rise the pension provided from social insurance fund, pension amount of 270,2 thousand people, who were determined the pension before 16 January 2004, was increased and it applied successfully. The pension amount of 152,5 thousand people, who received pension amounted 22600 tugrugs, was increased to 32000 tugrugs and 15,7 billion tugrugs will be used it; the pension amount of 38,6 thousand people, who were received pensions amounted 22601 and 31999 tugrugs, was increased by 250 per cent and 3,1billion tugrugs will used for it; the pension amount of 45,0 thousand people, who were received pension 32000 tugrugs and more that it, was increased by 15 per cent and 3,7 billion tugrugs will be used for it; the pension amount of 26,1 thousand people, who were received proportional pension equaled 15000 tugrugs, was increased by 20000 tugrugs and 1,4 billion tugrugs will be used for it; the pension amount of 6,4 thousand people, who were received the proportional pension equaled 15001-18000 tugrugs, was increased by 25 per cent and 0,3 billion tugrugs will be used for it, the pension amount of 1,5 thousand people, who were received the pension amounted 18001 and more than it, was increased by 15 per cent and 0,1 billion tugrugs will be used for it. In total, 24, 3 billion tugrugs were spent for pension additionally.

Figure 17

Full persion recipients from Social Insurance Fund, in thousand persons

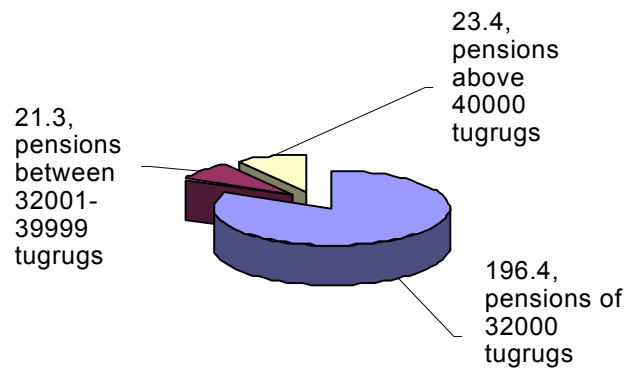

Proportionate (reduced) pension recipients from Social Insurance Fund, in thousand persons

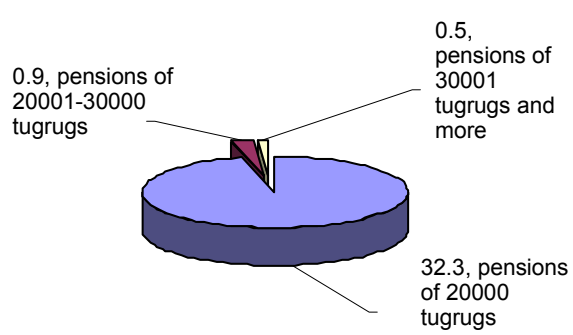

Of the citizens receiving compensation allowance due to the temporary suspension of their pensions because they have not reached retirement age, on average about 2.0-3.0 thousand citizens shift to the social insurance pensions every year, so the number of such citizens has been declining. In 2004, 2294 people moved to the social insurance pensions, while 6164 people are covered by the compensation. By Resolution \#5 of the SGH of January 8,2004 , the minimum amount of compensation for citizens whose pensions were temporarily suspended was set at Tg 32000, effective from January 2004. This amount is 1.4 times higher the the previous minimum compensation level. 
The compensation allowance amount, by tugrugs

\begin{tabular}{|l|c|c|c|c|c|c|}
\hline & 1999 & 2000 & 2001 & 2002 & 2003 & 2004 \\
\hline $\begin{array}{l}\text { The allowance } \\
\text { amount }\end{array}$ & 11000 & 16000 & 18850 & 22600 & 22600 & 32000 \\
\hline
\end{tabular}

The allowances for the industrial injuries and disablement, pregnancy and birth were provided from the allowances insurance fund.

The insurant, which paid the unemployment insurance commission at least two years and out of them last two years without gaps, can be provided the unemployment allowances from the unemployment insurance fund. The month commission amount is depended from the wages amount, insurant was received and the period of commission paid.

The insurants of the industrial injuries and disablement insurance or profession disease insurance are provided pension, allowances and compensation from the industrial injuries and disablement insurance and profession disease insurance fund.

The amendments in Law of pension, allowance and compensation of the industrial injuries and disablement and the profession disease delivered from the social insurance fund were approved in plenary meeting of the parliament in May 2004. In order to expand the service extent from the industrial injuries and disablement insurance and profession disease insurance fund, according to this law some provisions were allowed such as the insurant, who lost labor capacity because of the industrial injuries or profession situation, is provided the sanatorium's operation cost where he was cared and the pension insurance commission till his retirement age is paid, the prize of prosthesis and treatment cost, which insurants is made in foreign countries, are covered the standard amount of the prize of prosthesis and treatment cost in Mongolia. As a result, the spending of insurance for industrial accidents and professional diseases improved, and it is annually increasing by tg 251.4 million.

Social insurance funds were fully transferred to the single treasury account in 2004, and in the result use and monitoring of insurance funds improved.

\subsection{Participation}

\subsubsection{Citizens and public participation in the of state policy and social development}

The key goal of technical assistance within the strategy to reduce poverty and is to supporting the activities to transfer into budget entities management and financing system, to develop a strategy for long term development and align it with the poverty reduction strategy, to determine the medium term economic development scope accurately, to intensify the civil servant reform, to increase the adequacy and quality of the state service capacity and to develop the system to control and make assessments on policy implementation efficiently as well as to strengthen the relationship between Government and civil society. 
There is world experience that users assess the state services and inform the policy makers about the disadvantages of the service and Government implements the measures to improve the service quality. A study was done in 2004 for some sectors with the purpose to implement these experiences in the context of Mongolian specifics. Select of the sectors to cover under the survey were based on the following issues.

The major part of aimag or rural budget spends for the health, education services on other hand the kinds and standards of these services are determined by policy makers. But there is no mechanism to control their implementation and consistence with the practice also user's assessment on these services.

Therefore, it is necessary to establish the mechanism that to increase the public control on complications of the budget revenue and allocation of the budget expenditure and to create the participation of city and countryside people or public participation spending the budget and determining the leading development trends.

The research manual entitled 'Assess the service by customers' was developed by Poverty Research Unit of Ministry of Finance and Economy and published and were delivered to public. Within the strategy to reduce poverty, the experiment research that using the methods, which are mentioned in the manual, to assess the services of the health, education and micro loan service by customers are done within the health, education and micro loan service extent funded by Trust Fund of the World Bank. As the results of the research, it is possible to improve the information quality delivering to the policy makers and to determine the methods to improve the adequacy and quality of state service as well as to control the customer interests.

The research unit stars the work that to assess the citizen society participation in the budget process of Mongolia (planning, discussing, approving and reporting) performed by the selected group of NGOs. Based on the results of the research, policy suggestion proposal are developed and prepared for delivery to the ministries, agencies, NGOs and public using the Medias.

There are about 2500 NGOs in Mongolia as of 2004, which was increased 4.2 times compared with 1996 and not only the service quality but also the financial capacity of them have improved respectively.

14 representatives of the NGOs participated in developing the economic growth support and poverty reduction strategy and the participation of NGOs in the implementation process will be continued on other words we will cooperate with them on the fields to do research on the specific issues and sectors, to organize conference and regional meetings, especially to organize the implementation of strategy to reduce poverty including society and business participation in aimag and soum levels and to control the implementation. Also, the participation of NGOs is working the assessment of strategy implementation and monitoring activities widely. 


\section{Five. Poverty Monitoring and Evaluation}

\subsection{Monitoring and Evaluation System for the EGSPRS Implementation}

Based on recommendations of the World Bank experts and the study of experience of Cambodia and Uganda, on effectively monitoring and evaluating the implementation of poverty reduction strategies, and the study tour to Tanzania organized with support of UNDP, a management and organization system was developed for monitoring, analyzing and evaluating the implementation of the EGSPRS. This system was approved by the Government Resolution 96 in April 2004. The purpose of the management and organization system for the analysis, monitoring and evaluation of the EGSPRS implementation process is to evaluate the impact of growth, especially in relation to the Millennium Development Goals, identify possible amendments to policy, and improve information exchange. The Government Resolution established that this system would consist of two main components: Strategic Management Section and Information Collection, Processing and Analysis Section.

The activities of the Strategic Management Section shall include preparing reports on the EGSPRS implementation process, reviewing and improving the strategy, organizing public discussions on progress reports, reporting to the Government and disseminating the reports.

The activities of the Information Collection, Processing and Analysis Section shall include collection of information on the implementation of the EGSPRS comprising quantitative and qualitative indicators especially of state budget performance and changes in outcome indicators; analysis; and provision of relevant information to the Strategic Management Section. 
Figure 17. Management and Organization Structure

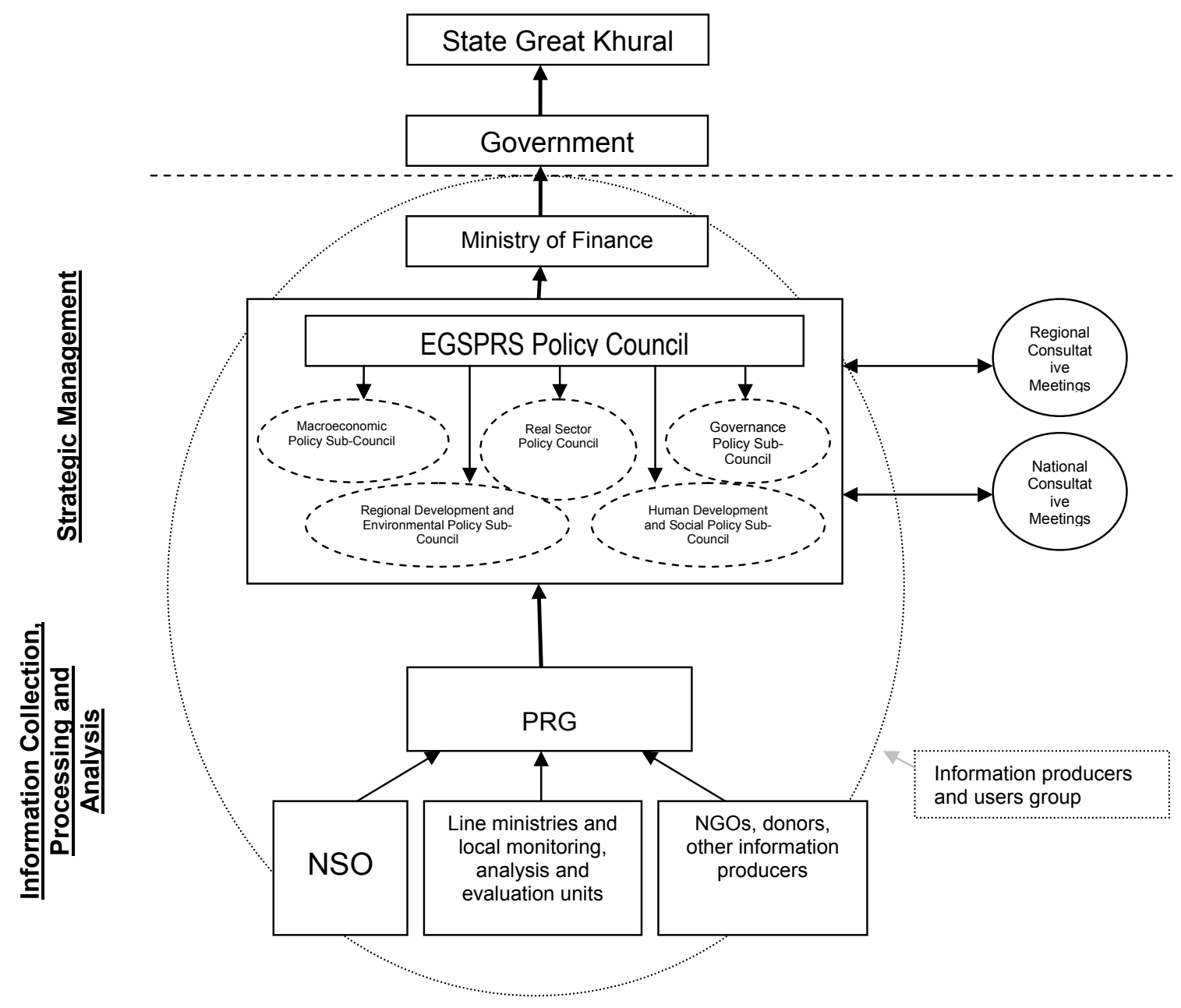


The Strategic Management Section consists of the Ministry of Finance and Economy (by former name), EGSPRS policy council, EGSPRS policy sub-councils, and national and regional consultative meetings. The council composition and responsibilities have been specified as follows:

1. Ministry of Finance: the Ministry of Finance shall report annually to the Government on the EGSPRS implementation process

2. EGSPRS Policy Council: the EGSPRS Policy Council was formed of non-staff members by the April 22, 2004 Order \#40 of the Prime Minister. The EGSPRS Policy Council is chaired by the Minister of Finance and members are representatives of line ministries, National Statistical Office, and local governments. The responsibilities of the Policy Council have been defined as follows:

a. Preparing reports on EGSPRS implementation process and renew strategy based on the information supplied by the involved parties

b. Organizing consultative meetings at national and regional level and reflect recommendations from these meetings in the EGSPRS implementation progress report

c. Introducing the EGSPRS implementation progress report to the Government through the Ministry of Finance

d. Disseminating the EGSPRS implementation progress report and other relevant information

3. EGSPRS shall have Policy Sub-Councils and these sub-councils shall work in 5 areas: Macro-Economy, Objective Sector, Human Development and Society, Regional Development and Environment and Governance. These Sub-Councils shall consist of non-staff members and shall be formed by the decision of the Chair of the Policy Council. The Sub-Councils consist of representatives from relevant ministries, local governments, donors (the member shall be selected by the donor agencies themselves), NGOs (the member shall be selected from the National NGO Forum) and other sector working groups. The responsibilities of the Sub-Councils are as follows:

a. Preparing EGSPRS implementation progress report for the given sector

b. Contributing recommendations and proposals to the EGSPRS Policy Council

c. Review, renew and improve outcome indicators' list for monitoring, analysis and evaluation in the given sector

4. National and Regional Consultative Meetings: the EGSPRS Policy Council shall organize annually National and Regional Consultative Meetings. The Consultative Meetings shall be attended by representatives of the Government, civil society, private sector, local governments and donors. The Consultative Meetings shall discuss the EGSPRS implementation progress reports developed by the EGSPRS Policy Council.

The Information Collection, Processing and Analysis Section consists of the Poverty Research Group, National Statistical Office, Monitoring, Analysis and Evaluation Offices and Departments of the relevant Ministries, relevant professionals from Aimag and City Governor's Offices, General Economic Policy Department of the Ministry of Finance and 
Economy (by former name), State Budget Policy and Coordination Office and Monitoring, Analysis and Evaluation Department, donors and Information Producer and User Groups. The membership and responsibilities of the above bodies have been specified as follows:

1. The work of analyzing and evaluating processed information and to provide logistics assistance to the Strategic Management Section will be performed. This work is being carried out by the staff of the Poverty Research Group that was working at the Ministry of Social Security and Labor within the framework of the Poverty Research and Employment Support Program funded by the UNDP. This group has been integrated into the General Economic Policy Department of the Ministry of Finance by the order of the Minister of Finance.

The Poverty Research Group has started its operation assuming responsibilities for commissioning research on poverty-related topics, developing recommendations based on the results of the research, compiling report and evaluation of strategy implementation progress and presenting the report to the Government and the World Bank. The group shall also organize seminars, meetings, consultations and discussions and all other activities necessary for compiling the EGSPRS implementation progress report in relation to the Millennium Development Goals, determining the content of the reports, collecting and processing information, analyzing and ensuring broader participation in this process. These tasks have been detailed in the management and organization structure for the monitoring, analysis and evaluation of the EGSPRS implementation process.

2. The National Statistical Office shall be responsible for providing relevant processed information to the Poverty Research Unit, developing an information data base on EGSPRS indicators, and providing the public with the correct information.

3. Monitoring, Analysis and Evaluation Units of line ministries and local governments include Monitoring, Analysis and Evaluation Offices, Departments and Professionals of line ministries and local governments as well as the Unified Economic Policy Department of the Ministry of Finance, the State Budget Policy and Coordination Office and Monitoring, Analysis and Evaluation Department thereof. The above organizations shall provide the Poverty Research Unit with relevant information according to an approved schedule and plan.

4. Civil society, donors, researchers and other information producers shall comprise representatives of civil society, donors, research institutions, private consulting companies, other information producers and researchers. These organizations shall provide relevant information within the approved scope of the list of monitoring, analysis and evaluation indicators and conduct on a contract basis research announced by the Poverty Research Group.

5. Information Producers and Users Group: the Poverty Research Group shall organize an Information Producers and Users Group that will operate on a regular basis. This group shall consist of non-staff members representing information producers and users, EGSPRS Policy Council and Sub-Councils, Poverty Research Unit, National Statistical Office, Monitoring, Analysis and Evaluation offices and 
departments of line ministries and local governments, civil society, donors, and research, analysis and consulting institutions.

6. Responsibilities of the Information Producers and Users Group include elimination of information discrepancy and overlap and identifying mechanisms for supplying necessary information.

\subsubsection{Information Collection}

In analyzing poverty, not only is necessary official information obtained from relevant ministries and the National Statistical Office but also data is used from the following research conducted through the National Statistical Office, UNFPA and Poverty Research Unit: Research of Mongolia's Labor Force, Reproductive Health Research, Research on Evaluating the Results of the Implementation of the Strategy on Improving Herder Families' SocioEconomic Security and Incomes by Increasing the Number of Their Livestock, Research on Evaluating the Methods of Integrating Herders' Capital into Economic Circulation, Research on Evaluating the Methods for Preventing Middle-Income Families from Falling into Poverty, Urban Poverty Research, Privatization Poverty and Impact on Inequality Research, Gender Analysis of the State Budget in the Social Security Sector, Sector Gender Analysis of Employment, and Gender Analysis of the Allocation and Spending of Loans and Aid Funds in Employment and Social Security Sector. Moreover, the Poverty Research Group has initiated research projects on following subjects: correlation and correspondence between priority areas and budget, civil society participation in budgetary process, impact of consumer prices on poor households, improving poverty assessment methodology, and increasing gender-sensitive budgeting capacity.

The national level seminar was organized in December 2004 for the purposes of delivering the collated policy recommendations resulting from these researches to policymakers.

Findings of research conducted through the Poverty Research Group are made available not only to all policy-level institutions but also to the general public at www.poverty.mn and www.openforum.mn.

Starting in 2004, poverty-related indicators where included in the list of indicators to be provided by local governments for identifying priorities in economic and social development plan for the following year.

With the aim of improving EGSPRS implementation monitoring, analysis and evaluation indicators, a World Bank consultant paid 2-week visits in August of 2003 and April of 2004 and provided concrete recommendations as a result of which the monitoring, analysis and evaluation matrix was developed as follows:

1. Millennium Development Goals and indicators for assessing their implementation (these indicators shall be developed based on the indicators mentioned in the Mongolia's National Report on Millennium Development Goals) 
2. EGSPRS indicators were divided into three levels:
a. National level
b. Regional level
c. Capital city level

3. Informal indicators (indicators produced by non-governmental organizations and research and analysis institutions shall be reviewed and used)

The indicators' matrix consists of content, baseline year for each indicator, measurements expressing each indicator, goals, frequency, information on the source, assumptions and explanations.

In identifying monitoring and analysis indicators, much attention was paid to linking the key indicators for Millennium Development Goals and the indicators for ensuring the achievement of key goals stated in Mongolia's EGSPRS. MDGs are related to the long term development for each country covering the period of 1990-2015 while the EGSPRS covers the period of 2003-2006. Hence, the coordination between the two was an important point of concern in developing indicators.

In order to increase civil society participation in information collection activities, much support is being directed to financing research projects from the Trust Fund. It is planned to hold 12 open for among non-governmental organizations and the activities have already started. Moreover, a pilot research project is being conduct to introduce the international practice of evaluating public services using 'consumer evaluation cards,' develop recommendations and manuals for improving the quality of public services to citizens. Based on the results of this pilot project, the Government of Mongolia is planning to conduct a research covering 10,000 households within the framework of the project on Developing Participatory Mechanisms for Poverty Monitoring to be implemented in cooperation with the Asian Development Bank.

\subsubsection{Analysis}

Analyzing research data and reflecting the findings in the development of policy is proving to be a new and challenging as well as rather time-consuming undertaking. Although research and analysis activities are being conducted, policy makers do not adequately use the findings of the research. Therefore, the need arose to develop a mechanism for analyzing findings of research and delivering those analyses to policy makers. This activity was integrated into the poverty monitoring system.

In the future, there is a need to conduct regular poverty census from the Government and improve the methodology for poverty assessment in addition to conducting national-level research projects. EGSPRS implementation report is prepared on the basis of the performance of the annual general directives for economic and social development. But as ministries prepare the report on performance of these directives as listing of measures completed, it is not feasible to give the assessment on this report from the poverty perspective. Therefore, there is a need to strengthen the analytical capacity of respective level people in the ministries, 
especially in terms of looking at the issue from the angle of such cross cutting issues as poverty, gender, governance and participation.

\subsubsection{Information Dissemination}

\section{The dissemination of information and public education on the implementation of the EGSPRS are conducted by the following three methods:}

1. Seminars and discussions organized at national and regional levels

2. Publication and distribution of the strategy document

3. Disseminating information through mass media

First regional and national seminars. A number of seminars on the EGSPRS were organized last year in several stages. Regional seminars were conducted between September 1 and October 29 of 2003: the Central region's seminar took place in Dundgovi aimag, the Western region's seminar in Bayan Ulgii aimag, the Khangai region's seminar in Uvukhangai aimag, and the Eastern region's seminar was held in Sukhbaatar aimag. The National Seminar was held in Ulaanbaatar on November 14 of 2003. All these seminars aimed at introducing the concept, principles, goals, objectives and implementation measures of the EGSPRS.

The seminars were attended by Governors, Chairs of the Citizens' Representatives' Khurals, Soum Governors, their deputies, staff of the Governor's offices, herders, NGO representatives of all 21 aimags. In addition, the national seminar was attended by members of the parliament, policy makers from relevant ministries, representatives of donor organizations, Federation of Trade Unions, Union of Private Entrepreneurs, Union for Supporting Domestic Industry and other NGOs.

In the course of the seminars, proposals were advanced by the participants themselves to form 5-7 person working groups for developing, implementing and monitoring the implementation of local-level poverty reduction strategies. These working groups would consist of representatives from local government, non-governmental organizations and the private sector. These proposals are being taken into account in designing the poverty monitoring system.

On February 12, 2004, a national consultative meeting was held in Ulaanbaatar entitled "Development of Monitoring, Analysis and Evaluation System for the Implementation of the Economic Growth Support and Poverty Reduction Strategy." The consultative meeting provided information on the EGSPRS, the information database developed based on the Millennium Development Goals and poverty indicators, participation of non-governmental organizations in the implementation of the EGSPRS, effective participatory organization of policy development in implementing the EGSPRS, establishment of the poverty monitoring system, experience of Uganda and Tanzania, and recommendations developed by World Bank consultants. In addition, the consultative meeting participants discussed the draft proposal on the establishment of the EGSPRS monitoring, analysis and evaluation system and the final document was approved by the Government. The consultative meeting was attended by over 70 individuals, 53 per cent of whom were from state organizations, 32 per cent were from nongovernmental organizations, and 15 per cent were representatives of international organizations. 
A national seminar on "Implementing the Economic Growth Support and Poverty Reduction Strategy" was organized on March 23 of 2004. During the seminar, the State Secretary of the Ministry of Finance gave a presentation on measures undertaken to achieve the policies and goals stated in the EGSPRS. This presentation was followed by others on macroeconomic stabilization, reports by the Ministry of Social Security and Labor, Ministry of Education, Culture and Science, Ministry of Health, Ministry of Environment, Ministry of Infrastructure, Gender Center for Sustainable Development and the report by the Poverty Research Group on the EGSPRS's objectives, the current status of its implementation, challenging issues and future activities. The reports were followed by open discussions. The seminar was attended by members of the parliament, officials from the President's Office, ministries, government agencies, donor organizations, local government representatives, representatives from the private sector and non-governmental organizations totaling approximately 200 participants.

A consultative meeting with non-governmental organizations was held on May 12 of 2004 with the purpose of selecting NGO representation to the Policy Council and Sub-Councils approved by the Government as part of the structure for monitoring, analyzing and evaluating the implementation process of the EGSPRS. The consultation was organized by the Poverty Research Group of the Ministry of Finance with the support of the UNDP. In order to ensure broader civil society participation in the seminar and select the NGOs to be members of the policy cub-councils, the Group announced the seminar through mass media and about 80 NGO representatives participated in the seminar.

Regional seminars on implementing the EGSPRS was organized in cooperation with nongovernmental organizations and the funding from the Trust Fund in Selenge, Arkhangai, Zavkhan and Dornogovi aimags between June 30 and July 8 of 2004. The seminars aimed at introduced the local population to the goals, implementation mechanism, and organization of the EGSPRS, receive local people's input into developing appropriate implementation structures at local level, ensure local citizens' participation in the EGSPRS implementation, and discuss potential challenges to the process and possible favorable conditions. In addition, the seminars provided a forum for reporting to the local population on various programs implemented to reduce poverty, their results and their implementation in rural areas and for discussing how the implementation could be improved.

The seminars were attended by a total of 411 participants including representatives of Aimag Governor's Offices, soum governors, deputy governors and staff, and social workers of the aimags of the 4 regions. The EGSPRS documents were officially delivered to the seminar participants and aimag and soum leadership, strategy monitoring and evaluation system was introduced, ensuring participation in the monitoring process was discussed, local leadership was encouraged to take lead in inspiring others to actively participate in the implementation and monitoring of the EGSPRS. Finally, group discussions were held on possible challenges to ensuring the implementation of the EGSPRS.

At the above-mentioned forums and seminars, the EGSPRS documents were distributed to the seminar participants and aimag and soum leadership, information was delivered on the establishment of the national system for strategy monitoring and evaluation, and concrete knowledge was obtained and shared on how to coordinate activities at local level. 
The following issues, among others, were highlighted by the seminar participants as particularly important:

- Create new positions in local government for a staff member who is consistently in charge of poverty-related issues and draw up a clear job description for this position

- Link the activities of the Poverty Research Unit with institutions at local level

- Improve the methodology for identifying and measuring poverty

- Identify methods of effective information collection from households and information distribution to households

- Incorporate material on poverty in the general education schools' curricula of life skills and healthcare lessons and include poverty-related topics in the university curricula

- Employ new position for full time staff in charge of poverty issues

- Organize a series of EGSPRS implementation seminars for new full time employees and trainers.

\section{Publication and Distribution of the Strategy}

With the funds from the Poverty Reduction Trust Fund, 1200 copies of The Economic Growth Support and Poverty Reduction Strategy were printed in Mongolian and 400 copies were printed in English. The copies are being distributed to governmental and non-governmental organizations and citizens. Copies were distributed to all aimags and soums through the regional seminars. As the initially published copies were all distributed, additional 800 copies were published and are being distributed to participants in respective forums.

The Poverty Research Group regularly publicizes information on the implementation of EGSPRS and related measures via its bi-monthly information sheet entitled "Poverty Issues."

\section{Dissemination through Mass Media}

Information on measures undertaken within the framework of the implementation of the EGSPRS and findings of research projects were presented to the public though publications in newspapers "Unen," "Udriin Sonin," and "Unuudur." A journalist works on the contract basis to distribute information about implementation progress of EGSPRS to general public within the frame of the Trust Fund, and information has been distributed through media on a monthly basis. The Internet web page www.poverty.mn was developed in cooperation with the NGO Mongolian Development Exit and with the support of the World Bank. The web page was launched on July 1, 2004. According to the bilateral contract, the web page shall be maintained and developed by the Mongolian Development Exit NGO during the first year and from then on the work shall be performed by the Mongolian Government. Hence, staff trainings were conducted to develop their capacity for maintaining and developing the web page.

The web page contains the following information: Millennium Development Goals declared by the UNDP, general information on the poverty reduction strategy document, links to internet sources on the experience of other countries implementing poverty reduction strategies, information on the Economic Growth Support and Poverty Reduction Strategy 
approved by the Government of Mongolia, information on and address of organizations cooperating on the implementation of this strategy, description of activities conducted to implement the strategy, definitions of poverty and other terms and concepts related to human development, results of projects and programs implemented for poverty reduction, research activities, questions for citizens to obtain their opinions in related to the strategy and other issues, all aimed at informing the public on the EGSPRS process. Also, policy documents such as General Directives for Economic and Social Development of Mongolia in 2003 and 2004, their implementation, budget performance for 2003, budget plan for 2004 and Government Action Program were published. 


\section{Six. Conclusion and Areas for Further Attention}

\subsection{Conclusion}

1. In the EGSPRS, provision of macro economic sustainability, liberalizing market relations and creating favorable business environment in order to speed up economic growth were identified as priority objectives. Government of Mongolia is considering that provision of long term macro economic sustainability is a key of the policy to implement the EGSPRS. Having 10.6 per cent of economic growth in the first year of implementing the strategy formed a base of further successful achievement of mid term objectives of the strategy.

2. Although economic growth of the country is increasing in the last several years, most of the economic growth came from agriculture and mining industries or primary sector industry that cannot be a base of further sustained growth and thus cannot increase substantial amount of job places.

Therefore, the government is required to focus on achieving EGSPRS objectives such as keeping the economic growth sustainably at the target level of the strategy, intensively developing more effective processing industries, increasing its value in the economic structure, upgrading mining product processing level and producing finished goods.

3. According to the HIES/LSMS surveys conducted in 2002/2003, it was determined that 36.1 per cent of total population or around 900.0 thousand peoiple are poor. In other words, it indicates that 36 persons out of every 100 persons have weak capacity to purchase food and non food consumption products and that poverty is widespread in the country. In terms of coverage, rural poverty is much higher than urban poverty (in rural areas $43 \%$ and in urban areas $30 \%$ ). Poverty level is the lowest in Ulaanbaatar city and 5 out of every 9 poors live in the soum center or countryside.

In 2004, the inflation rate was high due to petrol price increase on international market and followingly domestic fuel, petrol and telecommunication price and tariff increase. From the beginning of the year, meat and meat product price increased by 24.1 per cent, housing, fuel and electricity price increased by 3.9 per cent, transportation and telecommunication service charge increased by 21.9 per cent respectively. Resulted by petrol price increase, goods and service price and charges increased in 2004 and it negatively effected life of poor and poverty deepening. Government measure to increase wages and pension by 25 per cent in 2004 sufficiently effected to reduce implications of the price increase.

4. In 2003-2004, the policies were implemented so as to create an environment for supporting real economic growth through improving sustained and healthier banking and financial system, keeping loan interest rate at the positive level in consistent with inflation rate and reducing nominal interest rate.

As of end 2004, weighed average loan interest of the commercial banks reached $30.0 \%$ for local currency loan, $17.9 \%$ for foreign currency loan and decreased by 3-4 units than 
2003 average interest. In 2004, loam amount issued to private sector reached 516.6 bln.tg which is an increase of $53.8 \%$ or $180.7 \mathrm{bln}$.tg than in end 2003 . It indicates that economic activities have activated and cash management and facilitation policy to reduce interest rate taken by the Central bank was effective although the loan demand was still high.

While operations of the banking and financial institutions have been sustaining and accelerating, citizen and entities' trust to the banks has been increased which is positively effecting the economic growth. However, access to finance and terms of finance is still a problem for poor and other citizens who have no asset as a collateral. In the last several years, following small credit and micro finance need of the small and medium businesses, Deposit and Savings Cooperatives and NBFIs have been developing faster. Agricultural sector development program that is being implemented through the Central Bank is leading to positive effects to improve regional and rural financial servcies. In addition, allocating ADB work place increasing loan and accumulated from its interest resources as a loan became an important measure that increased total loan portfolio.

According to the regional development concept of Mongolia, branches of the Central Bank are being established in the local areas. Measures such as increasing regions' access to banking and financial services, delivering services efficiently and equally and providing them with information are being taken through these branches as part of the work to support establishment of bank branches and NBFIs in the rural areas. In support of the ADB, deposit and savings cooperation support project has been implemented sisnce 2003 .

5. During 2003-2005, the Parliament of Mongolia approved Law on Regional Management and Coordination, Medium term strategy on regional development, and the government approved and started enforcement of "Regional Development Promotion Fund" and "Procedures on Establishing Regional Agreement" consistently with above mentioned legislation. These legal acts had formed legal framework to deepen and implement regional development concept.

Work on "Millennium road" project and building core road and power line that connect regional pillar centers-towns and local development centers under the regional development concept has been intensively continuing.

In relation to new government structure, organization and composition of the National Committee on Regional Development Promotion, its working office and regional councils were revised and resources required for their operations are financed by the budget. In relation to regional development orientation, grades and ranking of the management and service organizations to run within a ministry, agencies, regions, regional pillar centers and towns have been revised and considered in the sector policies. As a result of this, a start to move a structure where Mongolia plans and coordinates its national development issues in regions, has been initialed. 
6. Main constraint for poor to go out of poverty is their low human resource capacity. Therefore, investing in education and health is an important step towards improving living condition of poors.

According to 2002/2003 HIES/LSMS, variable cost norm per student has been determined by poverty level, urban and rural disparities, expenditure of non poor household for primary and secondary education is 50 per cent higher than the one spent by poor household respectively.

Measures such as reducing drop-outs, providing kids of vulnerable familes and ordinary families whose four and more children go to the general secondary school, with school supplies in order to cover kids of vulnerable group under the education training, financing dormitory cost for the student of general secondar school and VTC from the state budget etc were continued to be taken during 2003-2004.

As a result of these measures, pre-school coverage (2-6 age) reached 44.9 per cent in academic year of 2004-2005. Government decided to limit number of newly enrolled college and university students in 2004-2005 who want to receive tuition fee loan and grant at 8905, informed the universities about it and issued loans and grants to students. Compared with 2003, the number of students eligible for student loan and grants increased by 2805 .

By the decision of the government, about $\mathrm{Tg} 20.0$ billion debt payments accumulated by use of state education fund loans that were never repaid, were written off. This measure in essence targets the poor as these loans were mostly given to children of families who could not pay their tuitions on their own.

As a result of policy implementation to strengthen material base of the health sector, increase human resources capacity and increase operational efficiency, infant mortality rate decreased from 23.5 in 2003 per 1000 live births to 22.8 in 2004, and mortality rate of children below 5 years decreased from 31.3 in 2003 to 29.5 in 2004, showing the potential to fulfill the goal of reducing infant and child diseases and mortality. Maternal mortality per 100000 live births decreased from 124 in 2002 to 109.5 in 2003 and to 98.8 in 2004, which is the unprecedented success. Mortality rate for mothers with lower education and many kids is common. This indicator is also high for poor herders and unemployed.

Besides these positive indicators, sickness and mortality of children from rural area and vulnerable family in ger district was higher among the below 5 year age children mortality. Children mortality rate is comparatively high in western aimags that are not connected to the general power system, that have poor infrastructure development and are located in the long distance from the center and it shows that population in that area could not have timely access to the health services.

A structure to deliver primary medical services to the population through family doctors and soum hospitals was formed, and the work to establish family group practitioners in the capital city, aimag center and bigger villages was completed. In order to improve the 
quality of essential health assistances performed by household hospitals and to develop the financing mechanism more efficiently, the expense tariff per person was increased and 10 population groups with different tariffs was decreased to 2 also the poverty percentage was determined differently in suburban districts and central districts. So that, the sustainable and accountability financing mechanism of the household hospitals was improved and the ger districts with vulnerable and poor people were financed more than others also it has possible that the adequacy and quality of essential health assistances and services can get better further.

The following measures were implemented in 2003 and 2004 regarding the issue of improving the quality of social welfare services by making them consistent with market principles, as it was reflected in the social protection sector strategy. By Resolution \# 5 of the Government of Mongolia, Childcare benefit provided from the Social Welfare Fund was increased by 1 to 20 percent to equal Tg 12420 starting from March 1, 2004.

According to government resolution \#3 (2004) to rise the pension provided from social insurance fund, pension amount of 270,2 thousand people, who were determined the pension before 16 January 2004, was increased and in 2004, 24.6 bln.tg was additionally spent for the increased pension. According to the Parliament resolution \#5 (2004), minimum compensation for citizens whose pension was tempoparily not issued was revised by 32000 tugrugs starting from January of 2004. This amount is 1.4 times higher than the previous compensation amount.

7. The SGH proclaimed 2004 as 'The Year of Support of Family Development' for the purposes of intensifying the implementation of Mongolian state policies on development of families. Under the National Program on Ensuring Gender Equality establishment of the National Committee on Gender Equality was renewed in 2005 and it was a positive step towards developing a mechanism for ensuring gender equality that is in line with international standards.

Research results showed that public servants lack gender knowledge, that they do not take into account gender issues in policy development and planning, and that gender statistics are not fully adequate in the sectors covered in the research. Thus, in support of the UNDP Resident Representative Office in Mongolia, a project on "Developing Capacity for Gender-Sensitive Budgeting" was implemented. Under the project, officials to be in charge of gender issues within the line ministries were selected and they attended a training on building capacity to develop a gender sensitive budget

8. One of the focus areas to implement the EGSPRS was to increase participation and to create monitoring and evaluation system for the implementation of the strategy. Under this framework, number of measures have been organized towards collaboration with NGOs, international banking and financial institutions, and local governments. In participation of these stakeholders, policy and sub policy committees have been working. Trainings and seminars shave been organized in order to increase public awareness of the strategy, disseminate it and to determine implementation monitoring indicators. 


\subsection{Areas for Further Attention}

Based on the countries's experience that are implementing the PRSP, the World Bank and the IMF submitted a 2005 Review describing the directions that require more attention in the future. Trends such as improving mid term orientation of the PRSP, improving multilateral accountability system between the countries and donor community that are implementing the strategy, increasing significant participation and providing consistency between the PRSP and the MTBF are very much consistent with areas described by the government to give more priority. In order to implement the PRSP.

1. Under the scope to improve mid term orientation of the PRSP:

- Conduct studies on articulation or consistency of mid and long term policy documents;

- Make some amendments into the EGSPRS in consistent with GAP;

- Take organizational measure in order to form PRSP database;

- Update monitoring, evaluation and analytical indicators of the PRSP, create a structure;

- Estimate detailed costs required for the PRSP implementation and to build capacity.

2. Under the scope to support real economic growth and to keep macro economic stability:

- Take a measure to keep the annual inflation at 5 per cent which is an appropriate rate for increasing industry and services in the micro level, creating sustained business environment and promoting the investment;

- Reduce loan interst rate by 2-3 points than the 2004 level through monetary policies;

- Keep stability of exhcange rate consistently with other macro economic indicators;

- Extend connectivity of bigger urban areas, ger district of a city and other small towns and increase coverage of internet connection and service;

- Conduct a study on whether legal regulation is needed for livestock insurance sector;

- Conduct a study on the opportunity to use insurnace mechanisms for reducing operational risks of micro financial institutions.

3. Under the scope to match employment promotion policy with economic growth support and poverty reduction policies in the macro level:

- Develop employment promotion sub programs while considering specifics of social groups;

- Support issuing leasing loan to the business entities that submitted a request to deal with small and medium size enterprises;

- In order to support small business entities, establish business development promotion incubator centers in Uvs, Darkhan-uul, dornod, Dornogobi and Uvurhangai aimags;

- Implement issues such as extending soum employment services and providing with sufficient resources and reserves through a pilot implementation in the soum social service center;

- Solve social welfare problems of the informal sector through implementing a project "Shadow economy, poverty and employment" in assistance of the ILO;

- Conduct a study on solving in-migration to the capital city;

- Implement special programs on employment promotion for invalids and pre-pension age population in assistance of donor community. 
4. Under the scope to form a mechanism that can provide gender equality:

- Develop a plan for the II phase of the National Program on Gender Equality and organize its implementation;

- Build capacity to develop gender sensitive policy and to reflect the gender issues in the development policies and their planning;

- Include gender statistics in the poverty reduction monitoring structure.

5. In terms of education:

- Accelerate restructuring VTC in consistent with the need to prepare skillful workers that can work on the latest technology and equipment since such advanced technology is being introduced into our enterprises and entites;

- Deepen education sector reform; upgrade training quality of all stage of schools;

- Implement research work aimed to implement national program on developing science and technology and to introduce its outocmes.

6. In terms of health: :

- Strengthen a system to deliver basic health services to the population through family doctors and soum hospitals;

- Improve implementation management and coordiantion of the public health policy and programs;

- Strengthen financial management capacity of the health sector;

- Reduce maternal mortality;

- Intensify policy that is to protect, prevent and support health and development of youth;

- Encourage investment in order to increase quality and access of health and medical aid and services to the population.

7. In terms of social welfare sector:

- Develop indicators to be covered under the social welfare and a methodology to describe household and citizens living condition through piloting new types of community based benefits and services;

- Form legal basis to create private pension system;

- Develop and implement pension insurance program for herders, private businesses and for those who received early pension due to special labor condition;

- Develop a policy options to increase pension age and reduce pension difference for those who were born before and after 1960;

- Improve access and effectiveness of the pro-poor services that are being implemented under the Sustainable Livelihood Project of the world Bank;

- Continue implementation of the "Susained rural poverty reduction program" funded by the International Fund for Agricultural Development in the selected aimags.

8. In terms of strengthening governance and widening participation;

- Establish good partnership relation among the state, civil society and private sector, encourage their cooperation and extend contracting out of some public services by NGOs; 
- Improve types and mechanisms of civil society participation in decision making, implementation and monitoring processes of the Parliament and the government;

- Improve state and community relationship management, to provide transparency in the operations of the public institutions.

9. In terms of regional development framework:

- Finalize preparing of Western, Hangai, Central, eastern and Ulaanbaatar regions' development programs, priority objectives and measures of the projects and start implementation;

- Attract and encourage foreign and domestic private sector investment and initiatives of public and entities to implement development program of making the Kharkhorin as a model city of Mongolia;

- Improve land ownership and utilization in connection with regional and urban development policies, and to strengthen legal and economic basis of making regional land efficiency as a main source to increase population income;

- In consistent with regional development concept, to develop infrastructure development strategy, encourage and continue to connect regional pillar centers, free zones, mining and tourism regions with foreign and domestic markets through adequate infrastructure network, and to extend support of neighbouring countries and international institutions to intensify foreign trade and economic cooperation through regions. 